

\section{DISCLAIMER}

This report was prepared as an account of work sponsored by an agency of the United States Government. Neither the United States Government nor any agency Thereof, nor any of their employees, makes any warranty, express or implied, or assumes any legal liability or responsibility for the accuracy, completeness, or usefulness of any information, apparatus, product, or process disclosed, or represents that its use would not infringe privately owned rights. Reference herein to any specific commercial product, process, or service by trade name, trademark, manufacturer, or otherwise does not necessarily constitute or imply its endorsement, recommendation, or favoring by the United States Government or any agency thereof. The views and opinions of authors expressed herein do not necessarily state or reflect those of the United States Government or any agency thereof. 


\section{DISCLAIMER}

Portions of this document may be illegible in electronic image products. Images are produced from the best available original document. 
Issued by Sandia National Laboratories, operated for the United States Department of Energy by Sandia Corporation.

NOTICE: This report was prepared as an account of work sponsored by an agency of the United States Government. Neither the United States Government nor any agency thereof, nor any of their employees, nor any of their contractors, subcontractors, or their employees, makes any warranty, express or implied, or assumes any legal liability or responsibility for the accuracy, completeness, or usefulness of any information, apparatus, product, or process disclosed, or represents that its use would not infringe privately owned rights. Reference herein to any specific commercial product, process,

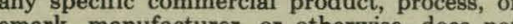
service by trade name, trademark, manufacturer, or otherwise, does not necessarily constitute or imply its endorsement, recommendation, or favoring by the United States Government, any agency thereof or any of their contractors or subcontractors. The views and opinions expressed herein do not necessarily state or reflect those of the United States Government, any agency thereof or any of their contractors or subcontractors.

Printed in the United States of America Available from

National Technical Information Service

U.S. Department of Commerce

5285 Port Royal Road

Springfield, VA 22161

NTIS price codes

Microfiche copy: A01 


\section{PAGES 1 to 2 WERE INTENTIONALLY LEFT BLANK}


SAND80-1968

Unlimited Release

Printed November 1981

SAND $-80-1968$

$-D E 82006870$

\title{
ELECTRON ENERGY AND CHARGE ALBEDOS-- \\ CALORIMETRIC MEASUREMENT VS MONTE CARLO THEORY
}

\author{
Grant J. Lockwood \\ Laurence E. Ruggles \\ Simulation Technology Research Division 4232 \\ Glenn H. Miller \\ Experiments Planning Division 1112 \\ John A. Halbleib \\ Theoretical Division 4231 \\ Sandia National Laboratories \\ Albuquerque, NM 87185
}

\begin{abstract}
A new calorimetric method has been employed to obtain saturated energy albedos for $\mathrm{Be}, \mathrm{C}, \mathrm{Al}, \mathrm{Ti}, \mathrm{Mo}, \mathrm{Ta}, \mathrm{U}$, and $\mathrm{UO}_{2}$ over the range of incident energies from 0.1 to $1.0 \mathrm{MeV}$. The technique was so designed to permit the simultaneous measurement of saturated charge albedos. In the cases of $\mathrm{C}, \mathrm{Al}, \mathrm{Ta}$, and $\mathrm{U}$ the measurements were extended down to about $0.025 \mathrm{MeV}$. The angle of incldence was varied frum $0^{\circ}$ (inuinial) to $75^{\circ}$ in steps of $15^{\circ}$, with selected measurements at $82.5^{\circ}$ in $\mathrm{Be}$ and $\mathrm{C}$. In each case, stateof-the-art predictions were obtained from a Monte Carlo model. The generally good agreement between theory and experiment over this extensive parameter space represents a strong validation of both the theoretical model and the new experimental method.

- Nevertheless, certain discrepancies at low incident energies, especially in high-atomic-number materials, and at all energies in the case of the $U$ energy albedos are not completely understood.
\end{abstract}

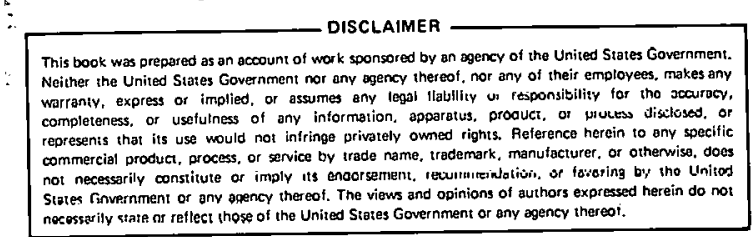




\section{ACKNOWLEDGMENT}

We are pleased to note the assistance we received from Allyn R. Phillips, who provided the programming for the online computer. 
I. Introduction

II. Calorimetric Method

III. Apparatus and Procedures $\quad$. 16

IV. Theoretical Model 20

V. Results

A. Euectren Fnorgy and Charge Albedos in Beryllium $\quad 25$

B. Electron Energy and Charge Albedos in Carbon $\quad 31$

C. Electron Energy and Charge Albedos in Aluminum $\quad 36$

D. Electron Energy and Charge Albedos in Titanium $\quad 43$

E. Dlectron Energy and Charge Albedos in Molybdenum 48

F. Electron Energy and Charge Albedos in Tantalum $\quad$ ก 54

G. Electron Energy and Charge Albedos in Uranium $\quad 64$

H. Electron Energy and Charge Albedos in Uranium Dioxide $\quad 75$

VI. Conclusions $\quad 80$

$\begin{array}{ll}\text { References } & 81\end{array}$

\section{ILLUSTRATIONS}

\section{Figure}

III-1 Faraday Cup and Experimental Mounting Platform . 17

III-2 Experimental Apparatus _. . 18

III-3 Data Collection and Processing System 20

V-1 Comparison of Experimental and Theoretical Energy Backscatter for Electrons Incident at $0^{\circ}$ and $60^{\circ}$ as a Function of Target Atomic Number 22

V-2 Comparison of Experimental and Theoretical Number Backscatter for Electrons Incident at $0^{\circ}$ and $60^{\circ}$ as a Function of Target Atomic Number 23

V-A. 1 Comparison of Experimental and Theoretical Energy Backscatter in Beryllium

V-A.2 Comporion of Exporimental and Theoretical Number Backscatter in Beryllium

V-B. 1 Comparison of Experimental and Theoretical Energy Baokecatter in Carbon

V-B. 2 Comparison of Experimental and Theoretical Number Backscatter in Carbon

V-C. 1 Comparison of Experimental and Theoretical Energy Backscatter in Aluminum

V-C.2 Comparison of Experimental and Theoretical Number Backsculler in Aluminum 


\section{ILLISSTRA TIONS (Cont)}

Figure

V-D. 1 Comparison of Experimental and Theoretical Energy Backscatter in Titanium

V-D. 2 Comparison of Experimental and Theoretical Number Backscatter in Titanium

V-E. 1 Comparison of Experimental and Theoretical Energy Backscatter in Molybdenum

V-E. 2 Comparison of Experimental and Theoretical Number Backscatter in Molybdenum

V-F. 1 Comparison of Experimental and Theoretical Energy Backscatter in Tantalum

V-F. 2 Comparison of Experimental and Theoretical Number Backscatter in Tantalım

V-F. 3 Comparison of Experimental and Theoretical Energy Backscatter in Tantalum as a. Function of Incident Energy Using Standard and Improved Theoretical Cross Sections

V-F. 4 Comparison of Experimental and Theoretical Number Backscatter in Tantalum as a Function of Incident Energy Using Standard and Improved 'I'heoretical Cross Sections

V-G. 1 Comparison of Experimental and Theoretical Energy Backscatter in Uranium

V-G. 2 Comparison of Experimental and Theoretical Number Backscatter in Uranium

V-G. 3 Comparison of Experimental and Theoretical Energy Backscatter in Uranium as a Function of Incident Energy Using Standard and Improved Theoretical Cross Sections

V-G. 4 Comparison of Experimental and Theoretical Number Backscatter in Uranium as a Function of Incident Fnergy Using Standard and Improved 'I'heoretical C'ross Sections

V-II. 1 Comparison of Experimental and Theoretical Energy Backscatter in Uranium. Dioxide

V-H. 2 Comparison of Experimental and Theoretical Number Backscatter in Uranium Dioxide

\section{TABLES}

Table

V-A(i) A Comparison of Total Energy Deposited in Beryllium

$V-A(i i) \quad I$ 'heoretically Calculated Fraction of the Incident Electron Energy That Escapes From Beryllium in the Form of Bremsstrahlung

V-A. 1 Fraction of Energy Backscattered From Beryllium

V-A. 2 Fraction of Electrons Backscattered From Beryllium

V-B Theoretically Calculated Fraction of the Incident Electron Energy That Escapes From Carbon in the Form of Bremsstrahlung

V-B. 1 Fraction of Energy Backscattered From Carbon

V-B. 2 Fraction of Electrons Backscattered From Carbon 
V-C(ii) Theoretically Calculated Fraction of the Incident Electron Energy That Escapes From Aluminum in the Form of Bremsstrahlung

V-C. 1 Fraction of Energy Backscattered From Aluminum

V-D Theoretically Calculated Fraction of the Incident Electron Energy That Escapes From Titanium in the Form of Bremsstrahlung

V-D. 1 Fraction of Energy Backscattered From Titanium

V-D. 2 Fraction of Electrons Backscattered From Titanium

$\mathrm{V}-\mathrm{E}(\mathrm{i}) \quad$ A Comparison of Total Energy Deposited in Molybdenum

V-E(ii) Theoretically Calculated Fraction of the Incident Electron Energy That Escapes From Molybdenum in the Form of Bremsstrahlung

V-E. 1 Fraction of Energy Backscattered From Molybdenum

V-E. 2 Fraction of Electrons Backscattered From Molybdenum

V-F(ii) Theoretically Calculated Fraction of the Incident Electron Energy That Escapes From Tantalum in the Form of Bremsstrahlung

V-F.1 Fraction of Energy Backscattered From Tantalum 57

V-F.2 Fraction of Electrons Backscattered From Tantalum 59

V-F.3 Fraction of Energy Backscattered From Tantalum Calculated With , Standard and Improved Cross Sections

V-F.4 Fraction of Electrons Backscattered From Tantalum Calculated With Standard and Improved Cross Sections

V-G(i) A Comparison of Total Energy Deposition in Uranium

V-G(ii) Theoretically Calculated Fraction of the Incident Electron Energy That Escapes From Uranium in the Form of Bremsstrahlung

V-G. 1 Fraction of Energy Backscattered From Uranium

V-G.2 Fraction of Electrons Backscattered From Uranium

V-G.3 Fraction of Energy Backscattered From Uranium Calculated With Standard and Improved Cross Sections

V-G. 4 Fraction of Electrons Backscattered From Uranium Calculated With Standard and Improved Cross Sections

V-H Theoretically Calculated Fraction of the Incident Electron Energy That Escapes From Uranium Dioxide in the Form of Bremsitrahlung

V-H, 1 Fraction of Energy Backscattered From Uranium Dioxide 


\section{ELECTRON ENERGY AND CHARGE ALBEDOS-- \\ CALORIMETRIC MEASUREMENT VS MONTE CARLO THEORY}

\section{Introduction}

Over the past few decades, an abundance of electron charge backscattering data, both integral and differential, has become available. 'However, a similar claim cannot be made in the case of electron energy backscatter. The only known attempt at a direct integral measurement is that of Wright and Trump. ${ }^{2}$ Integral energy reflection information is usually obtained either from twodimensional integration of angular-dependent pulse-height distributions or from theoretical models. The former method involves angular interpolation and/or extrapolation and careful corrections for detector response. The latter alternative will remain especially undesirable until the backscatter predictions of these models have themselves been adequately verified through comparison with accurate experimental measurements.

For material thicknesses greater than the range of the source electrons and where bremsstrahlung losses are small, the complements of absolute, high-precision, electron energy deposition data should yield indirect, though more reliable, values of saturated integral electron energy albedos. This follows from the identity

$$
R_{e} \equiv 1-\left(D+E_{\gamma}\right) / E_{o}
$$

where

$$
\begin{aligned}
R_{e} & =\text { desired reflection coefficient } \\
D & =\text { total deposited energy } \\
E_{\gamma} & =\text { ocoaping bremsstrahlung energy } \\
E_{o} & =\text { kinetic energy of the incident. electrons }
\end{aligned}
$$

However, most methods of measuring energy deposition that might be considered absolute (e.g. , passive dosimetry) are not precise enough to yield accurate backscatter data for low atomic number media. Other methods such as ionization chambers are more precise, but not generally considered absolute. Indeed, the complement of the integral energy reflection coefficient, which now can only be obtained in one of the two ways described above, is often used to normalize the energy deposition data.

Recently, an improved technique for the absolute measurement of energy deposition using calorimeters was developed. ${ }^{3}$ This paper presents the results of a series of experiments in which backscattered energy was determined from precise energy deposition measurements using this technique. The fraction of the energy backscattered for electrons incident on beryllium (Be), 
carbon ( $\mathrm{C}$ ), aluminum ( $\mathrm{Al}$ ), titanium ( $\mathrm{Ti}$ ), molybdenum (Mo), tantalum (Ta), uranium (U), and uranium oxide $\left(\mathrm{UO}_{2}\right)$ were determined as a function of the energy and angle of incidence of the source electrons. 'J'he energies 11sed were nominally $0.1,0.3,0.5$, and $1.0 \mathrm{MeV}$ fur dill materials. Additional results at about $0.025,0.050$, and $0.075 \mathrm{MeV}$ were obtained for $\mathrm{C}$, Al, Ta, and U. The angle of incidence was varied from $0^{\circ}$ to $75^{\circ}$ in steps of $15^{\circ}$ with additional measurements at $82.5^{\circ}$ in $\mathrm{Be}$ and $\mathrm{C}$. As far as we know, these data represent the first systematic integral measurements of electron energy albedos.

To complement the determination of backscattered energy in the situations described above, we also measured the fraction of electrons backscattered. Significant discrepancies remain in the existing data; for example, there is a scatter of at least $25 \%$ in the results given in Reference 1 for 1.0-MeV electrons normally incident upon $\mathrm{A}_{\mathrm{r}} l$.

The calorimetric method is reviewed in Section II. The experimental apparatus and procedures are described in Section III. Code verification is an important application of these data. In Section IV we describe how the TIGER code ${ }^{4}$ was used to generate a state-of-the-art prediction for each experimental albedo and to estimate the small corrections for bremsstrahlung escape, Section $\mathrm{V}$ is a complete systematic, graphical and tabular presentation of both experimental and theoretical results, including excerpts that have appeared in previous publications. ${ }^{5,6}$ Concluding remarks are contained in Section VI.

II Calorimetric Method

The analysis of the calorimetric response for the particular method used in this experiment was given in some detail in a previous report. ${ }^{3}$ The majnr part of that dioouodion ia reproduced here with smali changes as appropriate to this particular problem. The reader may refer to the previous report if he is interested in the more complete discussion.

For our purpose, we consider a circular calorimeter of uniform thickness (w)*, radius $\left(r_{0}\right)$, density $(\rho)$, specific heat $(c)$, thermal conductivity $\left(\mathrm{K}_{1}\right)$, and thermal emissivity $(\varepsilon)$, where cgs units are used throughout. The calorimeter is supported by a number of short wires, each of length $\mathrm{L}$ and thermal conductivity $\mathrm{K}_{2}$; the total croso sectional area of all suppurt wires combined is A. These wires are assumed to terminate in a perfect heat einlr. It is assumied Ulial there is no azimuthal temperature variation. The difference between the temperature at radius $r$ and that of the heat sink as a function of radius and time is $u(r, t)$.

\footnotetext{
${ }^{*} w$ was cliusen to be greater than the range of the most energetic electrons.
} 
Simple considerations lead to the following differential equation ${ }^{3}$ :

$$
\frac{1}{r} \frac{\partial}{\partial r}\left(r \frac{\partial u}{\partial r}\right)-\alpha^{2} u=\beta^{2} \frac{\partial u}{\partial t}-\frac{\dot{q}(r, t)}{w K_{1}} \text {. }
$$

where

$$
\alpha^{2}=\frac{8 \sigma \epsilon \mathrm{T}_{\mathrm{o}}^{3}}{\mathrm{wK}_{1}} \text {. and } \beta^{2}=\frac{\rho \mathrm{c}}{\mathrm{K}_{1}}
$$

In these expressions all symbols have been defined except the following:

$\sigma=$ the Stefan-Boltzmann constant

$T_{0}=$ the Kelvin temperature of the enclosure and heat sink

$\dot{q}(r, t)=$ the rate of heat input per unit area

NOTE: $\mathrm{T}^{4}-\mathrm{T}_{0}^{4}$ has been approximated by $4 \mathrm{~T}_{0}^{3} \mathrm{u}$

Our method employs beam modulation where the beam is a $100 \%$ modulated square wave (on-off) of period $t_{0}$. The areal rate of heat input is then given by

$$
\begin{array}{lll}
\dot{\mathrm{q}}(\mathrm{r}, \mathrm{t})=\dot{\mathrm{q}}(\mathrm{r}) & \text { for } & \mathrm{Nt}_{\mathrm{o}}<\mathrm{t} \leq(\mathrm{N}+1 / 2) \mathrm{t}_{\mathrm{o}} \\
\dot{q}(r, t)=0 & \text { for } & (\mathrm{N}+1 / 2) \mathrm{t}_{\mathrm{o}}<\mathrm{t} \leq(\mathrm{N}+1)_{0},
\end{array}
$$

where $\mathrm{N}$ is an integer. The initial condition is

$$
u(r, 0)=0 \text {, }
$$

and the boundary condition is

$$
\left.\frac{\partial u(r, t)}{\partial r}\right|_{r=r_{0}}=-\gamma^{2} u\left(i_{0}, t\right)
$$

Here $\gamma$ is defined by

$$
\gamma^{2}-\frac{\mathrm{K}_{2} \mathrm{~A} / \mathrm{L}}{2 \pi \mathrm{r}_{0} \mathrm{wK}_{1}}
$$

The equilibrium solutions $(N \rightarrow \infty)$ to Eq (2) are given by

$$
u(r, t)=\sum_{n-1}^{\infty} A_{n} J_{0}\left(k_{n} r\right)\left[1-\mu_{n} e^{-t^{\prime} / \tau_{n}}\right], N_{0}<t \leq(N+1 / 2) t_{0}
$$


and

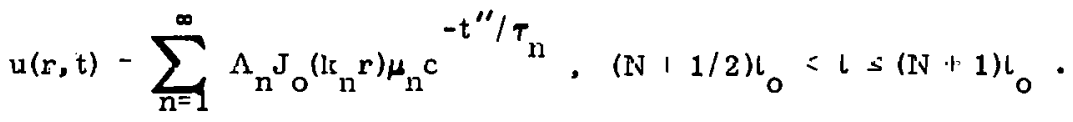

Here $t^{\prime}$ and $t^{\prime \prime}$ are the times measured from $N t_{0}$ and $(N+1 / 2) t_{0}$, respectively. The $k_{n}{ }^{\prime} s$ are the roots of $\mathrm{Eq}(5)$, which are obtained from

$$
k_{n} J_{1}\left(k_{n} r_{0}\right)=\gamma^{2} J_{0}\left(k_{n} r_{0}\right)
$$

and the $\tau_{n}$ 's are given by

$$
\tau_{n}=\frac{\beta^{2}}{\alpha^{2}+k_{n}^{2}}
$$

The $\mu_{n}{ }^{\prime}$ s are defined by

$$
\mu_{n}=\left[1+e^{-t_{0} / 2 \tau_{n}}\right]^{-1}
$$

$J_{0}$ and $J_{1}$ are the zero- and first-order Bessel functions. The $A_{n}$ 's are the Fourier-Bessel coefficients that are given by

$$
A_{n}=\frac{2 \tau_{n}}{w \rho c r_{0}^{2}} \frac{1}{J_{0}^{2}\left(k_{n} r_{0}\right)+J_{1}^{2}\left(k_{n} r_{0}\right)} \int_{0}^{r} m \dot{q}(r) J_{0}(k r) r d r .
$$

where $r_{m}$ is the maximum radius at which there is heat input. It is convenient to define $f(r)$, so that

$$
\dot{\mathrm{q}}(\mathrm{r})=\frac{\dot{\mathrm{Q}}_{\mathrm{o}}}{\pi r_{\mathrm{m}}^{2}} \mathrm{f}(\mathrm{r}), \quad \text { and } \int_{0}^{r_{\mathrm{m}}} \mathrm{f}(\mathrm{r}) 2 \pi \mathrm{rdr}=\pi \mathrm{r}_{\mathrm{m}}^{2}
$$

Here $\dot{Q}_{n}$ is the total rate of heat input. Then we obtain

$$
A_{n}=\frac{2 \dot{Q}_{0} \tau_{n}}{\pi r_{0}^{2} w \rho c} \frac{1}{J_{0}^{2}\left(k_{n} r_{0}\right)+J_{1}^{2}\left(k_{n} r_{0}\right)} \frac{1}{r_{m}^{2}} \int_{0}^{-r} m(r) J_{0}\left(k_{n} r\right) r d r .
$$


For the special case where $f(r)=1$ (i.e., the energy is put in uniformly over a circle of radius $r_{m}$, we obtain

$$
A_{n}=\frac{2 \dot{Q}_{0} T_{n}}{\pi r_{0}^{2} w \rho c} \frac{1}{J_{0}^{2}\left(k_{n} r_{0}\right)+J_{1}^{2}\left(k_{n} r_{0}\right)} \frac{J_{1}\left(k_{n} r_{m}\right)}{k_{n} r_{m}}
$$

We will assume such an input for the discussion that follows. At critical points the consequences of this assumption will be noted.

It was shown in Reference 3 that a measurement of the amplitude of the modulated temperature signal in many.cases does not give a satisfactory measurement of the energy deposition. This is true because the amplitude is very dependent on the geometry of the energy input term. Thus, the sensitivity is dependent on the radius over which energy deposition occurs. We search for an alternative method of determining deposition from. calorimeter temperature variation.

Equation (8) indicates that the time constants of successive terms in Eq (6) decrease rapidly as $k_{n}$ increases. Examination of a table of roots of Eq $(7)^{7}$ shows that $k_{n}$ increases rapidly with $n$, thus causing a rapid decrease in $\tau_{n}$. In a typical case, successive time constants were calculated to be $75,1.25,0.4$, and $0.2 \mathrm{~s}$ for $\mathrm{n}=1,2,3$, and 4 , respectively. This immediately suggests that, due to the negative exponential, all terms other than the first can be depressed by taking the time derivative at a time $\left(t_{d}\right)^{*}$ in each half-cycle that is large compared to $\tau_{2}$. We would then have

$$
\left.\frac{d u}{d t}\right|_{t=t_{d}}= \pm \sum A_{n} J_{0}\left(k_{n} r_{o}\right) \frac{\mu_{n}}{\tau_{n}} e^{-t_{d} / \tau_{n}}
$$

The plus or minus algebraic signs are obtained for the two half-cycles in Eq (6). If the condition $t_{d} \gg \tau_{2}, \tau_{3}$, etc, prevails, then

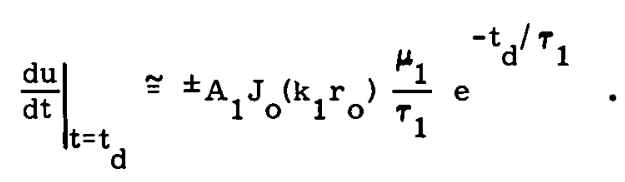

This solves no problem unless $A_{1}$ is a constant (independent of $r_{m}$ ); it is, in fact, a good approximation. Since $r_{m} \leq r_{0^{\prime}}$ we consider the range of $k_{1} r_{0}$.

Because of the small value of $k_{1} r_{0}(<2.405)$, the value of the factor

$$
\frac{2 \mathrm{~J}_{1}\left(\mathrm{k}_{1} \mathrm{r}_{0}\right)}{\mathrm{k}_{1} \mathrm{r}_{0}}
$$

\footnotetext{
${ }_{t_{d}}$ is a particular value of either $t$ ' or $t^{\prime \prime}$.
} 
is limited by

$$
1 \geq \frac{2 \mathrm{~J}_{1}\left(\mathrm{k}_{1} \mathrm{r}_{\mathrm{m}}\right)}{\mathrm{k}_{1} \mathrm{r}_{\mathrm{m}}} \geq 0.43 \text {, }
$$

with the limits arranged in order of increasing $k_{1} r_{m}$. While this is a large change, it is also unrealistic. In general, the characteristics of the support wires that determine $\gamma^{2}$ in Eq (7) will be chosen so that $k_{1} r_{0}$ will be no more than about 0.5 , resulting in a lower limit of

$$
\frac{2 J_{1}\left(k_{1} r_{0}\right)}{k_{1} r_{0}}=0.97 .
$$

While this is very satisfactory, this lower limit is still overly generous. In most cascs, $r_{m}$ will never be greater than $0.3 \mathrm{r}_{0}$; then the lower limit is about 0.997 instead of 0,97 .

The foregoing makes it clear that the derivative method provides a sensitivity that is very nearly constant. At this point one must reexamine the assumption that the energy is deposited in a manner independent of azimuth. Without attempting to solve the more general problem where $\dot{q}=\dot{q}(r, \phi)$, we can make an observation. If there is a $\phi$-dependence either by displacing the deposition axis or by making the beam asymmetrical, then the result is to introduce Bessel functions of order greater than zero into the series of Eq (6). These terms will also have time constants short compared to $\tau_{1}$, and therefore will be removed by the derivative process. Experimentally, the beam position was varied over a wide range $\left(\sim 30 \%\right.$ of $\left.r_{0}\right)$ with only small $(\sim 2 \%)$ variations in sensitivily. Typically the alignment in an experiment is maintained to within $0.05 \mathrm{r}_{u^{*}}$ However. asymmetries may become large for oblique incidence.

From Eqs (13) and (15), one may now obtain an expression for $\dot{Q}_{0}$. The approximations

$$
\underset{\mathrm{k}_{1} \mathrm{r}_{\mathrm{m}}}{2 \mathrm{~J}_{1}\left(\mathrm{k}_{1} \mathrm{r}_{\mathrm{m}}\right)}=1 \text {. }
$$

and

$$
\frac{J_{0}\left(k_{1} r\right)}{J_{0}^{2}\left(k_{1} r_{0}\right)+J_{1}^{2}\left(k_{1} r_{0}\right)}=1
$$

are made. These are both good within a few tenths of a percent for typical cases. This gives

$$
\dot{\mathrm{Q}}_{0}=\left.\pi \mathrm{r}_{0}^{2} w \rho c\left(1+e^{-\mathrm{t}_{0} / 2 \tau_{1}}\right) e^{t_{d} / \tau_{1}} \frac{d u}{d t}\right|_{t=t_{d}} .
$$


Equation (16) indicates that one is to take the derivative at $t=t_{d}$, calculate $e^{t_{d} / \tau_{1}}$, and insert these as factors into the equation. Several considerations enter into the choice of $t_{d}$; it must be large compared to $\tau_{2}$. In addition, it might be chosen to minimize variations in (or errors in the value of) $\tau_{1}$. By differentiating the $\tau_{1}$-dependent factors with respect to $\tau_{1}$ and setting the derivtive equal to zero, one finds that

$$
t_{d}=\frac{t_{o}}{2} e^{-t_{o} / 2 \tau_{1}}\left[1+e^{-t_{o} / 2 \tau_{1}}\right]^{-1}
$$

However, this criterion is not generally compatible with $t_{d} \gg \tau_{2}$. The problem was finally solved in the following manner. The data were processed in real time by an on-line digital computer (see Section III). The derivative was calculated continuously for $t_{d} \gg \tau_{2}$, and the computer produced a least-squares linear fit of $\ln \left(\frac{d u}{d t}\right)$ as a function of $t_{d^{*}}$. From this, the derivative could be calculated at any given time (even at $t_{d} \leqslant \tau_{2}$ ) with maximum precision, since all available data were used.

The calorimeters used in this experiment were calibrated by means of a $100-\mathrm{keV}$ positive ion accelerator. The same modulation rate and energy-deposition rate was used in each case. The use of positive ions is advantageous because (a) the range at this energy is much less than the calorimeter thickness, (b) backscatter is very small, and (c) bremsstrahlung production is negligible.

The design of total stopping calorimeters is much less complicated than that of thin-foil calorimeters. In the latter case, it was important to have large thermal conductivity and low thermal emissivity. While these are still desirable for thick calorimeters, the importance is diminished. Thus, materials that are marginal for thin calorimeters because of these properties are quite satisfactory for total stopping purposes. The thermal-coupling problem ${ }^{3}$ that was so important in the thin-foil case is nearly nonexistent here. The discussion concerning support wires, thermocouples, and modulation period in connection with thin foils ${ }^{3}$ is also applicable here. 


\section{Apparatus and Procedures}

The experimental method employed to determine back scattered energy uses the complements of absolute, high-precision, electron energy deposition measurements. These measurements use a square-wave modulated (on-off) electron beam and a calorimeter. The calorimeter is made of the material under investigation and is thicker than the range of the most energetic electrons used. The apparatus consists of a $1.0-\mathrm{MeV}$ electron accelerator, a large vacuum chamber with a beammeasuring Faraday cup, and an experimental package.

The electron accelerator delivers monoenergetic electron beams of up to $34 \mu \mathrm{A}$. The energy range is from 0.025 to $1.2 \mathrm{MeV}$. Because of the charging system design, the voltage ripple is less than $100 \mathrm{~V}$ at $1.0 \mathrm{MeV}$. A Sandia-designed voltage regulator has been incorporated that provides regulation within $1 \mathrm{kV}$ at $1.0 \mathrm{MV}$. The beam energy is knowri to approximately $0.5 \%$. A highprecision calorimetric system was developed for determining beam energy. 8 Prior to this development, the electron energy was calibrated by comparing pulses produced in a solid-state ion chamber by electrons from thin conversion sources with those produced by electrons from the accelerator. The energy determined by the solid-state ion chamber system was found to be high by a few percent. Since the reflected energy is obtained by dividing the energy deposited by the incident energy, all such determinations were made using the actual incident energy. These determinations are shown for each material in Section $V$.

The stainless-steel vacuum chamber.is $1.22 \mathrm{~m}$ in diameter, contains a Faraday cup, and has an experimental mounting platform (Figure IU-1). The Faraday cup, which is in line with the beam, precedes the mounting platform and is equipped with a solenoid-actuated end plate. This . end plate is used to electromechanically modulate the beam that is measured by the cup during the "off" half-cycle. Since the cup subtends only a very small solid angle for electrons backscaltered from the experimental package (located on the mounting platform), there is negligible probability of interference in the measurement of energy or charge deposited. The position of the mounting platform, which follows the Faraday cup, is adjustable and permits the experimental package to be located on the beam axis and positioned with the face of the calorimeter at the platform's axis of rotation. With this arrangement, the experimental package can be rotated about the beam axis in order to vary the angle of incidence. With the separated in-line Faraday cup, the beam-current measurement is not affected by the position of the experimental package. When energy deposition was measured for incident angles other than zero degrees, two methods of setting and determining the angle were employed. At first, the angle was set by physically rotating the mounting platform and reading the angle from the scale and vernier located on the shaft. Since the radiation cell had to be entered to change angles, the data were taken with the angle set to one sirle of $0^{\circ}$ only. This meant that if there was a small uncertainty in $0^{\circ}$ that would not significantly affect the normally incident data, this uncertainty would be added to the angle determination. The angle was read to $\pm 0.5^{\circ}$, and we estimate the uncertainty in $0^{\circ}$ to be $\pm 0.5^{\circ}$. When we used this method, we made at least one measurement of reflected energy and charge at a large angle set on both sides of $0^{\circ}$ 
and the percent difference was determined. For reflected energy and number, this difference was generally less than $1 \%$ and $2 \%$, respectively. To correct this problem, a new system was installed. In this system, the angular position of the mounting platform is continuously adjustable from the control room by means of an electric motor. The angle of rotation was measured to $0.1^{\circ}$ with a shaft encoder. With this arrangement, all angular measurements were obtained from the average of two determinations made when the platform was set at the desired angle on either side of $0^{\circ}$. Thus, any small uncertainty in $0^{\circ}$ would essentially be removed by this method. For each material, a list is given in Section $V$ that identifies the angle determination method used as either hand or remote set. The beam axis is defined by an aperture located in front of the Faraday cup and a similar aperture on the movable mount at the front edge of the platform. The second aperture is movable and so can be used to locate the beam on axis; it can then be moved from the path so that electron scattering from it does not occur and hence does not affect the measurement.

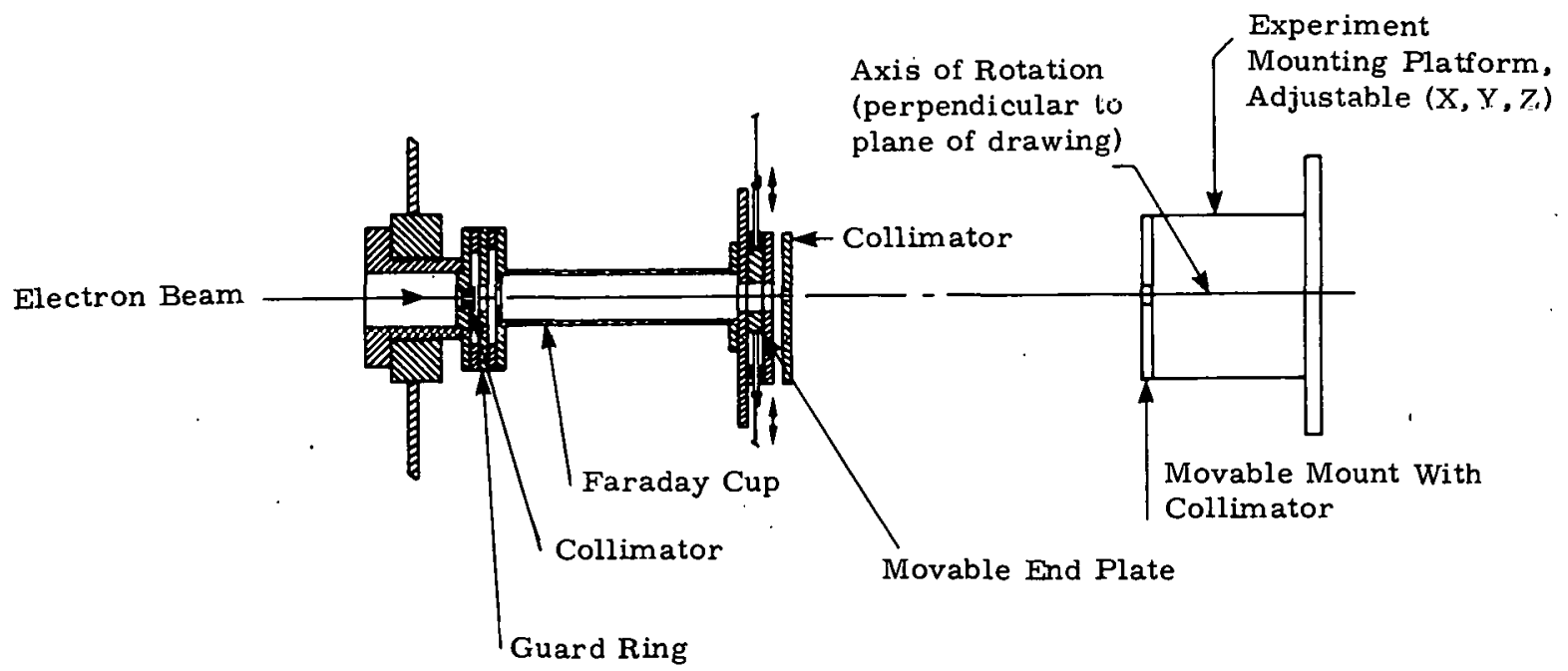

Figure III-1 Faraday Cup and Experimental Mounting Platform

The experimental apparatus used to make the deposition measurements is shown in Flyure III-2. The main components are the calorimeter, thermocouple, and reference junction. The apparatus could be fitted with a Faraday cup shield for calibration. This will be discussed later.

The calorimeters are circular and serve as targets for both energy- and charge-deposition measurements. For each material the selected thickness was slightly greater than the range of electrons at maximum energy. The diameter was made large enough to tolerate a slight misalignment to the beam at incidence angles of $75^{\circ}$ or greater. This resulted in a typical diameter of $5 \mathrm{~cm}$. 


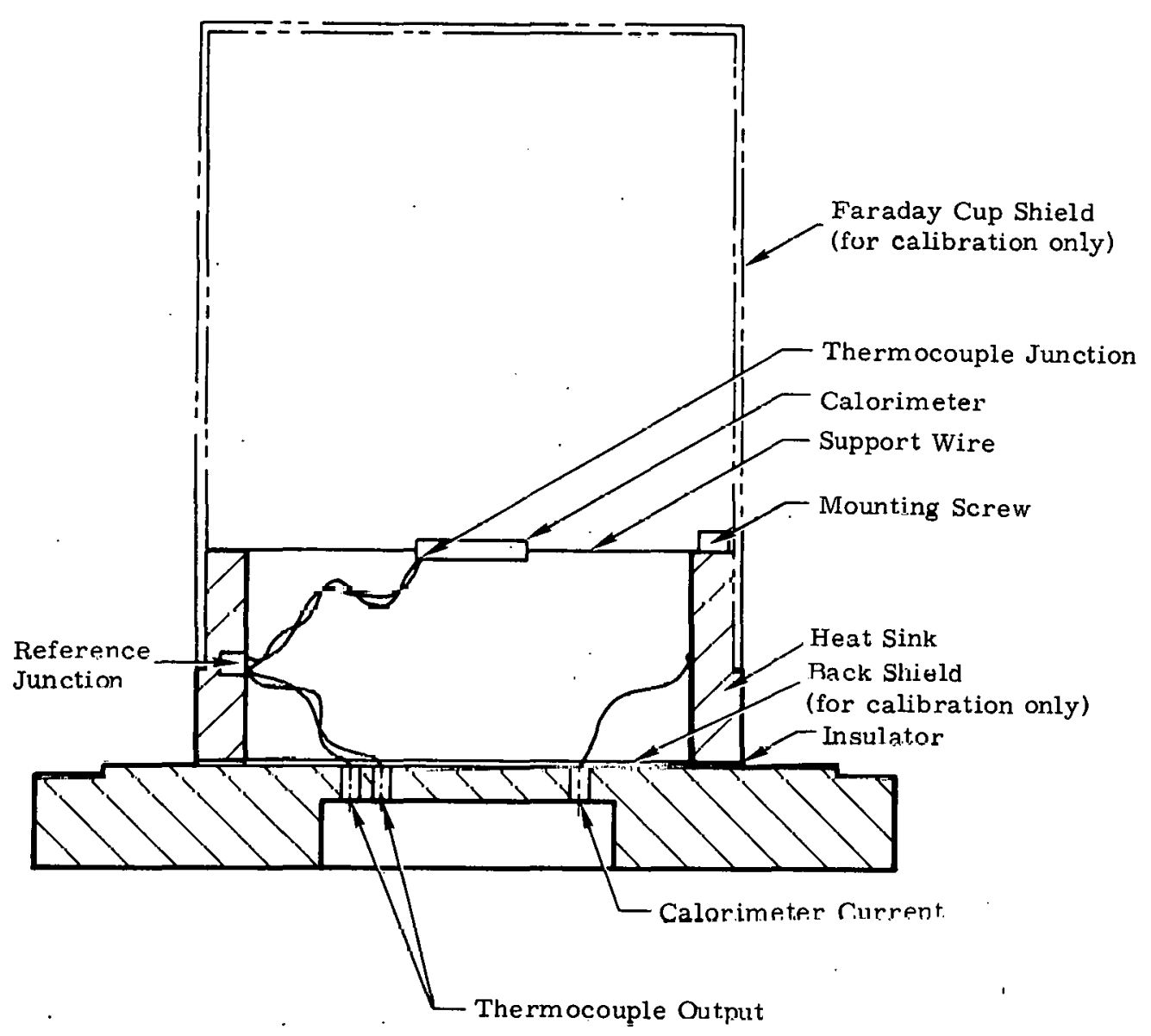

Figure III-2 Experimental Apparatus

'I'he thermocouple was made of No. 40, Chromel-Constantan thermocouple wire, The tharmocouple junction was usually located on the circumference of the calorimeter. In several cases. hrurever, the properties of the calorimeter material resulted in an abnormally large second time constant. After the beam current switched, the large second time constant produced a very long turnaround time for the thermocouple signal. In these cases, the thermncounle junstinn wns lncated at the zero of the Bessel function in the second term of the expression for cquilibrium temperature (Eq (6)) so that this term did not contribute. This location is at about 0.6 of the calorimcter radius; placing the thermocouple junction there resulted in a faster turnarnund. The referonoo junetion was located in the mounting-ring heat sink (see Figure III-2).

'I'he calorimeter and mounting ring were mounted to a base plate, but electrically insulated from it. Each element was connected to a hermetically sealcd BNC connector mounted in the base plate. This allowed for the measurement of total electron current deposited as well as the calorimeler. lliermocouple signal. The base plate was compatible with both the mounting platform in the vacuum chamber on the electron accelerator and the vacuum chamber on the heavy-ion accelerator used for calibration. This arrangement allowed the evperimontal apparatus lu lue uluved from the electron accelerator to the heavy-ion accelcrator without disturbing any of the internal electrical connections. 
Calibration of the calorimeter was accomplished by means of a heavy-ion accelerator. Since the range of heavy ions of $100-\mathrm{keV}$ energy is much less than the thickness of any of the calorimeters and since the reflection coefficient and the bremsstrahlung production are very small, the energy deposited in the calorimeter was determined by multiplying the incident beam current by the accelerating potential. The beam current measurement was made using a Faraday cup shield (FCS) attached to the experimental apparatus (Figure II-2). The FCS satisfied the requirements for a deep Faraday cup, insuring that the escape of secondary electrons ejected from the calorimeter by impact of the heavy ions was negligible. The accelerating potential was measured with a calibrated voltage divider and corrected for ion-source potentials. This accelerating potential is known to within $\pm 1 \%$. The incident ion beam was modulated in calibration to produce a symmetric square wave having the same period used with the electron measurements. Thus, the response of the calorimeter was determined for a well-defined rate of energy input.

The fraction of electrons backscattered was determined using a very straightforward method. The incident beam current $\left(i_{b}\right)$ was measured in the in-line Faraday cup. The deposited cur rent $\left(i_{d}\right)$ was measured with the target (calorimeter) maintained at a positive potential of approximately $55 \mathrm{~V}$. This was adequate to return the great majority of secondary electrons without significantly affecting the backscattered primaries. The fraction of electrons backscattered is given by $1-i_{d} / i_{b}$. Data acquisition and reduction was performed with an on-line computer.

The fraction of energy backscattered was obtained by subtracting the deposited energy from the incident energy and dividing the result by the incident energy. This was corrected for energy escaping in the form of bremsstrahlung as discussed in Section V. The data for determining the energy deposited was collected and processed by the on-line computer. A block diagram of the system is shown in Figure III-3. All measuring instruments used in the calibration are the same as those used to obtain the experimental data. The beam modulation period $\left(t_{0}\right)$ was selected to satisfy the requirement that $t_{o}$ should be a few times the first time constant $\left(\tau_{1}\right)$ of the calorimeter. Several cycles were examined by the computer. The rate of change of the thermocouple voltage (dv/dt) with time, normalized to the beam current $\left(i_{b}\right)$, was calculated continuously for times $\gg \tau_{2}$ (the second time constant), and the computer produced a linear least-squares fit of

$$
\left(\ln \frac{1}{i_{b}} \frac{d v}{d t}\right)
$$

as a function of time. From this the derivative could be calculated at any given time with maximum precision, since all available data were used. In practice the derivative was either calculated at a desired time, $t_{d}$, or at the intercept. When the intercept was used, it was corrected for variations in the first time constant $\tau_{1}$. Thus, a quantity $S$ is defined as

$$
S=\text { Intercept }\left(1+e^{-t_{o} / 2 \tau_{1}}\right)
$$

The method of data reduction used with each material will be given in Section $\mathrm{V}$ as either $t_{\mathrm{d}}$ or $\mathrm{S}$. 


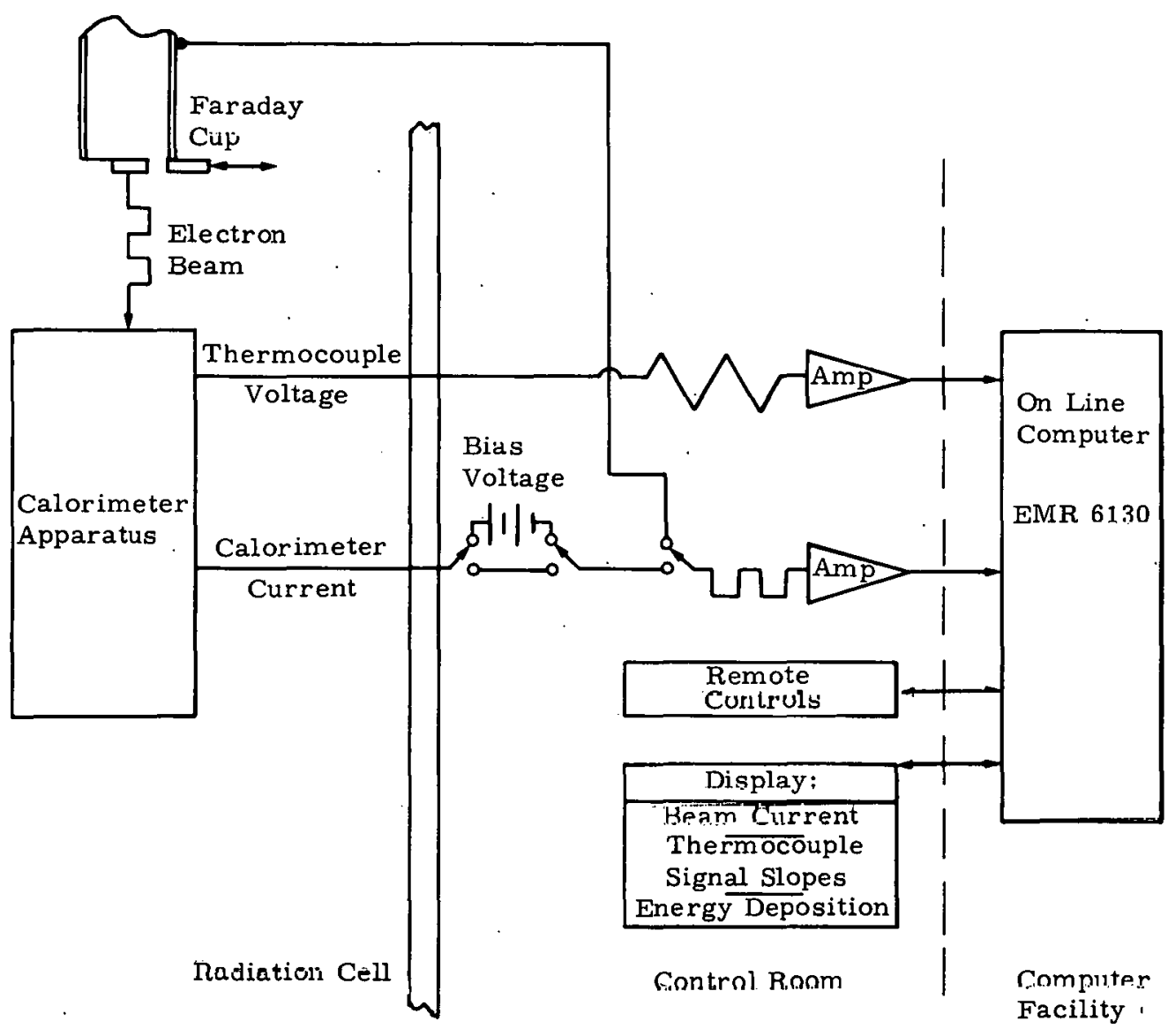

Figure III 3 Data Collection and Processing System

IV. 'Theoretical Model

All theoretical results were obtained from the one-dimensional, coupled, electron/photon. Monte Carlo transport code, TIGER. ${ }^{4}$ The TIGER code describes the generation and transport of the electron/photon cascade in multislab geometries from several megaelectronvolts down to $1.0 \mathrm{ke} V$ for electrons and to $10.0 \mathrm{keV}$ for photons. It combines condensed-history electron Monte Carlo ${ }^{9}$ with conventional single-scattering photon Monte Carlo. The electron transport includes energyloss straggling, elastic scattering and the production of knock-on electrons, continuous bremsstrahlung radiation, characteristic x-rays, and annihilation radiation. Photon transport inoludes the photoelectric, Compton, and pair-production interactions along with the production of the corresponding secondary particles. Electron cross sections and sampling distributions are obtained from a modified version of DATAPAC-4 and LIBRARY TAPE 2 of the ETRAN Monte Carlo code system. 10 The photon cross sections are the analytical fits of Biggs and Lighthill. ${ }^{11}$ The method is more accurate at higher energies with a less rigorous description of the particle cascade at lower energies where the atomic shell structures of the transport media become important. The only shell effects considered are ionization of, fluorescence of, and Auger emission from the K-shell of the highestatomic-number element in each material. 
For each choice of target, incident energy, and incident angle, a single TIGER calculation yields the electron energy albedo $\left(R_{e}\right)$ and bremsstrahlung escape energy $\left(E_{\gamma}\right)$ appearing in Eq (1). The number of primary histories ranges from 6000 for high- $Z$ targets at high angles of incidence to 200000 for Be at normal incidence. The resulting one-sigma statistical uncertainties in the calculated albedos are $1 \%$ to $2 \%$. Uncertainties in the bremsstrahlung escape energies were less than $10 \%$ as long as these energies were greater than $0.5 \%$ of the incident energies. As discussed in Section V, at incident energies $20.1 \mathrm{MeV}$, the "experimental" albedos were obtained by substituting these bremsstrahlung escape energies, along with the measured energy depositions and incident energies, into Eq (1).

The theoretical albedos include all backscattered electrons with energies greater than 0.004 and $0.002 \mathrm{MeV}$ for incident energies of 1.0 and $0.5 \mathrm{MeV}$, respectively. At lower incident energies, they include all backscattered electrons with energies $>0.001 \mathrm{MeV}$. In order to make the albedo calculations more efficient, a trapping procedure was employed. When the energy of an electron became so low that it could no longer escape from the target, this energy was deposited and the history was terminated. A special calculation without trapping for $\mathrm{U}$ at an incident energy of $1.0 \mathrm{Me} \mathrm{V}$ and normal incidence verified that this trapping procedure had no effect on the prediction of bremsstrahlung escape.

The cross section data used in the theoretical model become less reliable as the incident energy decreases, especially for high-Z targets. In particular, the Mott elastic-scattering cross section with Moliere screening becomes less accurate. Using improved numerical cros's sections, 12 we carried out additional calculations of electron backscatter in $\mathrm{Ta}$ and $\mathrm{U}$ for source energies in the 0.01 - to $0.10-\mathrm{MeV}$ range at incident angles of $0^{\circ}$ and $60^{\circ}$. In subsections $\mathrm{V}-\mathrm{F}$ and $\mathrm{V}-\mathrm{G}$ we present tabulated and graphical comparisons of the results obtained with the standard and improved cross sections, as well as a comparison with the measured data. Predictions obtained with the improved cross sections are consistently higher than those obtained with the standard cross sections. Still, at $0.033 \mathrm{MeV}$ (the lowest energy at which experimental results were obtained), the maximum differenre hetween the two theoretical predictions (occurring for the energy albedo in Ta at normal incidence) is only about $10 \%$. On the other hand, the experimental result for this same case is about $40 \%$ higher than the standard prediction. Disagreement among the three results decreases at higher source energies and incident angles. However, at $0.010 \mathrm{MeV}$ (where we have no experimental data), predictions with the new cross sections are (a) $25 \%$ higher for Ta-number albedos, (b) $50 \%$ higher for Ta-energy albedos and U-number albedos, and (c) $100 \%$ higher for U-energy albedos than those obtained with the old cross sections. 


\section{Results}

Absolute electron energy and charge albedos have been mcasured for eight materials. Measurements were triade as a function of energy and angle of incidence. The energy range was from $0.025 \mathrm{MeV}$ to $1.0 \mathrm{MeV}$. The angle of incidence was varied from $0^{\circ}$ to $75^{\circ}$ in steps of $15^{\circ}$, and was extended for selected materials to $82.5^{\circ}$. These measurements are compared with the predictions of the electron-photon Monte Carlo transport code, TIGER. ${ }^{4}$ The results are presented graphically and tabulated in subsections $\mathrm{V}-\mathrm{A}$ through $\mathrm{V}-\mathrm{H}$ at the end of this section. For each material, variations both in the experimental system and data reduction that affect the data are listed. To present an overview of the results. Figures V-1a and V-1b show the fraction of energy backscattered at angles of incidence of $0^{\circ}$ and $60^{\circ}$ for 1.0 and $0.1 \mathrm{MeV}$, respectively, as a function of atomic number. Figures V-2a and V-2b present corresponding results for the fraction of electrons backscattered.

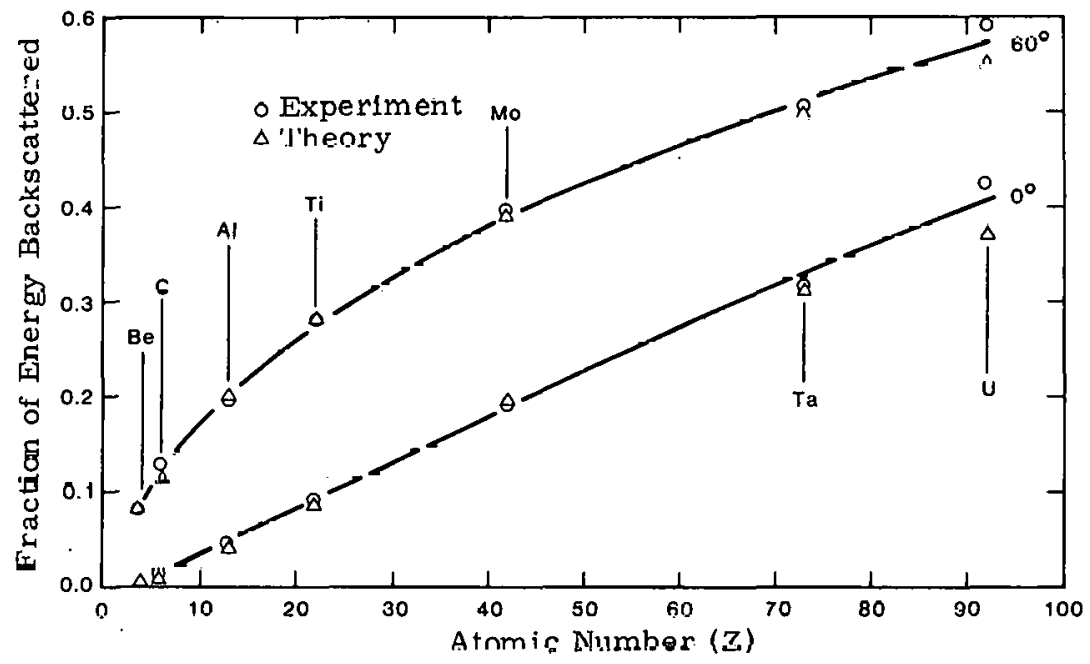

a. 1.0-MeV Electrnns

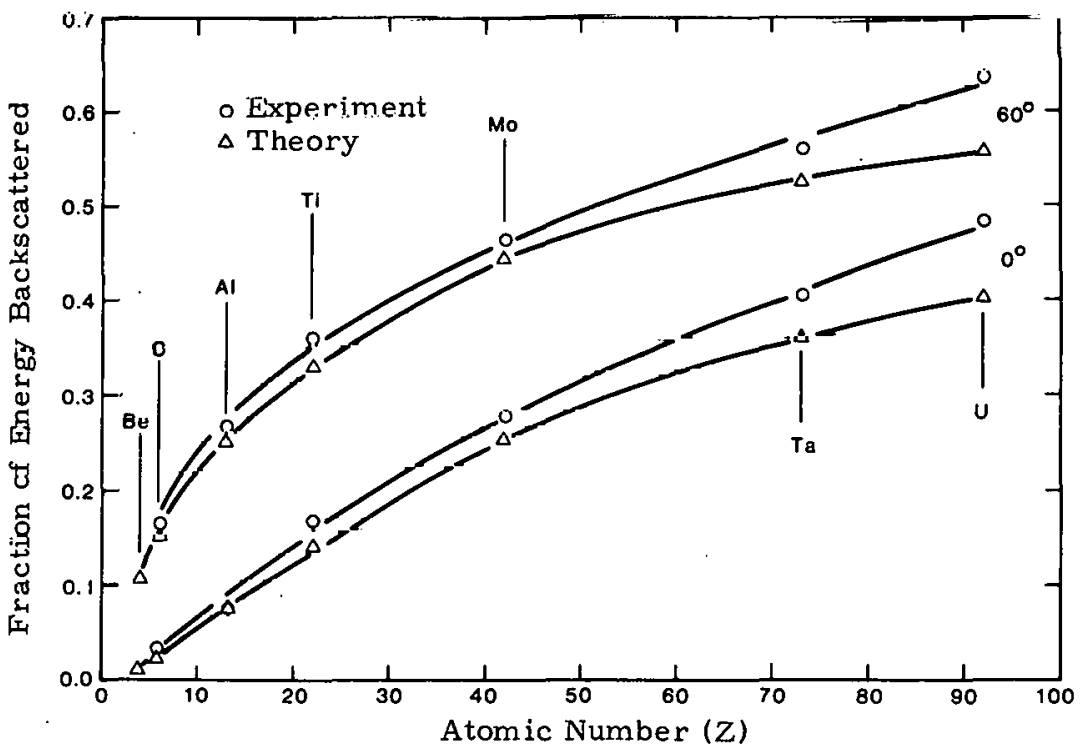

b. 0.1-MeV Electrons

Figure V-1 Comparison of Experimental and Theoretical Energy Backscatter for Electrons Incident at $0^{\circ}$ and $60^{\circ}$ as a Function of Target Atomic Number 


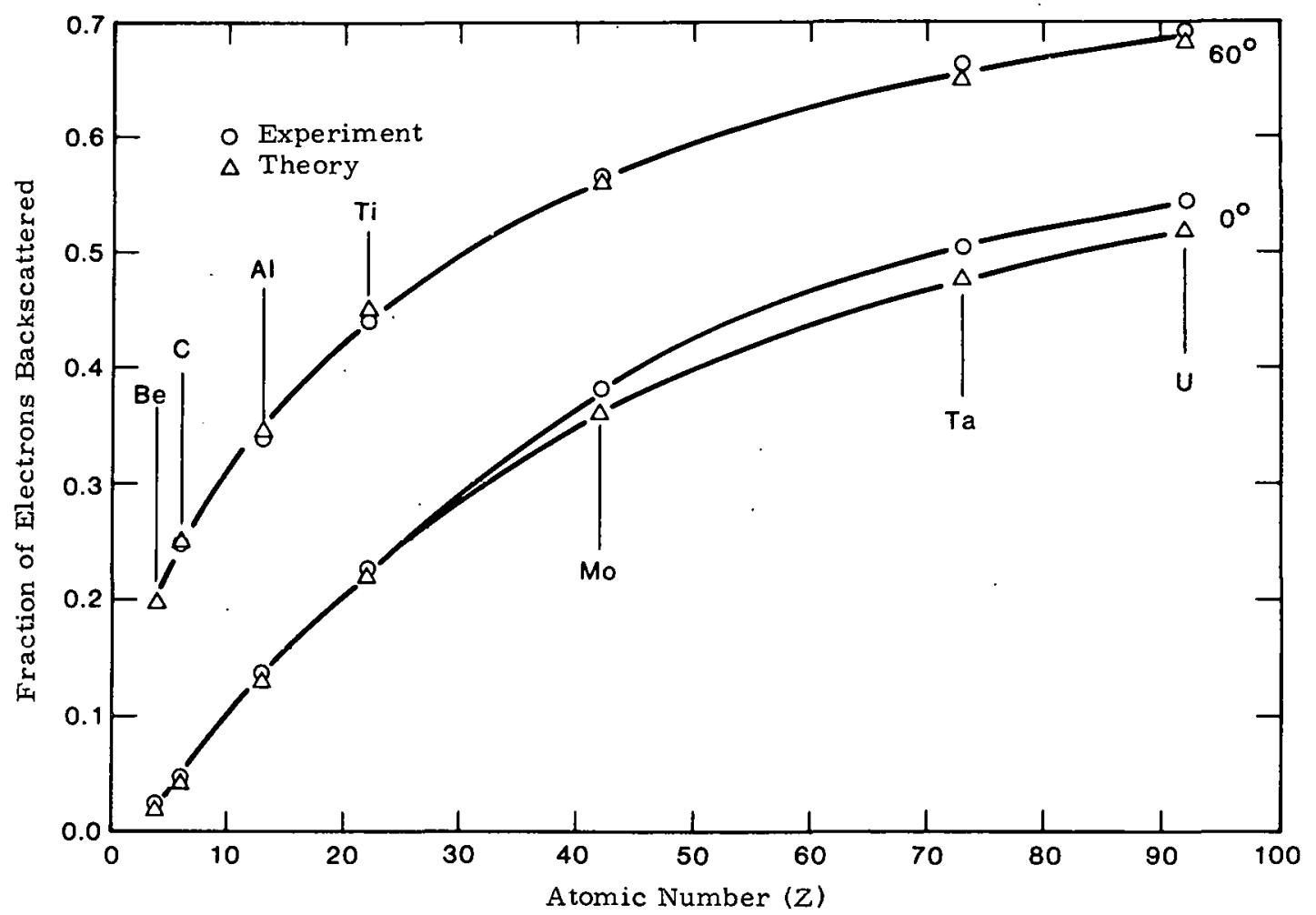

a. 1.0-MeV Electrons

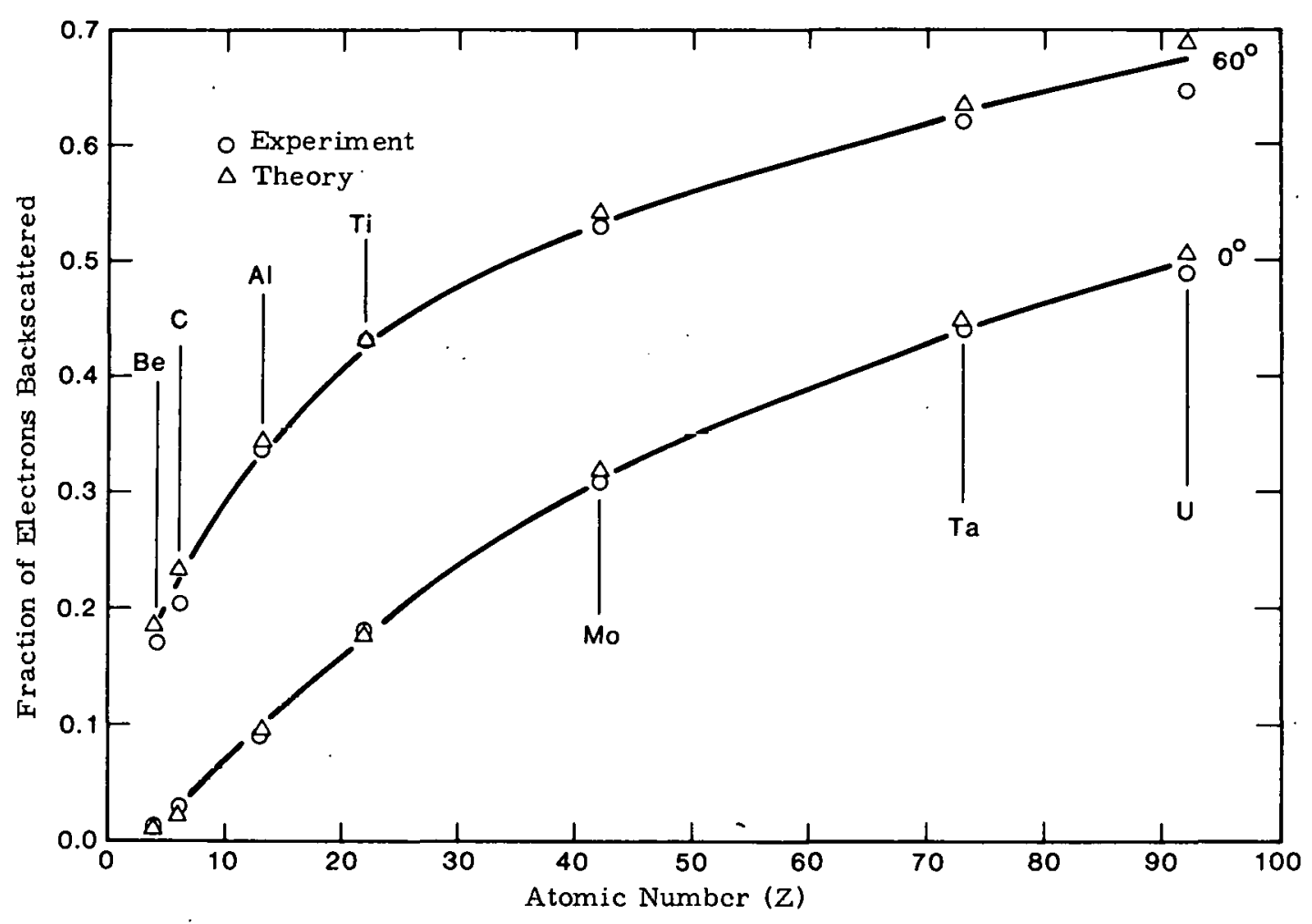

b. $0.1-\mathrm{MeV}$ Electrons

Figure V-2 Comparison of Experimental and Theoretical Number Backscatter for Electrons Incident at $0^{\circ}$ and $60^{\circ}$ as a Function of Targel Atomic Number 
The experimental results were obtained by subtracting the measured, cieposited energy from the incident energy and dividing the result by the incident encrgy. From this was subtracted the fraction of energy escaping in the form of bremsstrablung as determined by the TIGER codo. The bremsstrahlung corrections are tabulated as a function of incident energy and angle, and are presented for each material at the end of this section. This bremsstrahlung correction is quite small for the energy range covered in these experiments. The estimated statistical accuracy of this calculated correction is better than $10 \%$, except at low energies and low atomic numbers where the correction becomes negligible. We could have added the corrections to the predicted results instead of subtracting them from the measured escape fraction. However, the quantity of more practical importance is the energy that escapes in the form of reflected electrons only.

The estimated one-sigma statistical error in the TIGER results was maintained at approximately $1 \%$ to $2 \%$ by following the appropriate number of histories. The percent experimental uncertuinty is estimated by the expression.

$$
100 \mathrm{~K}_{i}(1-R)^{-1}\left[1+\left(\mathrm{K}_{d} / \mathrm{K}_{\mathrm{i}}\right)^{2} \mathrm{R}^{2}\right]^{1 / 2}
$$

where $R$ is the ratio of the deposited to the incident energy, and $\mathrm{K}_{\mathrm{d}}$ and $\mathrm{K}_{\mathrm{i}}$ are the fractional uncertainties in the deposited and incident energies, respectively. This expression follows directly from the assumption that the total uncertainty is just the square root of the sum of the sriares of the uncertainties in the measurements of the deposited and incident energies. It is the factor $(1-\mathrm{R})^{-1}$ that explicitly demonstrates the high precision required as the deposited energ. approaches the incident energy at small angles of incidence for materials of low atomic number.

For eảch material presented, a list is given that identifies the analysis methnd and angle de-

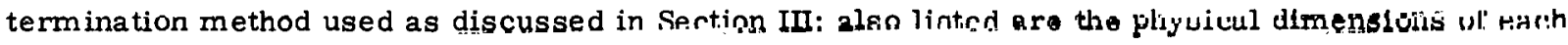
calorimeter. In addition, for $\mathrm{Be}, \mathrm{Al}, \mathrm{Mo}, \mathrm{Ta}$, and $\mathrm{U}$, electron energy deposition profiles have been measured $^{3}$ and integrated to obtain the total energy deposited. These values are listed along with the values from the TIGER calculation and the total energy deposited as measured with the total stopping calorimeters.

Finally, the theoretical predictions of the TIGER code calculations were perfnrmod uoing im proved numerical cross sections for electron backscatter in Ta and $U$ at low energies. For a discussion of these calculations. see Section IV. The rooulto obtained wilh the standard and improved Ciruss seclion are tabulated and compared graphically with the measured data in subsections $V-F$ and $\mathrm{V}-\mathrm{G}$. 
A. Electron Energy and Charge Albedos in Beryllium (Be)

Energies (MeV): $1.033,0.521,0.314$, and 0.109

Angles $\left({ }^{\circ}\right): 1,16,31,46,61,76$, and 83.5

Analysis Method: $t_{d}$

Angle Determination Method: Hand set

\section{Calorimeter}

Diameter: $2.54 \mathrm{~cm}$

Thickness: $0.381 \mathrm{~cm}$

Table V-A(i)

A Comparison of Total Energy Deposited in Beryllium

\begin{tabular}{|c|c|c|c|c|}
\hline \multirow[b]{2}{*}{$\begin{array}{c}\text { Nominal } \\
\text { Energy } \\
(\mathrm{MeV}) \\
\end{array}$} & \multirow[b]{2}{*}{$\begin{array}{l}\text { Angle } \\
\text { (deg) } \\
\end{array}$} & \multicolumn{3}{|c|}{ Fraction of Energy Deposited } \\
\hline & & $\begin{array}{c}\text { TIGER } \\
\text { Calculation } \\
\end{array}$ & $\begin{array}{c}\text { Total } \\
\text { Stopping } \\
\text { Measurement } \\
\end{array}$ & $\begin{array}{c}\text { Integrated } \\
\text { Differential } \\
\text { Measurement }\end{array}$ \\
\hline 0.5 & 0 & 0.994 & 0.995 & 0.998 \\
\hline 0.3 & 0 & 0.993 & 0.993 & 0.994 \\
\hline 0.1 & 0 & 0.991 & 0.990 & 1.00 \\
\hline
\end{tabular}

Table V-A(ii)

Theoretically Calculated Fraction of the Incident Electron Energy That Escapes From Beryllium in the Form of Bremsstrahlung

\begin{tabular}{|c|c|c|c|c|c|c|c|}
\hline \multirow{2}{*}{$\begin{array}{c}\text { Energy } \\
\text { (MeV) }\end{array}$} & \multicolumn{7}{|c|}{ Angle of Incidence } \\
\hline & $1^{\circ}$ & $16^{\circ}$ & $31^{\circ}$ & $46^{\circ}$ & $61^{\circ}$ & $76^{\circ}$ & $83.5^{\circ}$ \\
\hline 1.0 & $1.86 \times 10^{-3}$ & - & $2.00 \times 10^{-3}$ & $1.91 \times 10^{-3}$ & $2.17 \times 10^{-3}$ & $1.62 \times 10^{-3}$ & $1.58 \times 10^{-3}$ \\
\hline 0.5 & $9.74 \times 10^{-4}$ & - & $9.31 \times 10^{-4}$ & $1.00 \times 10^{-3}$ & $1.06 \times 10^{-3}$ & $7.25 \times 10^{-4}$ & $7.25 \times 10^{-4}$ \\
\hline 0.3 & $5.85 \times 10^{-4}$ & - & 5. $40 \times 10^{-4}$ & $6.91 \times 10^{-4}$ & $7.06 \times 10^{-4}$ & 5. $64 \times 10^{-4}$ & - \\
\hline 0.1 & $1.72 \times 10^{-4}$ & - & 1. $75 \times 10^{-4}$ & $2.64 \times 10^{-4}$ & $1.72 \times 10^{-4}$ & - & - \\
\hline
\end{tabular}




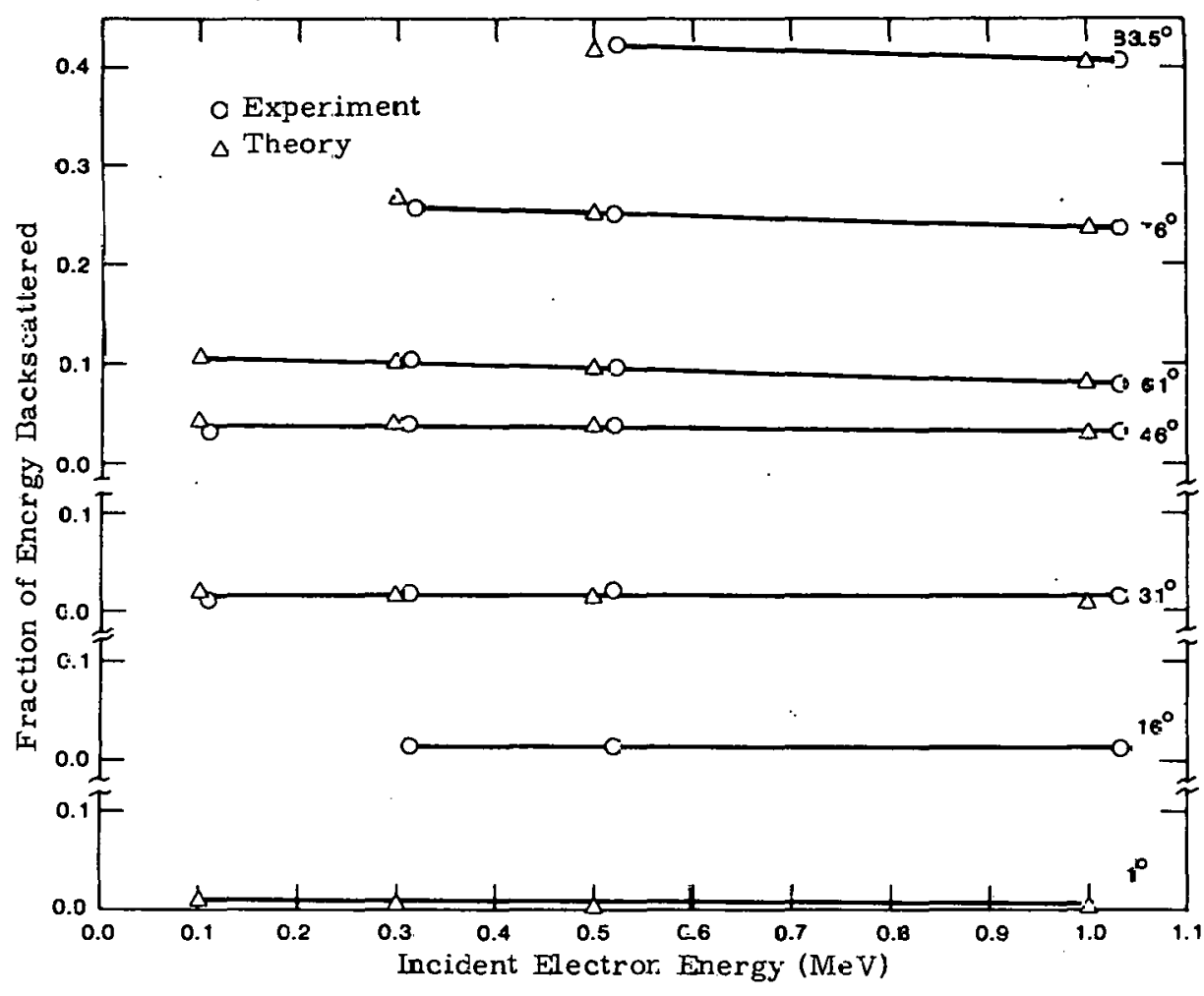

a. Comparison as a Function of Incident Energy

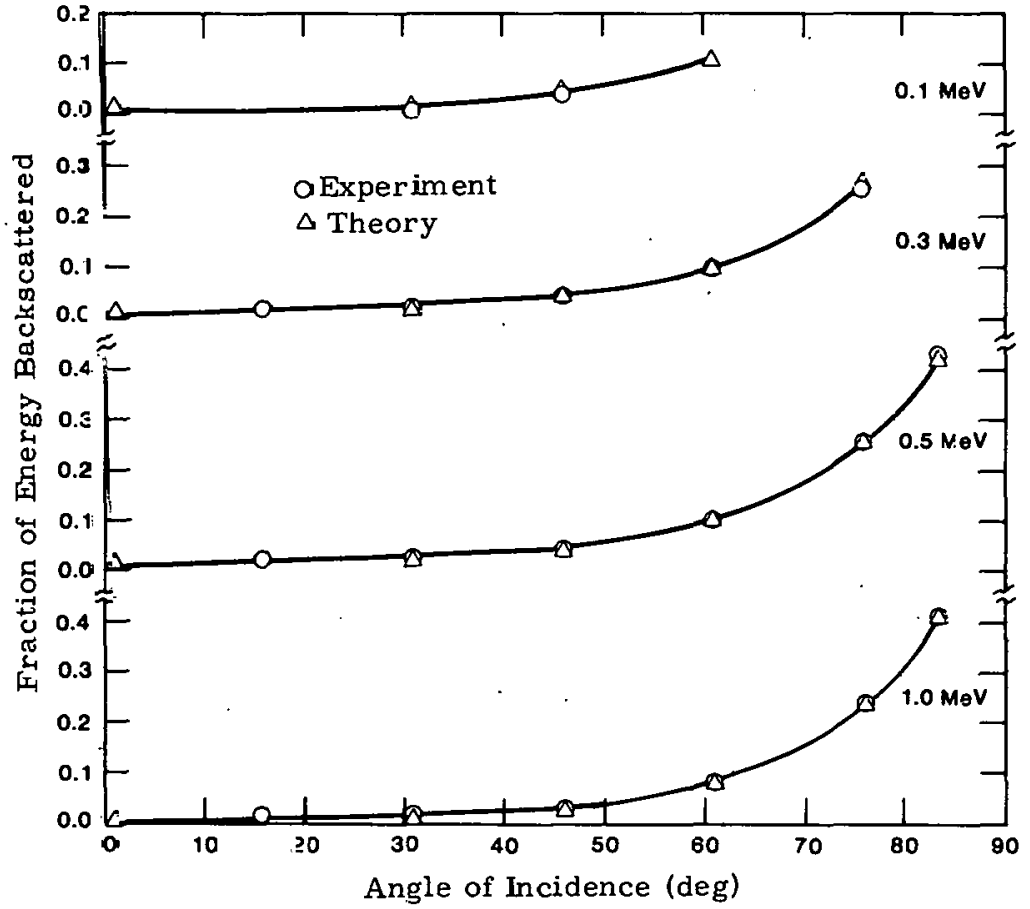

b. Comparison as a Function of Incident Angle

Figure V-A. 1 Comparison of Experimental and Theoretical Energy Backscatter in Beryllium 
Table V-A. 1

Fraction of Energy Backscattered From Beryliium 1,2

Angle of Incidence

\begin{tabular}{|c|c|c|c|c|c|c|c|c|}
\hline \multirow{2}{*}{\multicolumn{2}{|c|}{$\begin{array}{c}\begin{array}{c}\text { Energs } \\
(\mathrm{MeV})\end{array} \\
\end{array}$}} & \multicolumn{7}{|c|}{ le of Incidence } \\
\hline & & $1^{\circ}$ & $16^{\circ}$ & $31^{\circ}$ & $46^{\circ}$ & $61^{\circ}$ & $76^{\circ}$ & $83.5^{\circ}$ \\
\hline Exp & 1.033 & - & $\Xi .16 \times 10^{-2}$ & 1. $59 \times 10^{-2}$ & $3.16 \times 10^{-2}$ & $7.85 \times 10^{-2}$ & 2. $36 \times 10^{-1}$ & $4.06 \times 10^{-1}$ \\
\hline Theory & 1.0 & $3.40 \times 10^{-3}$ & $-\quad$. & $9.58 \times 10^{-3}$ & 2. $68 \times 10^{-2}$ & $8.0 \times 10^{-2}$ & $2.39 \times 10^{-1}$ & $4.05 \times 10^{-1}$ \\
\hline Exp & 0.521 & - & $2.34 \times 10^{-3}$ & $2.15 \times 10^{-2}$ & $3.76 \times 10^{-2}$ & $9.52 \times 10^{-2}$ & $2.47 \times 10^{-1}$ & $4.25 \times 10^{-1}$ \\
\hline Theory & 0.5 & $5.42 \times 10^{-3}$ & - & $1.37 \times 10^{-2}$ & $3.44 \times 10^{-2}$ & $9.53 \times 10^{-2}$ & $2.50 \times 10^{-1}$ & $4.17 \times 10^{-1}$ \\
\hline Exp & 0.314 & - & $\Xi .42 \times 10^{-2}$ & 1. $90 \times 10^{-2}$ & $3.89 \times 10^{-2}$ & $1.01 \times 10^{-1}$ & $2.55 \times 10^{-1}$ & - \\
\hline Theory & 0.3 & $6.77 \times 10^{-3}$ & - & 1. $65 \times 10^{-2}$ & $3.87 \times 10^{-2}$ & $1.03 \times 10^{-1}$ & $2.64 \times 10^{-1}$ & - \\
\hline $\operatorname{Exp}$ & 0.109 & - & - & $9.48 \times 10^{-3}$ & $3.25 \times 10^{-2}$ & - & - & - \\
\hline Theory & 0.1 & $9.53 \times 10^{-3}$ & - & 1. $99 \times 10^{-2}$ & $4.43 \times 10^{-2}$ & $1.06 \times 10^{-1}$ & - & - \\
\hline
\end{tabular}

$1_{\text {Experimental }}$ results adjusted by subtracting the fraction of energy esca jing in the form of bremsstrahlung as determined by the TIGER code. To adjust the $16^{\circ}$ experimental resilts, the average of the calculated $1^{\circ}$ and $31^{\circ}$ adjustments was used.

2 Experimental values for $1^{\circ}$ not obtained. Values obtained from calculated energy escape for energy calibration (reflected electrons orly). 


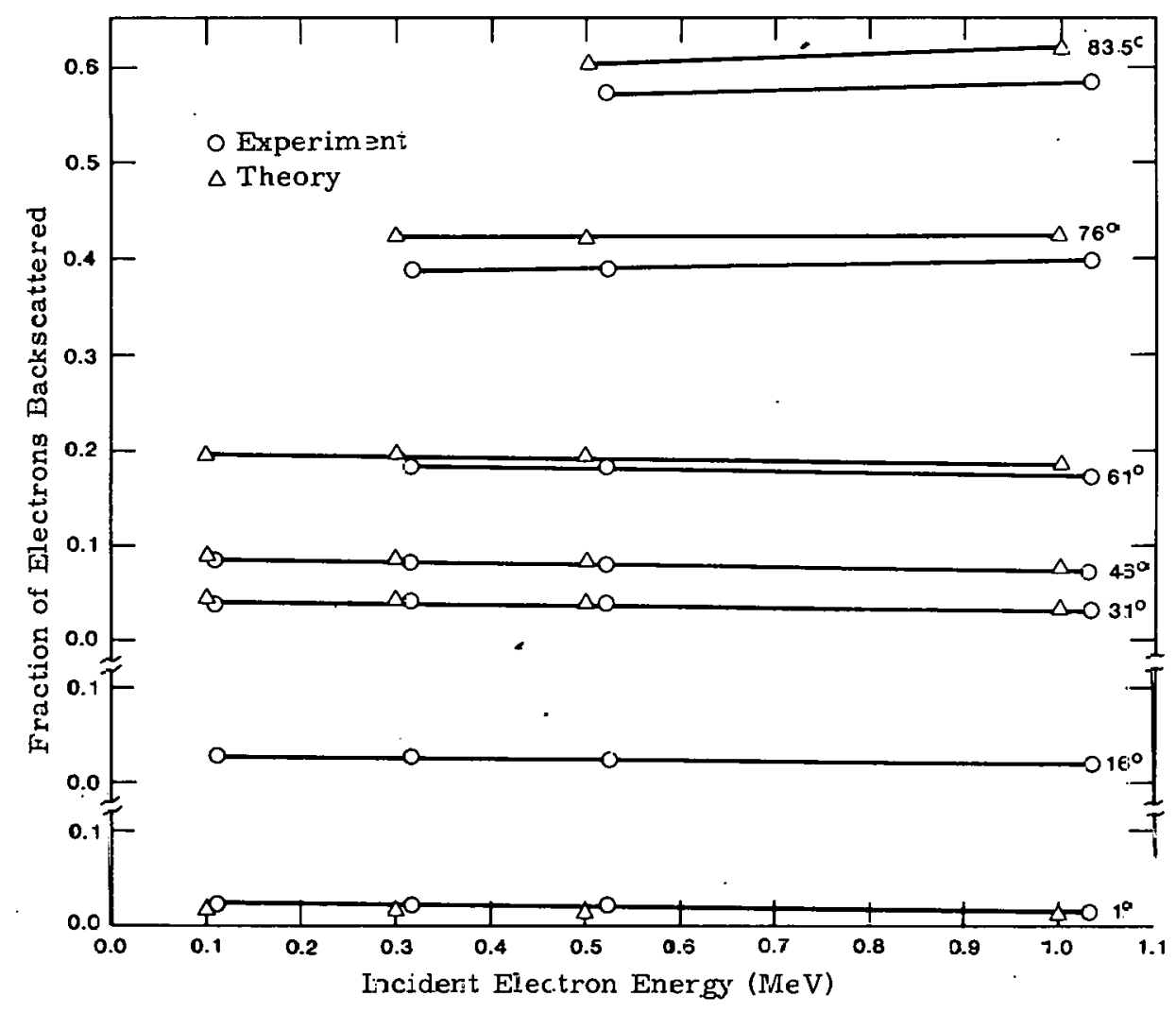

a. Comparison as a Function o? lncident Energ:

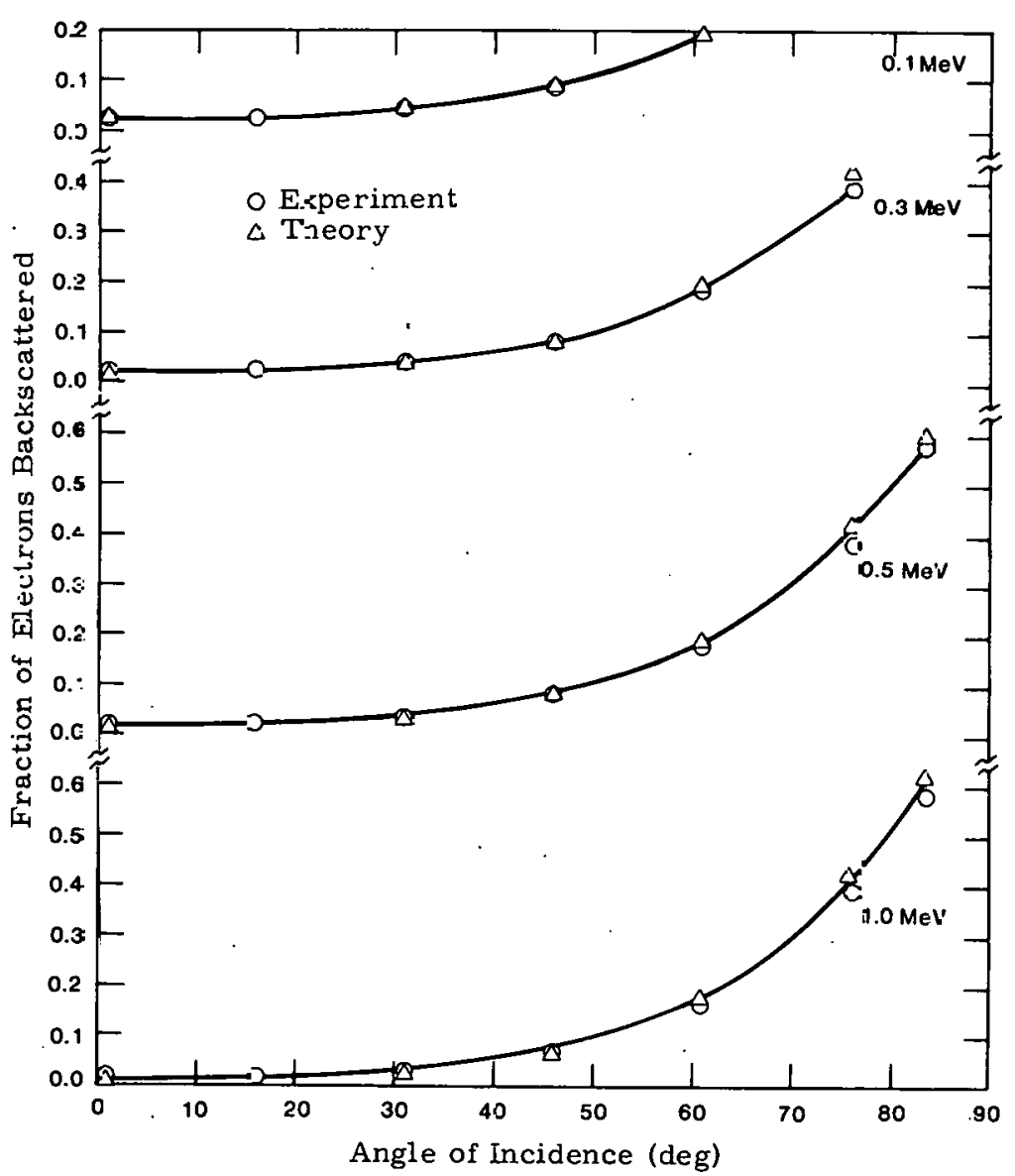

b. Comparison as a Function of Incident Angle

Figure V-A.2 Comparison of Experimental and Theoretical Number Backszatter in Beryllium 
Table V-A.2

Fraction of Electrons Backscattered From Beryllium

Angle of Incidence

\begin{tabular}{|c|c|c|c|c|c|c|c|c|}
\hline \multirow[b]{2}{*}{. } & \multirow{2}{*}{$\begin{array}{c}\text { Energy } \\
\text { (MeV) }\end{array}$} & \multicolumn{7}{|c|}{ Angle of Incidence } \\
\hline & & $1^{\circ}$ & $16^{\circ}$ & $31^{\circ}$ & $46^{\circ}$ & $61^{\circ}$ & $76^{\circ}$ & $83.5^{\circ}$ \\
\hline Exp & 1.033 & $1.20 \times 10^{-2}$ & 1. $74 \times 10^{-2}$ & $3.06 \times 10^{-2}$ & $6.96 \times 10^{-2}$ & $1.70 \times 10^{-1}$ & $3.96 \times 10^{-1}$ & $5.84 \times 10^{-1}$ \\
\hline Theory & 1.0 & $1.07 \times 10^{-2}$ & - & $2.91 \times 10^{-2}$ & $7.40 \times 10^{-2}$ & $1.85 \times 10^{-1}$ & 4. $26 \times 10^{-1}$ & $6.20 \times 10^{-1}$ \\
\hline $\operatorname{Exp}$ & 0.521 & $2.11 \times 10^{-2}$ & 2. $17 \times 10^{-2}$ & $3.75 \times 10^{-2}$ & $7.89 \times 10^{-2}$ & $1.83 \times 10^{-1}$ & $3.87 \times 10^{-1}$ & $5.72 \times 10^{-1}$ \\
\hline Theory & 0.5 & $1.40 \times 10^{-2}$ & - & $3.60 \times 10^{-2}$ & $8.29 \times 10^{-2}$ & $1.97 \times 10^{-1}$ & $4.20 \times 10^{-1}$ & $6.03 \times 10^{-1}$ \\
\hline $\operatorname{Exp}$ & 0.314 & $2.10 \times 10^{-2}$ & 2. $63 \times 10^{-2}$ & $4.10 \times 10^{-2}$ & $8.33 \times 10^{-2}$ & $1.84 \times 10^{-1}$ & $3.87 \times 10^{-1}$ & - \\
\hline Theory & 0.3 & $1.63 \times 10^{-2}$ & - & $3.97 \times 10^{-2}$ & 8. $67 \times 10^{-2}$ & $1.98 \times 10^{-1}$ & 4. $23 \times 10^{-1}$ & - \\
\hline Exp & 0.109 & $2.23 \times 10^{-2}$ & $2.68 \times 10^{-2}$ & $3.80 \times 10^{-2}$ & 8. $39 \times 10^{-2}$ & - & - & - \\
\hline Theory & 0.1 & $2.01 \times 10^{-2}$ & - & $4.25 \times 10^{-2}$ & $9.11 \times 10^{-2}$ & $1.96 \times 10^{-1}$ & - & - \\
\hline
\end{tabular}




\section{B. Electron Energy and Charge Albedos in Carbon}

Energies (MeV): $1.0,0.5,0.3,0.1,0.075,0.05$, and 0.025

Angles $\left({ }^{\circ}\right): 0,15,30,45,60,75$, and 82.5

Analysis Method: S

Angle Determination Method: Remote set

\section{Calorimeter}

Diameter: $5.08 \mathrm{~cm}$

Thickness: $0.478 \mathrm{~cm}$

\section{Table V-B}

Theoretically Calculated Fraction of the Incident Electron Energy That Escapes From Carbon in the Form of Bremsstrahlung

\begin{tabular}{|c|c|c|c|c|c|c|c|}
\hline \multirow[b]{2}{*}{$\begin{array}{c}\text { Energy } \\
\text { (MeV) } \\
\end{array}$} & \multicolumn{7}{|c|}{ Angle of Incidence } \\
\hline & $0^{\circ}$ & $15^{\circ}$ & $30^{\circ}$ & $45^{\circ}$ & $60^{\circ}$ & $75^{\circ}$ & $82.5^{\circ}$ \\
\hline 1.0 & $2.57 \times 10^{-3}$ & - & $2.84 \times 10^{-3}$ & $2.69 \times 10^{-3}$ & $2.70 \times 10^{-3}$ & $2.34 \times 10^{-3}$ & $2.35 \times 10^{-3}$ \\
\hline 0.5 & 1. $31 \times 10^{-3}$ & - & $1.29 \times 10^{-3}$ & $1.60 \times 10^{-3}$ & $1.43 \times 10^{-3}$ & 1. $56 \times 10^{-3}$ & $8.35 \times 10^{-4}$ \\
\hline 0.3 & $8.11 \times 10^{-4}$ & - & $7.97 \times 10^{-4}$ & 8. $25 \times 10^{-4}$ & $6.65 \times 10^{-4}$ & $2.33 \times 10^{-4}$ & 8. $77 \times 10^{-4}$ \\
\hline 0.1 & $2.45 \times 10^{-4}$ & - & $2.67 \times 10^{-4}$ & $3.11 \times 10^{-4}$ & 1. $55 \times 10^{-4}$ & $3.50 \times 10^{-4}$ & - \\
\hline 0.075 & $1.94 \times 10^{-4}$ & - & $1.53 \times 10^{-4}$ & 1. $79 \times 10^{-4}$ & $1.53 \times 10^{-4}$ & $3.84 \times 10^{-4}$ & - \\
\hline 0.05 & $8.69 \times 10^{-5}$ & - & $1.10 \times 10^{-4}$ & $6.00 \times 10^{-5}$ & $6.09 \times 10^{-5}$ & $3,04 \times 10^{-5}$ & - \\
\hline 0.025 & $4.21 \times 10^{-5}$ & - & $3.95 \times 10^{-5}$ & $2.50 \times 10^{-5}$ & $4.51 \times 10^{-5}$ & $6.57 \times 10^{-5}$ & - \\
\hline
\end{tabular}




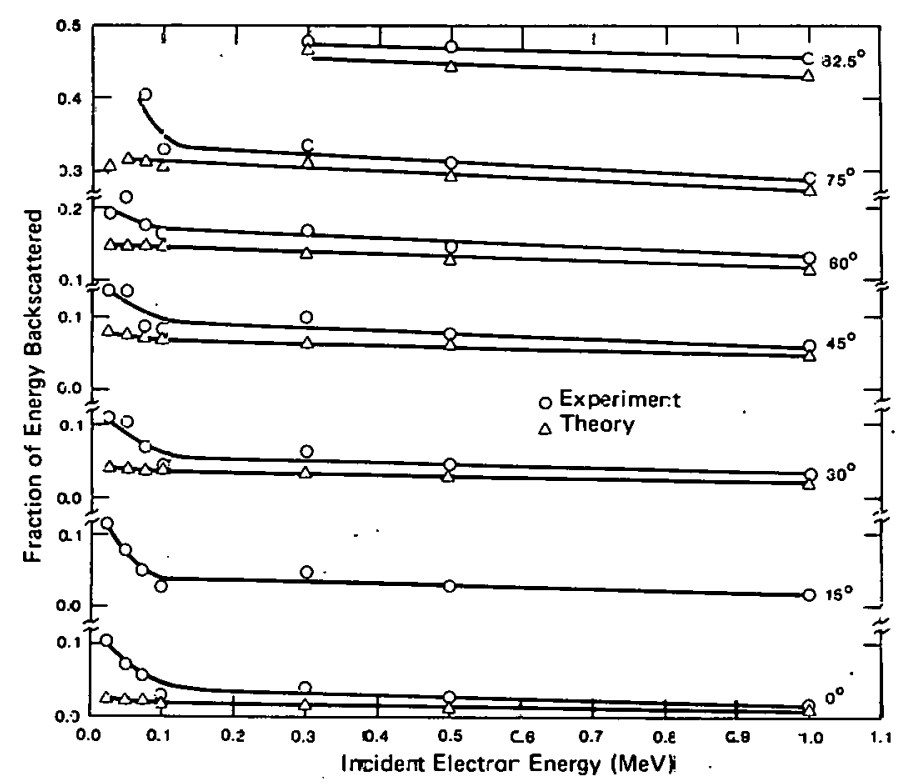

a. Comparson as a Funation of Incident Energy
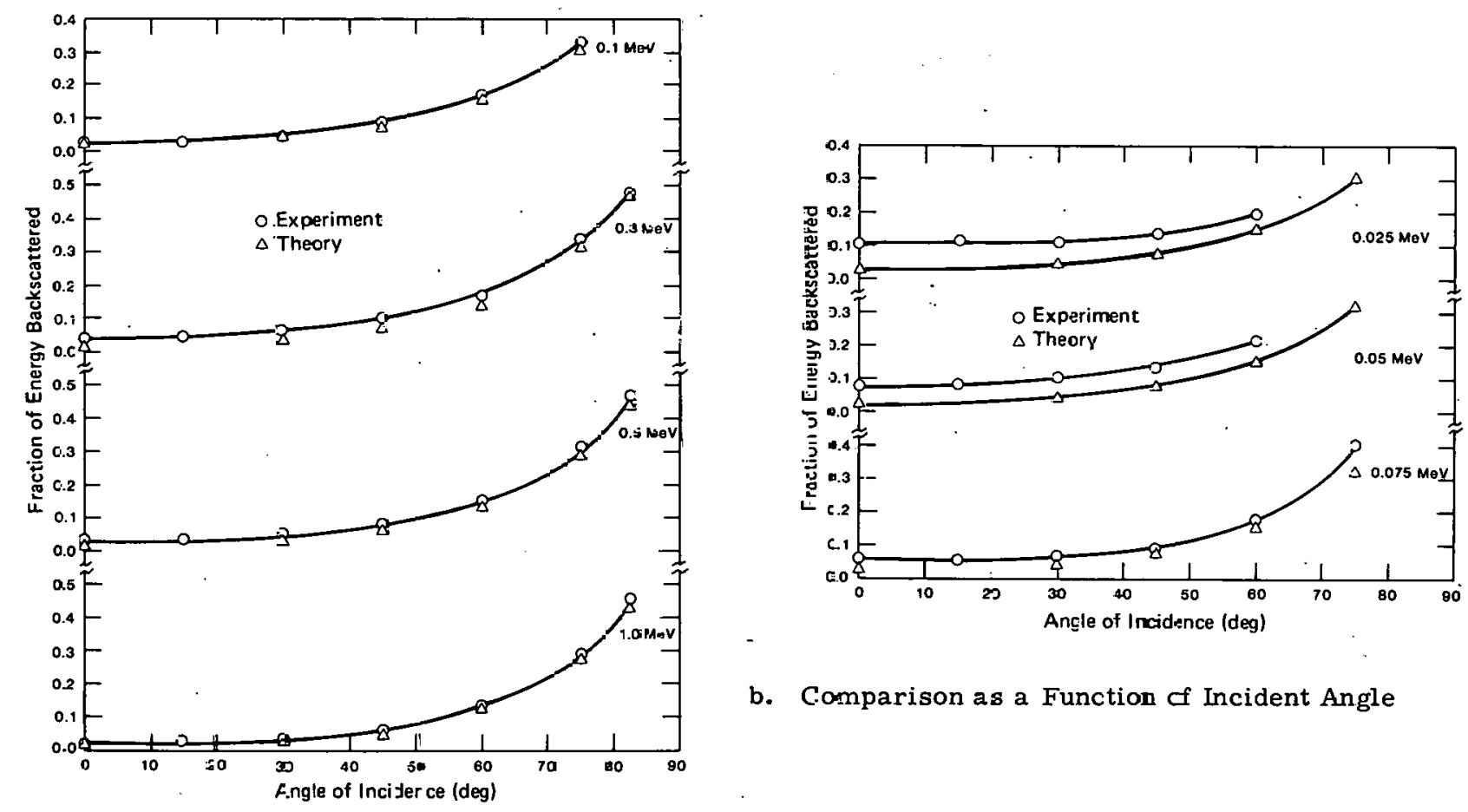

b. Comparison as a Function of Incident Angle

Figure V-3. 1 Comparison of Exfernental and Tr.eoretical Energy Backscatter in Carbon 
Table V-B. 1

Fraction of Energy Backscattered From Carbon ${ }^{1}$

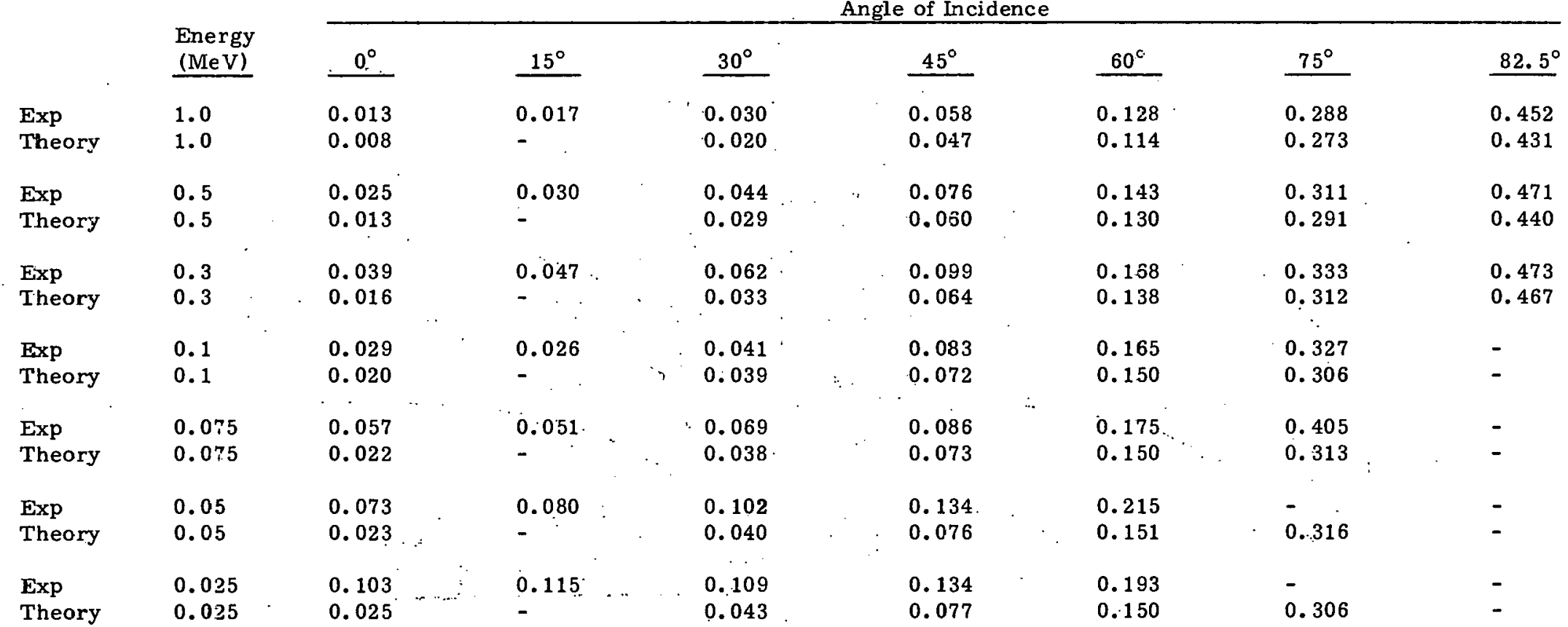

Experimental results adjusted by subtracting the fraction of energy escaping in the form of bremsstrahlung as determined by the TIGER code. To adjust the $15^{\circ}$ experimental results, the average of the calculated $0^{\circ}$ and $30^{\circ}$ adjustments was used. 


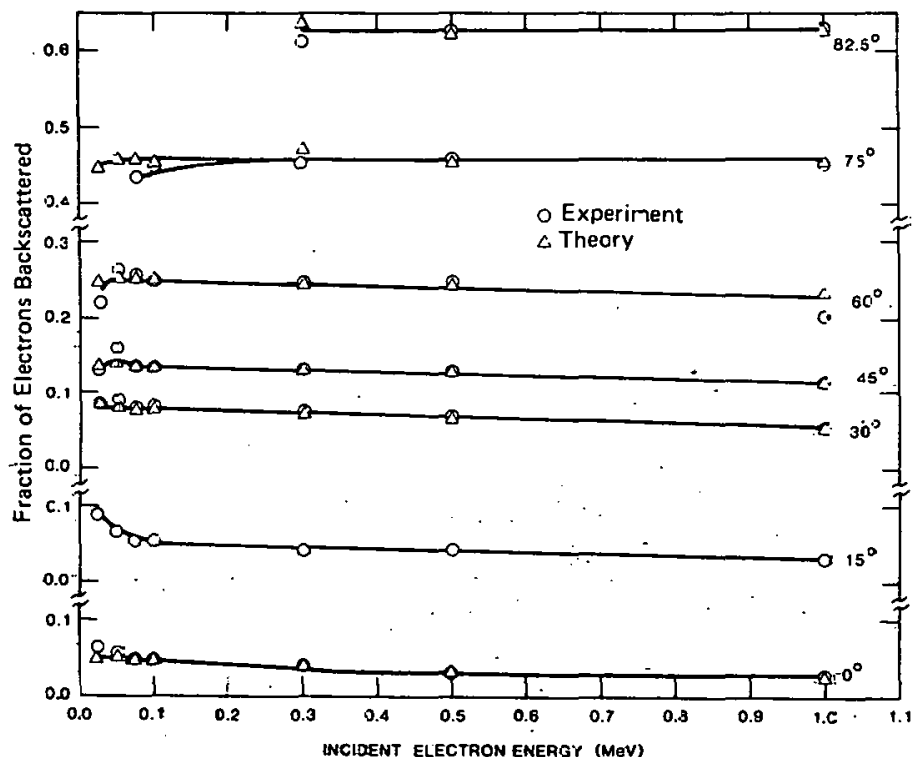

a. Compazison as a Function of Incident Energy
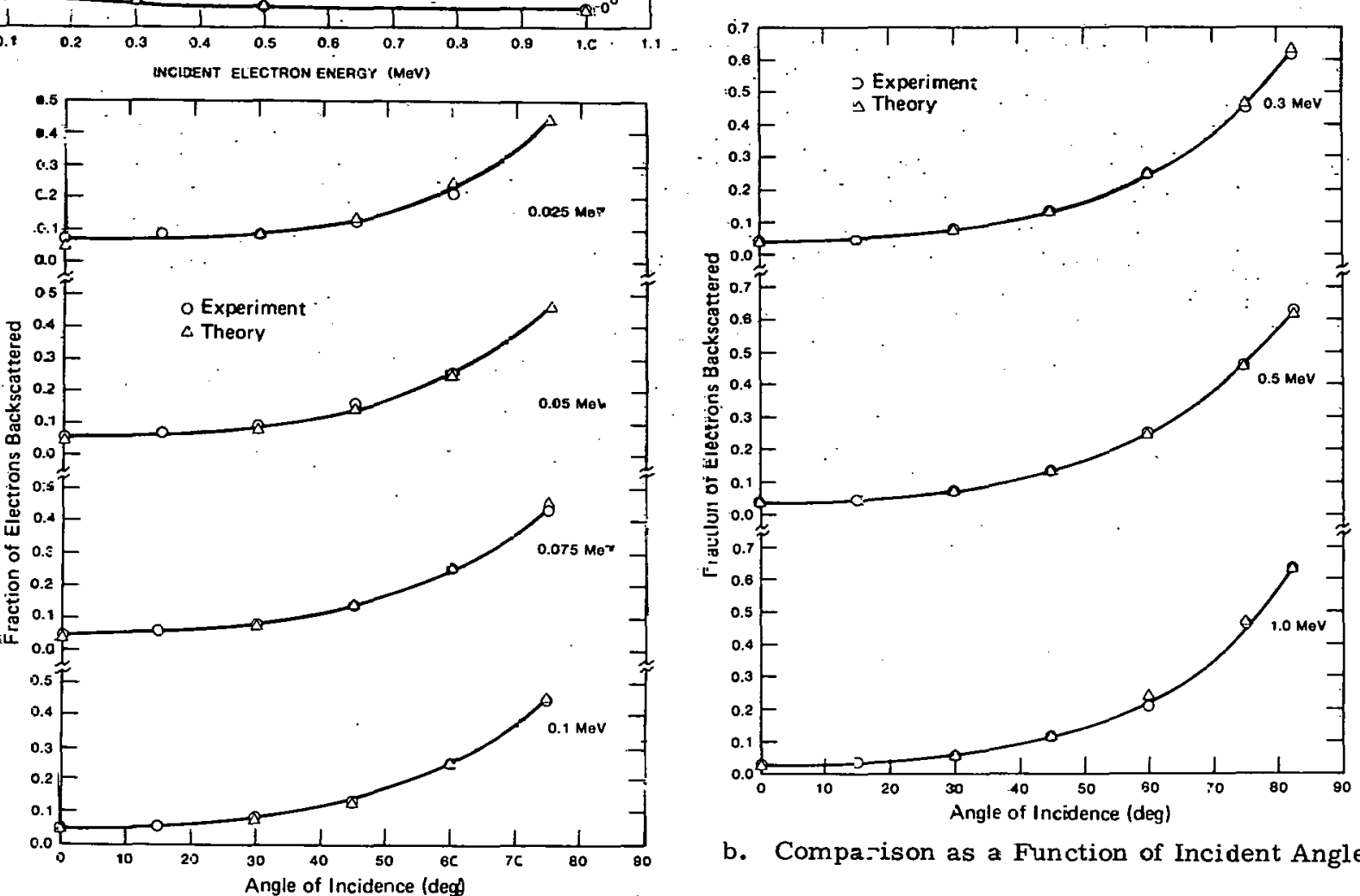

b. Compa-ison as a Function of Incident Angle

Figure V-B. 2 Comparison of Experimental and.Theoretical Number Backscatter in Carbon 
Table V-B. 2

Fraction of Electrons Backscattered From Carbon

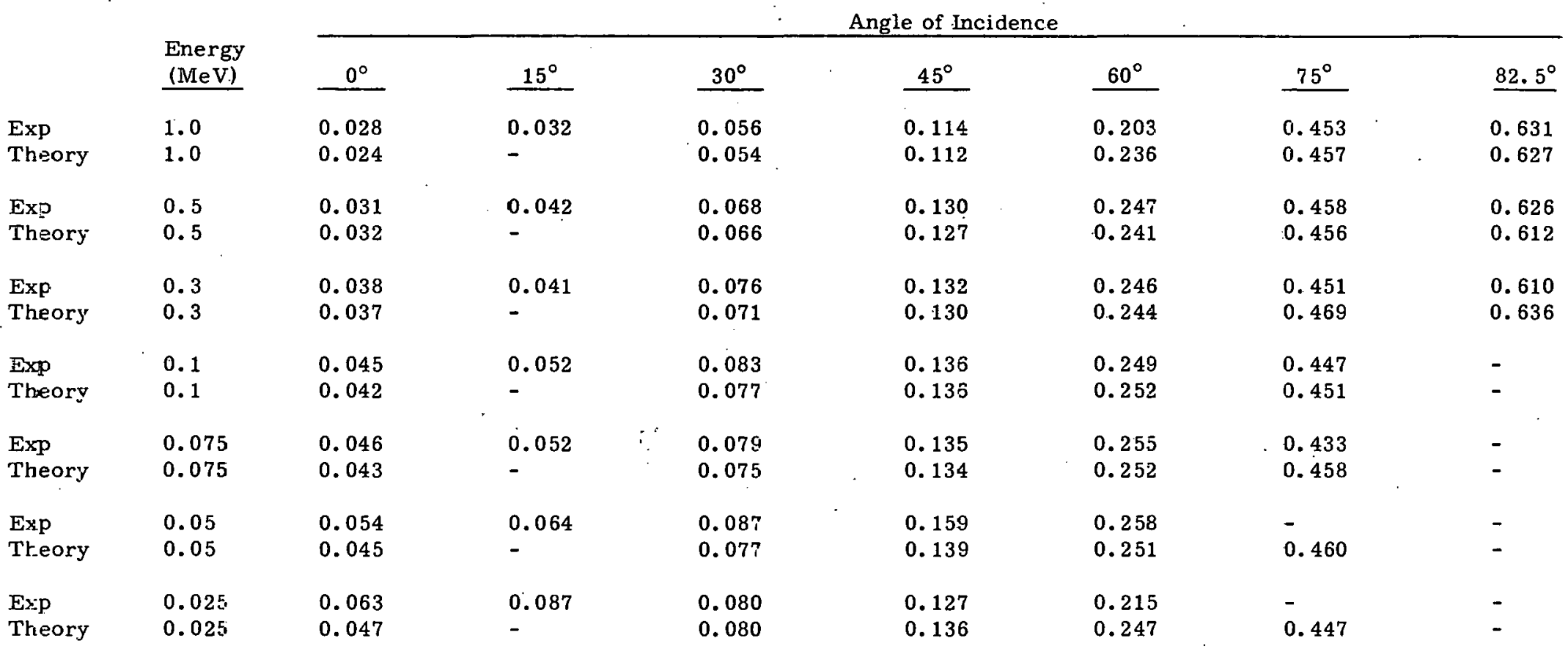




\section{Electron Energy and Charge Albedos in Aluminum}

Energies (MeV): $1.033,0.521,0.314,0.109,0.084,0.058$, and 0.032

Angles $\left({ }^{\circ}\right): 0,15,30,45,60$, and 75

Analysis Method: $t_{d}$

Angle Determination Method: Hand set

\section{Calorimeter}
Diameter: $5.08 \mathrm{~cm}$
Thickness: $0.264 \mathrm{~cm}$

Table $\mathrm{V}-\mathrm{C}(\mathrm{i})$

A Comparison of Thtal Enorgy Deposited in Alumluum

\begin{tabular}{|c|c|c|c|c|}
\hline \multirow[b]{2}{*}{$\begin{array}{c}\text { Nominal } \\
\text { Energy } \\
\text { (MeV) } \\
\end{array}$} & \multirow[b]{2}{*}{$\begin{array}{l}\text { Angle } \\
\text { (deg) }\end{array}$} & \multicolumn{3}{|c|}{ Fraction of Energy nennsited } \\
\hline & & $\begin{array}{c}\text { TIGER } \\
\text { Calculation }\end{array}$ & $\begin{array}{c}\text { Total } \\
\text { Stopning } \\
\text { Measurement }\end{array}$ & $\begin{array}{c}\text { Integrated } \\
\text { Differential } \\
\text { Measurament }\end{array}$ \\
\hline 1,0 & 0 & 0.854 & 0.040 & $0 . \dot{y} j y$ \\
\hline 1.0 & 60 & 0.785 & 0.800 & 0.735 \\
\hline 0.5 & 0 & 0.942 & $0: 948$ & 0.919 \\
\hline 0.5 & 60 & ก. 7.64 & $0.7 n 9$ & 0.760 \\
\hline 0.3 & $\dot{0}$ & 0.933 & 0.946 & 0.908 \\
\hline 0.3 & 60 & 0.760 & 0.750 & 0.732 \\
\hline
\end{tabular}


Table V-C(ii)

Theoretically Calculated Fraction of the Incident Electron Energy That Escapes From Aluminum in the Form of Bremsstrahlung

Encrgy

$(\mathrm{MeV})$

1.0

0.5

0.3

0.109

0.084

0.058

0.032

Angle of Incidence

$\begin{array}{lll}0^{\circ} & \frac{15^{\circ}}{5.57 \times 10^{-3}} & \frac{30^{\circ}}{5.38 \times 10^{-3}} \\ 2.49 \times 10^{-3} & 2.55 \times 10^{-3} & 5.51 \times 10^{-3} \\ 1.64 \times 10^{-3} & 1.69 \times 10^{-3} & 2.62 \times 10^{-3} \\ 5.26 \times 10^{-4} & 5.43 \times 10^{-4} & 1.59 \times 10^{-3} \\ 3.47 \times 10^{-1} & 3.21 \times 10^{-4} & 5.10 \times 10^{-4} \\ 1.93 \times 10^{-4} & 2.08 \times 10^{-4} & 4.07 \times 10^{-4} \\ 8.37 \times 10^{-5} & 9.85 \times 10^{-5} & 2.56 \times 10^{-4} \\ & & 6.30 \times 10^{-5}\end{array}$

$\frac{45^{0}}{5.24 \times 10^{-3}}$
$2.82 \times 10^{-3}$
$1.50 \times 10^{-3}$
$4.97 \times 10^{-4}$
$3.64 \times 10^{-4}$
$2.65 \times 10^{-4}$
$9.26 \times 10^{-5}$

$\frac{60^{\circ} .}{5.08 \times 10^{-3}}$

2. $73 \times 10^{-3}$

1. $11 \times 10^{-3}$

3. $75 \times 10^{-4}$

4. $57 \times 10^{-4}$

1. $37 \times 10^{-4}$

1. $46 \times 10^{-5}$

$9.26 \times 10^{-5}$

$75^{\circ}$

4. $73 \times 10^{-3}$

2. $14 \times 10^{-3}$

1. $14 \times 10^{-3}$

5. $03 \times 10^{-4}$

1. $72 \times 10^{-4}$

2. $33 \times 10^{-4}$

1. $43 \times 10^{-4}$ 


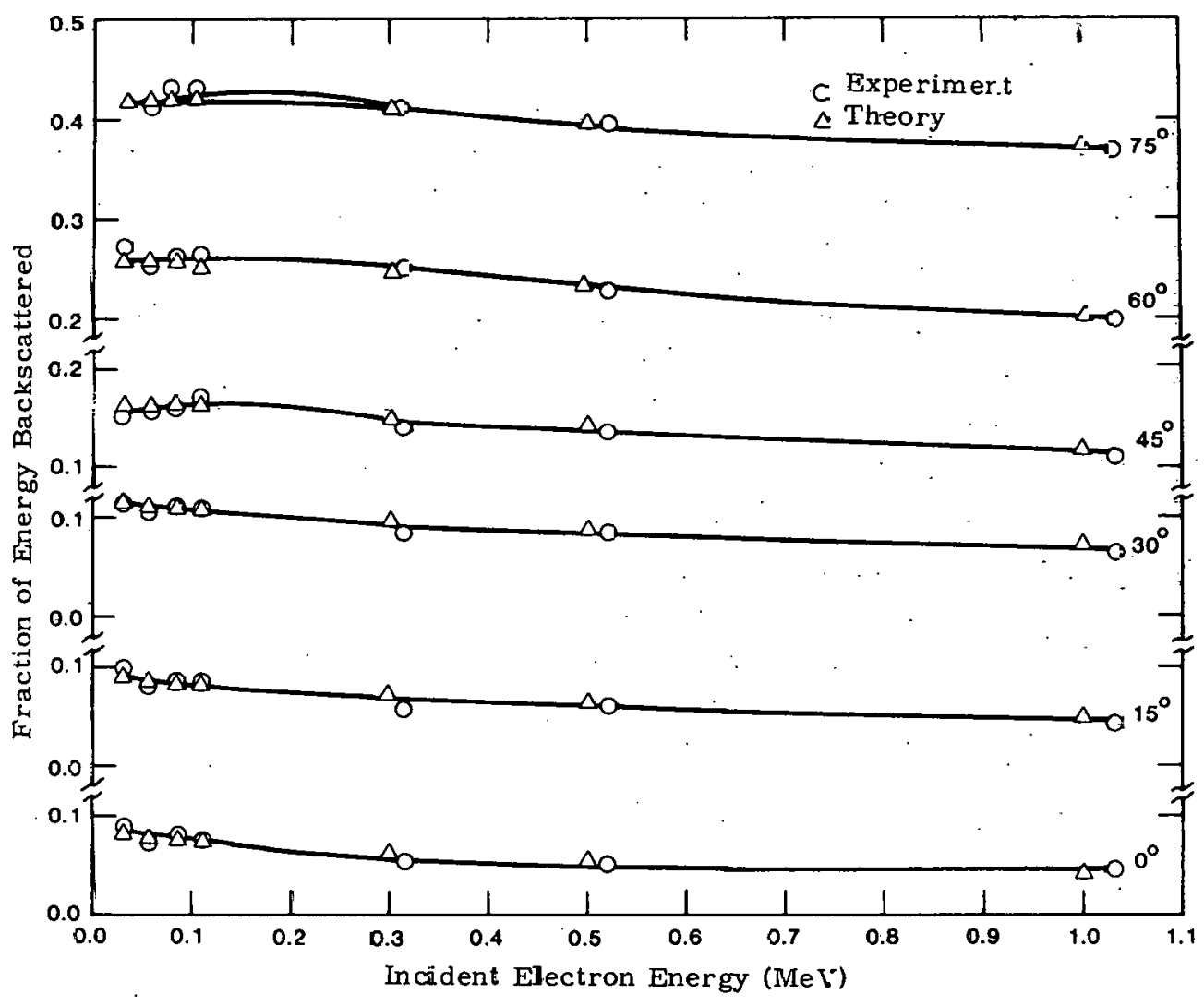

a. Corr.parison as a Function of Incidenl Energy

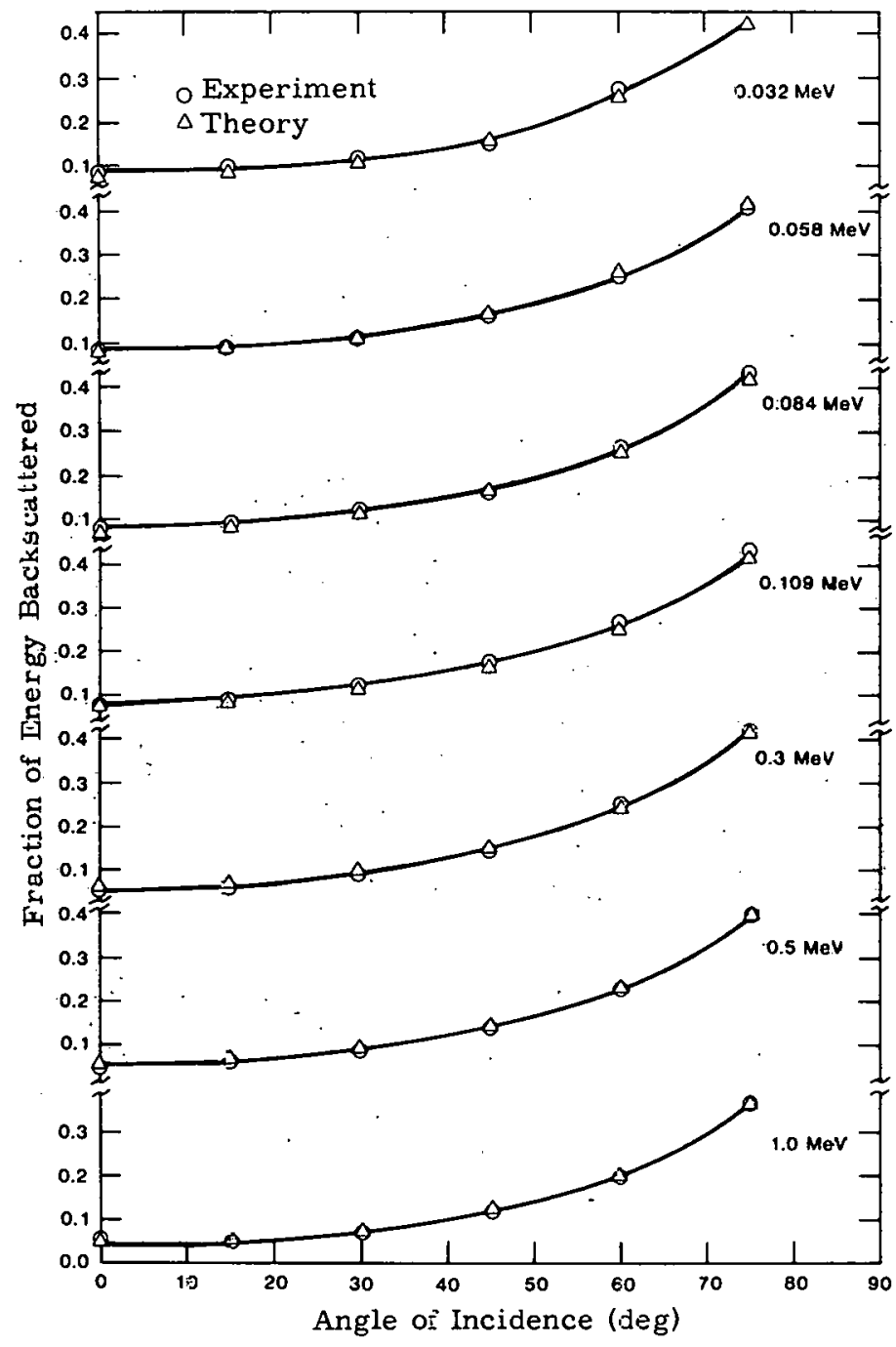

b. Comfarison as a Function of Incident Angle

Iigure V-C. 1 Comparison of Experimental and Theoretical Enærgy Backsca:ter in Aluminum 
Table V-C. 1

Fraction of Energy Backșcattered From Aluminum ${ }^{1}$

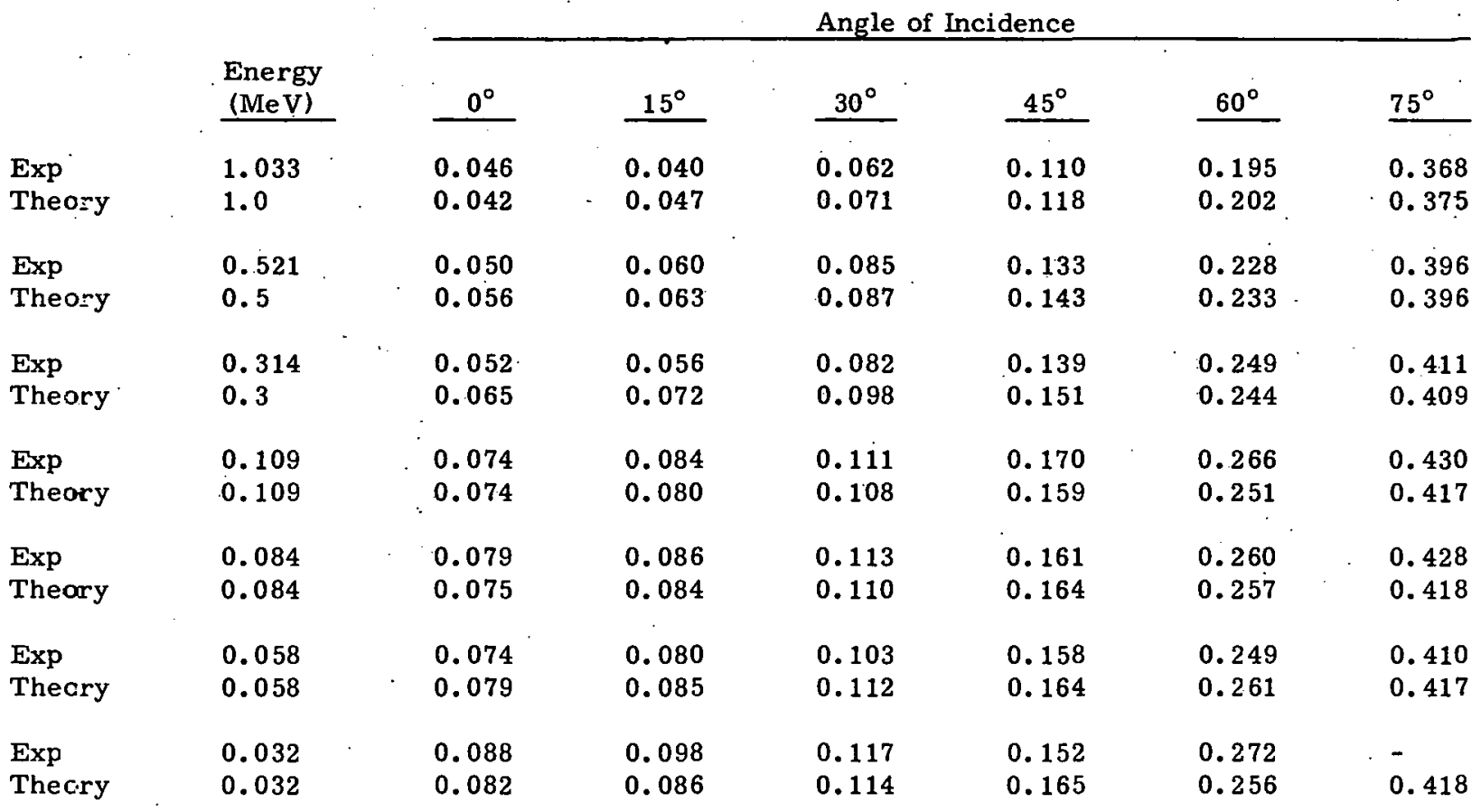

1 Experimental results adjusted by subtracting the fraction of energy escaping in the form of bremsstrahlung as determined by the TIGER code. 


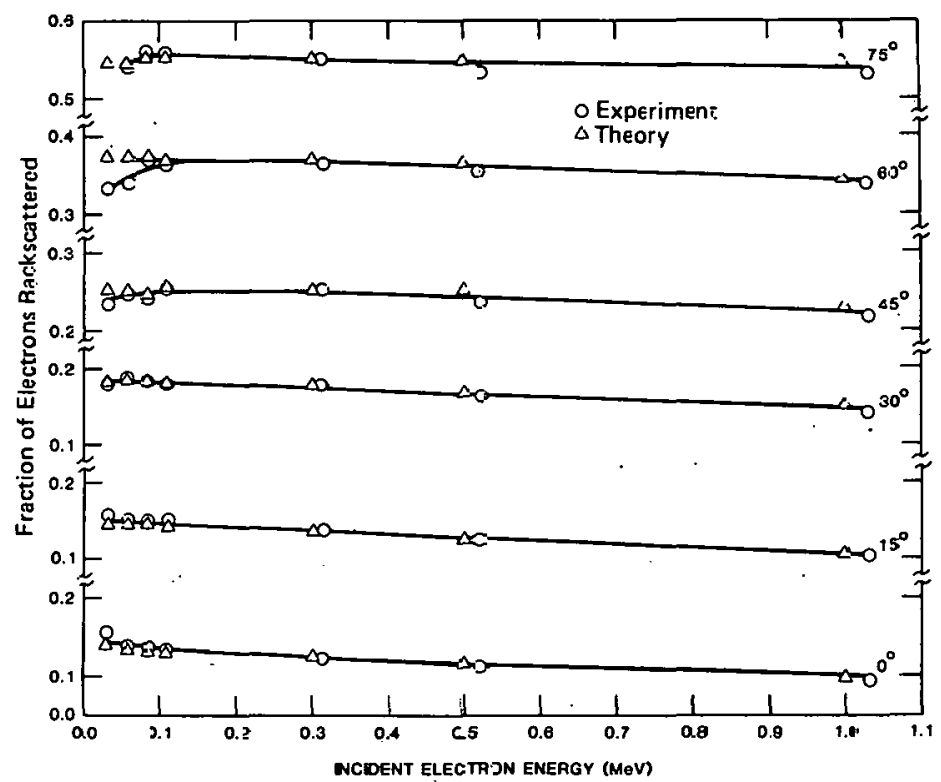

a. Comparison as a Fundion of Incident Energy
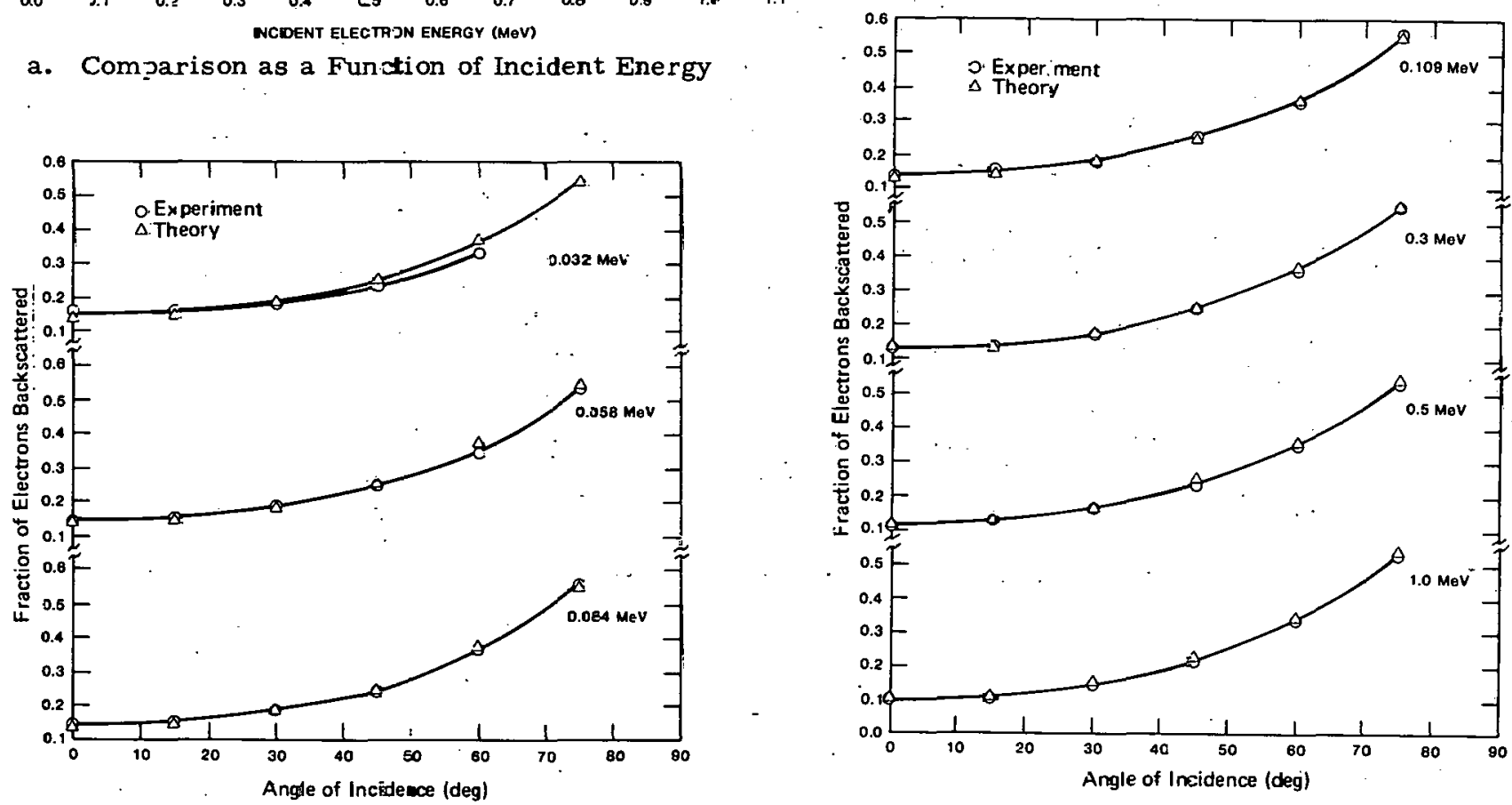

b. Comparison as a Function of Incident Angle

Figure V-C. 2 Comperison of Experimental and Theoretical Number Backscatter in Aluminum 
Table V-C. 2

Fraction of Electrons Backscattered From Aluminum

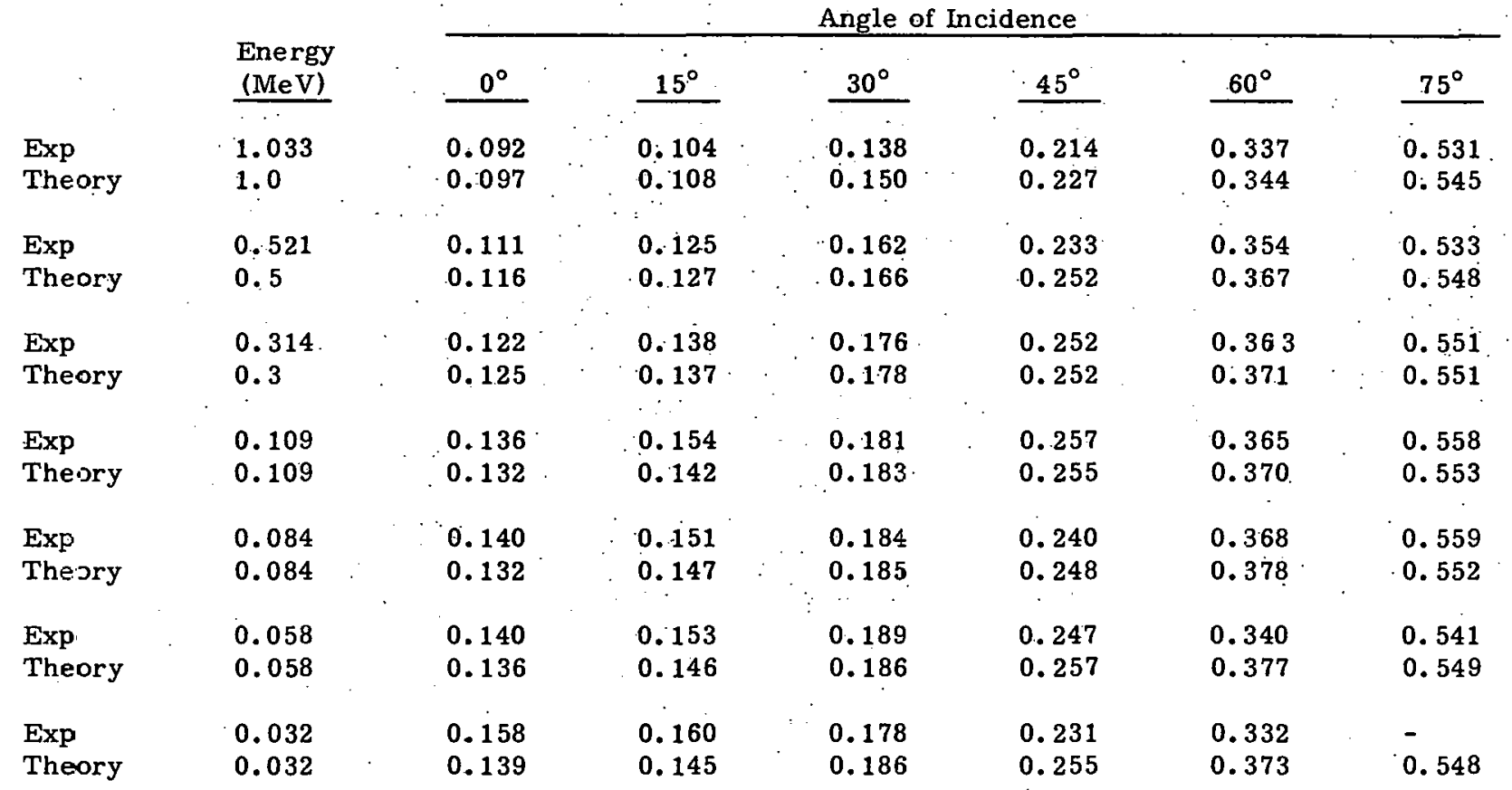




\section{Electron Energy and Charge Albedos in Titanium}

Energies (MeV): $\quad 1.033,0.521,0.314$, and 0.109

Angles $\left({ }^{\circ}\right): \quad 0,15,30,45,60$, and 75

Analysis Method: $t_{d}$

Angle Determination Method: Hand set

\section{Calorimeter}

Diameter: $5.08 \mathrm{~cm}$

Thickness: $0.163 \mathrm{~cm}$

Table V-D

Theoretically Calculated Fraction of the Incident Electron Energy That Escapes From Titanium in the Form of Bremsstrahlung

Angle of Incidence

0.5

4. $75 \times 10^{-3}$

$9: 94 \times 10^{-3}$

$9.95 \times 10^{-3}$

$45^{\circ}$

$60^{\circ}$

$8.99 \times 10^{-3}$

7. $79 \times 10^{-3}$

$75^{\circ}$

0.3

2. $73 \times 10^{-3}$

4. $74 \times 10^{-3}$

4. $39 \times 10^{-3}$

4. $26 \times 10^{-3}$

$4.15 \times 10^{-3}$

$6.71 \times 10^{-3}$

0.1

6. $32 \times 10^{-4}$

2. $98 \times 10^{-3}$

$2.56 \times 10^{-3}$

$2.78 \times 10^{-3}$

$2.16 \times 10^{-3}$

$3.09 \times 10^{-3}$

$6.84 \times 10^{-4}$

9. $37 \times 10^{-4}$

$3.80 \times 10^{-4}$

5. $65 \times 10^{-4}$

2. $40 \times 10^{-3}$

5. $84 \times 10^{-4}$ 


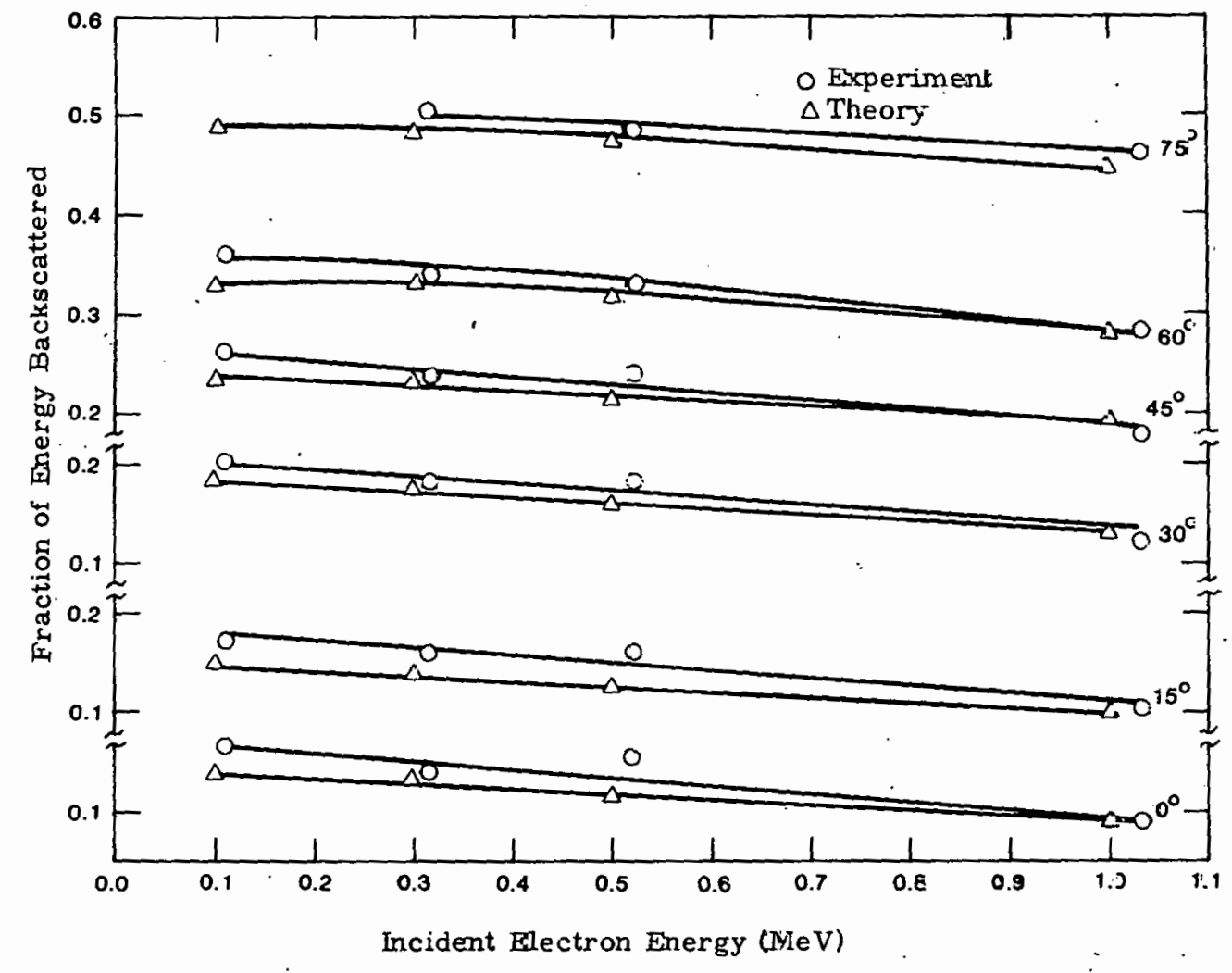

a. Comparison as a Function of Incident Energy

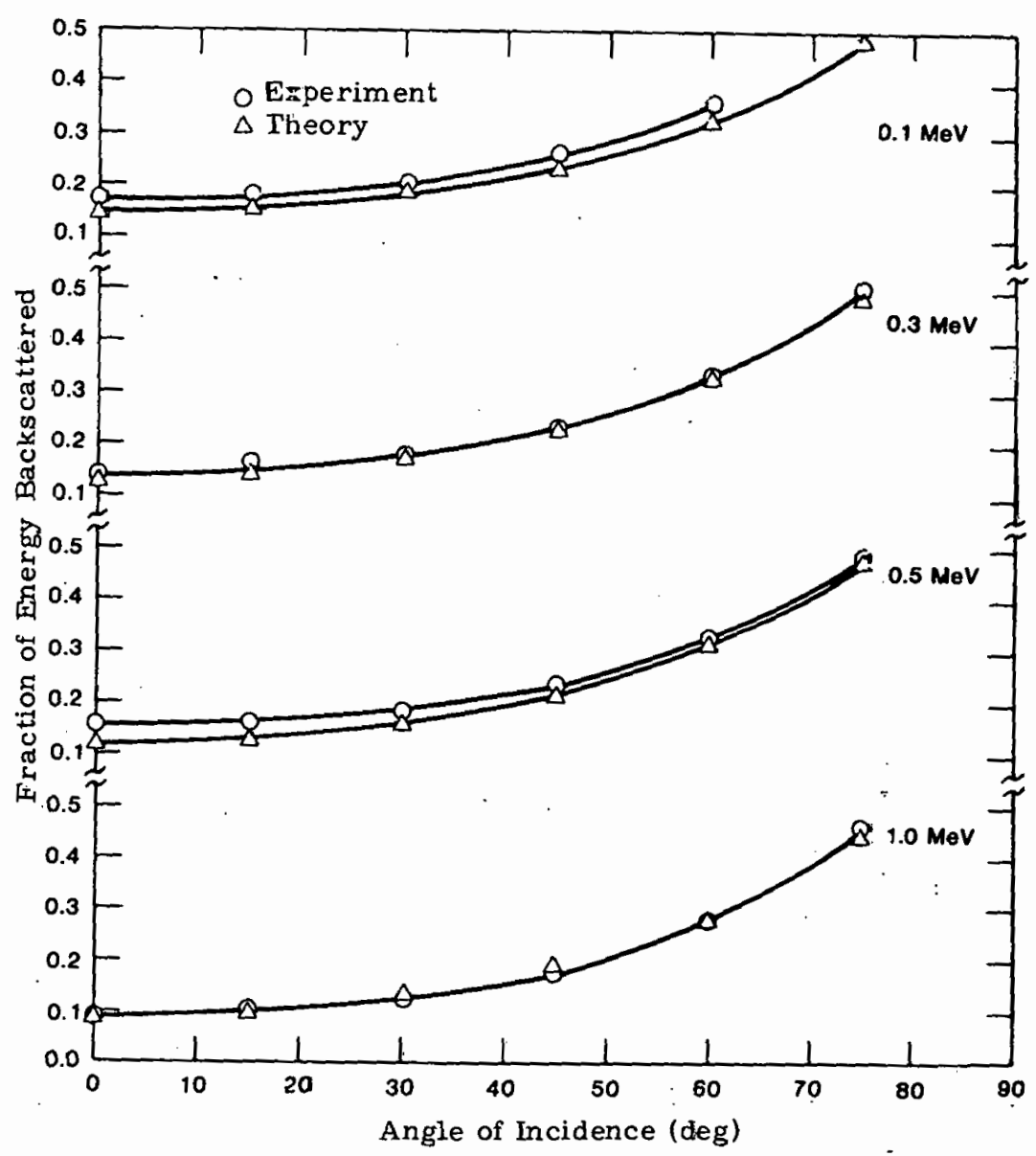

j. Comparison as a Function of Incident Angle

Figure V-D. 1 Comparison of Experimental and Thesretical Energy Backscatter in Titanium 
Table V-D. 1

Fraction of Energy Backscattered From Titanium ${ }^{1}$

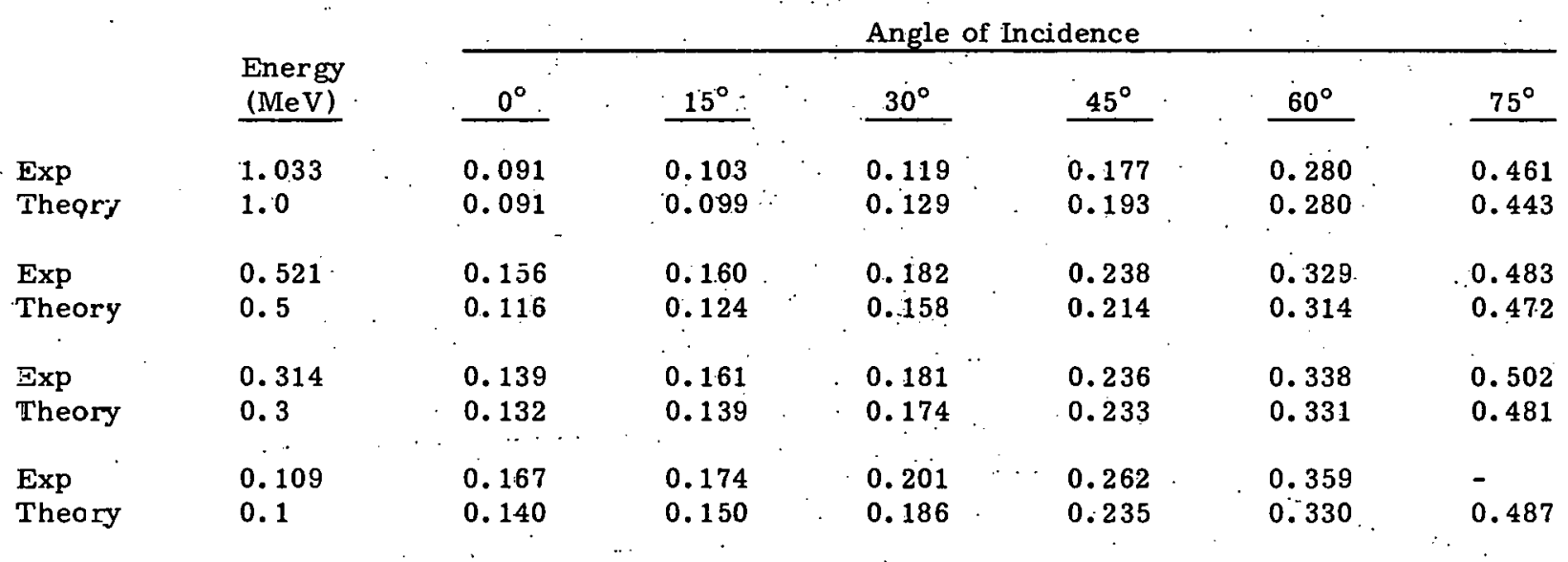

$1_{\text {Experimental }}$ results adjusted by subtracting the fraction of energy escaping in the form of bremsstrahlung as determined by the TIGER code. 


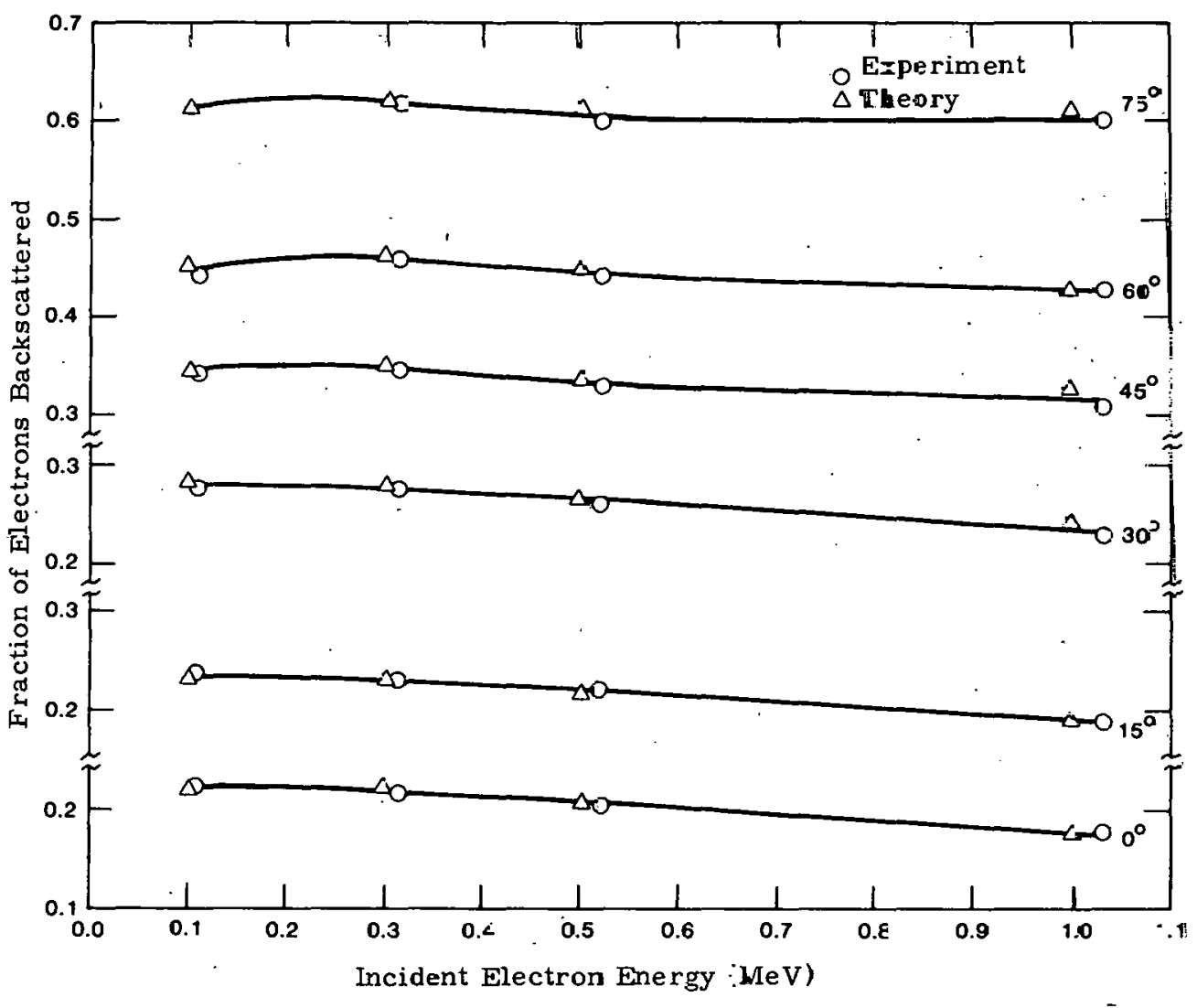

a. Comparisor. as a Function of Incident Ener $\not$;

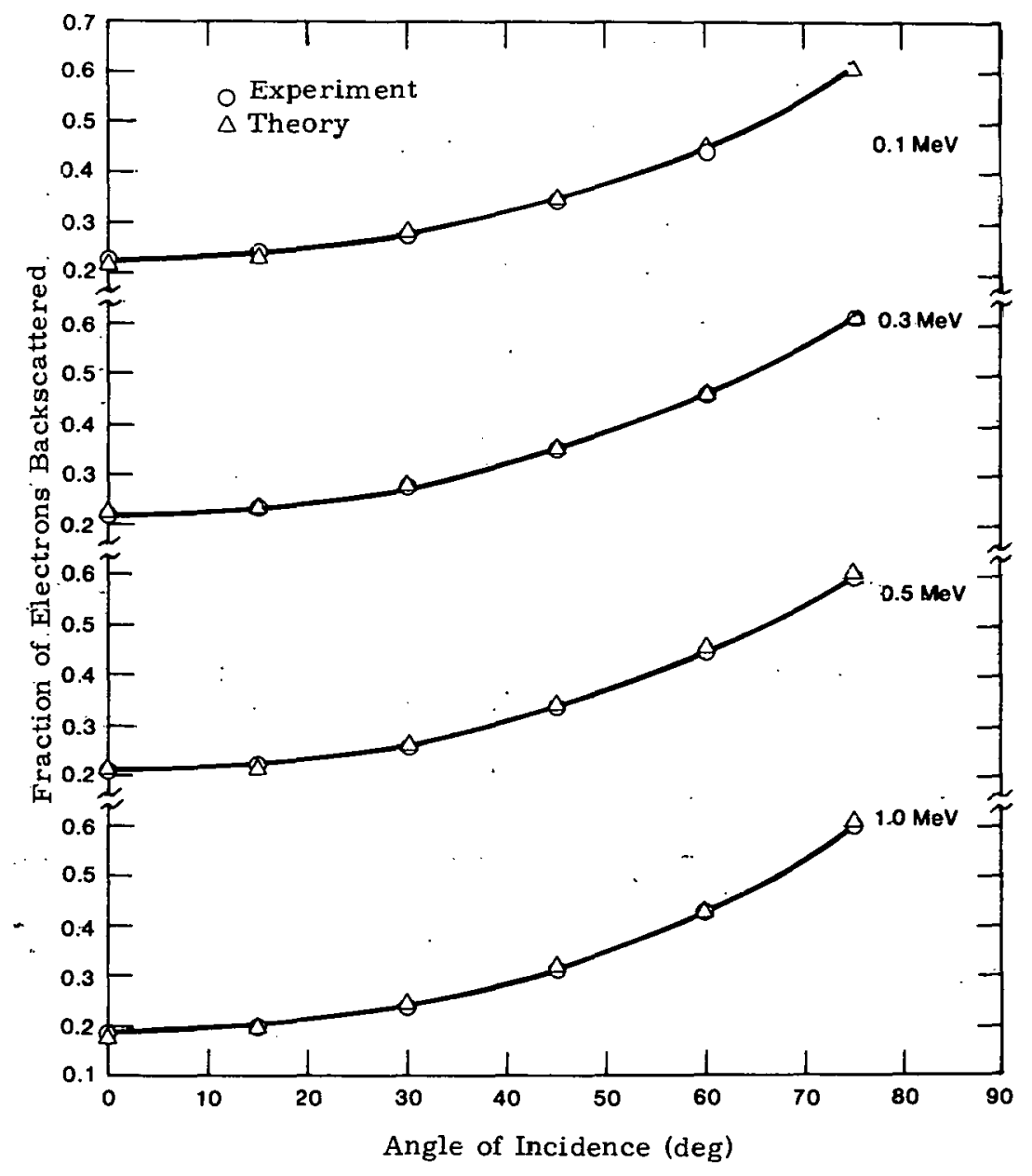

b. Comparison as a Function of Incident Angle

Figure V-D 2 Comparison of Experimental and Theoretical Nimber Backscatter in Titanium 
Table V-D. 2

Fraction of Electrons Backscattered From Titanium

\begin{tabular}{|c|c|c|c|c|c|c|c|}
\hline \multirow{2}{*}{\multicolumn{2}{|c|}{ (Me.v) }} & \multicolumn{6}{|c|}{ - Angle of Incidence } \\
\hline & & $0^{\circ}$ & $15^{\circ}$ & $30^{\circ}$ & $45^{\circ}$ & $60^{\circ}$ & $75^{\circ}$ \\
\hline $\operatorname{Exp}$ & 1.033 & 0.180 & 0.190 & 0.230 & 0.309 & 0.430 & 0.600 \\
\hline Theory & 1.0 & 0.178 & 0.193 & 0.240 & 0.326 & 0.431 & 0.612 \\
\hline Exp . & 0.521 & 0.203 & 0.221 & 0.257 & 0.331 & 0.443 & 0.597 \\
\hline Theory & 0.5 & 0.207 & 0.218 & 0.266 & 0.337 & 0.452 & 0.614 \\
\hline $\operatorname{Exp}$ & 0.314 & 0.217 & 0.231 & 0.274 & 0.348 & 0.459 & 0.617 \\
\hline Theory & 0.3 & 0.224 & 0.232 & 0.279 & 0.353 & 0.463 & 0.619 \\
\hline $\operatorname{Exp}$ & 0.109 & 0.226 & 0.239 & 0.273 & 0.343 & 0.441 & - \\
\hline Theory & 0.1 & 0.223 & 0.235 & 0.284 & 0.345 & 0.453 & 0.611 \\
\hline
\end{tabular}


E. Electron Energy and Charge Albedos in Molybdenum

Energies (Me V): $1.033,0.521,0.314$, and 0.109

Angles $\left({ }^{\circ}\right): 0,15,30,45,60$, and 75

Analysis Method: $t_{d}$

Angle Determination Method: Hand set

\section{Calorimeter}

Diameter: $5.08 \mathrm{~cm}$

Thickness: $0.091 \mathrm{~cm}$

Table V-E(i)

A Cumparison of Total Energy Deposited in Molybdenum

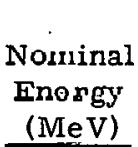

1. ?

1.0

0.6

0.5

0.3

0.3

0.1

\section{Angle}

(deg)

0

60

0

60

0

ถิเ)

0
Fraction of Finergy Dopooitod

\begin{tabular}{lcc}
$\begin{array}{c}\text { TIGEll } \\
\text { Calculation }\end{array}$ & $\begin{array}{c}\text { Total } \\
\text { Stopping } \\
\text { Measurement }\end{array}$ & $\begin{array}{c}\text { Intęgrated } \\
\text { Differential } \\
\text { Measurement }\end{array}$ \\
\cline { 2 - 2 } & 0.797 & 0.770 \\
0.602 & 0.595 & 0.557 \\
0.762 & 0.749 & 0.746 \\
0.580 & 0.568 & 0.544 \\
0.753 & 0.750 & 0.694 \\
0.667 & 0.546 & 0.533 \\
0.740 & 0.721 & 0.690
\end{tabular}


Table V-E(ii)

Theoretically Calculated Fraction of the Incident Electron Energy

That Escapes From Molybdenum in the Form of Bremsstrahlung

Energy
$(\mathrm{MeV})$

1.0

0.5

0.3

0.1

Angle of Incidence

\begin{tabular}{|c|c|c|c|c|c|}
\hline $0^{\circ}$ & $15^{\circ}$. & $30^{\circ}$ & $45^{\circ}$ & $60^{\circ}$ & $75^{\circ}$ \\
\hline 1. $22 \times 10^{-2}$ & 1. $25 \times 10^{-2}$ & 1. $32 \times 10^{-2}$ & $1.10 \times 10^{-2}$ & 1. $13 \times 10^{-2}$ & $8.18 \times 10^{-3}$ \\
\hline $6.10 \times 10^{-3}$ & 5. $57 \times 10^{-3}$ & 5. $64 \times 10^{-3}$ & $5.34 \times 10^{-3}$ & $4.84 \times 10^{-3}$ & $3.84 \times 10^{-3}$ \\
\hline $3.18 \times 10^{-3}$ & $3.36 \times 10^{-3}$ & $2.84 \times 10^{-3}$ & $2.71 \times 10^{-3}$ & $2.83 \times 10^{-3}$ & $2.21 \times 10^{-3}$ \\
\hline 1. $27 \times 10^{-3}$ & 1. $49 \times 10^{-3}$ & $6.65 \times 10^{-4}$ & $1.11 \times 10^{-3}$ & $8.34 \times 10^{-4}$ & 8. $21 \times 10^{-4}$ \\
\hline
\end{tabular}




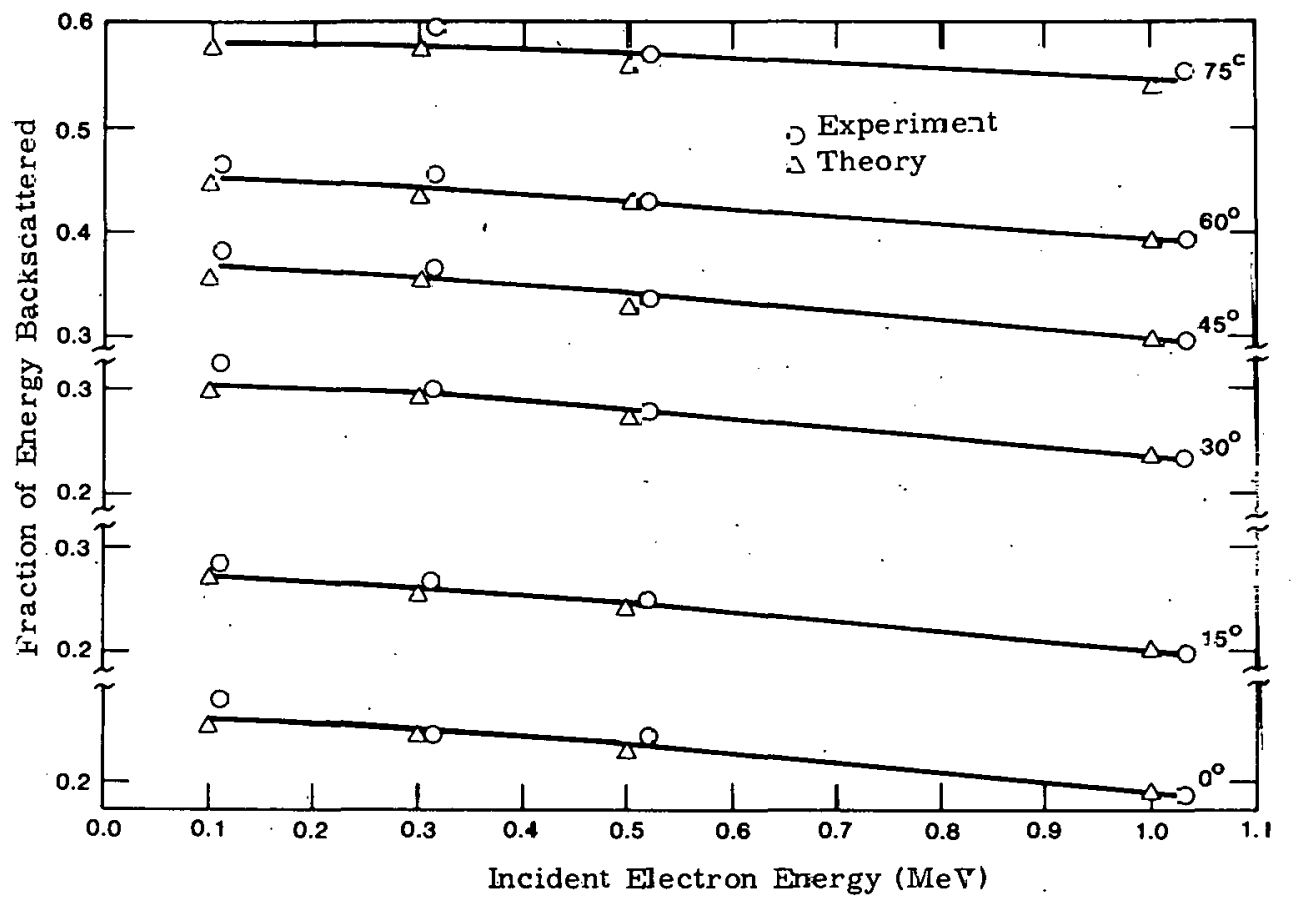

a. Comparison as a Function of Incident Energy

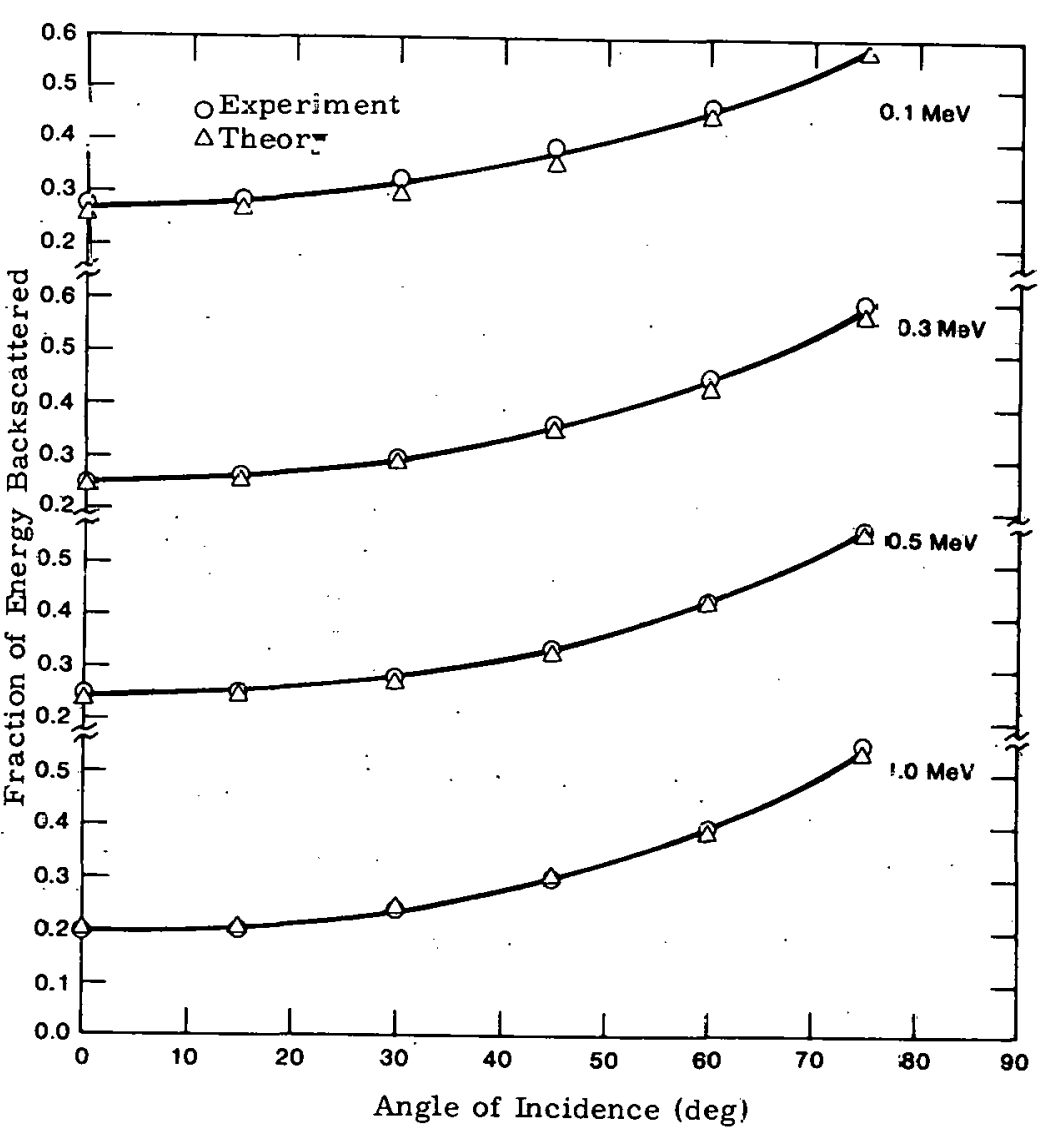

b. Comparison as a Function of Incident Angle

Figure V-E. 1 Comparison of Experimental and Theoretical Energy Backsca:ter in Molybdenum 
Table V-E. 1

Fraction of Energy Backscattered From Molybdenum ${ }^{1}$

\begin{tabular}{|c|c|c|c|c|c|c|c|}
\hline & \multirow{2}{*}{$\begin{array}{l}\text { Energy } \\
(\mathrm{MeV})\end{array}$} & \multicolumn{6}{|c|}{ Angle of Incidence } \\
\hline & & $0^{\circ}$ & $15^{\circ}$ & $30^{\circ}$ & $45^{\circ}$ & $60^{\circ}$ & $75^{\circ}$ \\
\hline Exp & 1.033 & 0.191 & 0.200 & 0.235 & 0.297 & 0.394 & 0.554 \\
\hline Thəory & 1.0 & 0.194 & 0.205 & 0.239 & 0.300 & 0.392 & 0.538 \\
\hline $\operatorname{Exp}$ & 0.521 & 0.245 & 0.251 & 0.278 & 0.337 & 0.427 & 0.568 \\
\hline Theory & 0.5 & 0.231 & 0.241 & 0.271 & 0.328 & 0.427 & 0.559 \\
\hline Exp & 0.314 & 0.247 & 0.266 & 0.299 & 0.365 & 0.452 & 0.594 \\
\hline Theory & 0.3 & 0.244 & 0.252 & 0.288 & 0.352 & 0.428 & 0.571 \\
\hline $\operatorname{Exp}$ & 0.109 & 0.278 & 0.284 & 0.325 & 0.383 & 0.464 & - \\
\hline Theory & 0.1 & 0.254 & 0.269 & 0.296 & 0.355 & 0.444 & 0.572 \\
\hline
\end{tabular}

${ }_{1}$ Experimental results adjusted by subtracting the fraction of energy escaping in the form of bremsstrahlung as determined by the TIGER code. 


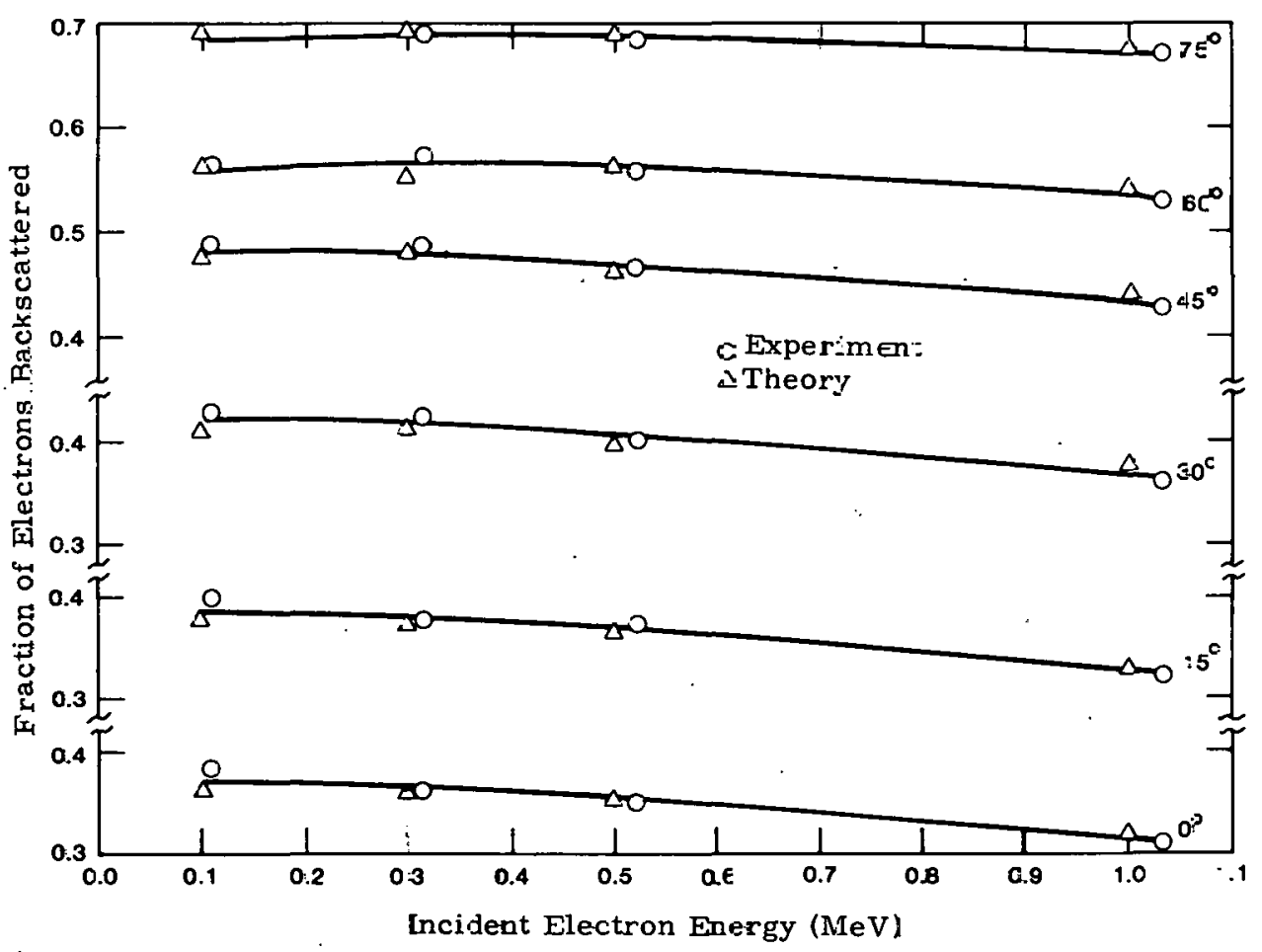

a. Comparison as a Function of Incident Energy

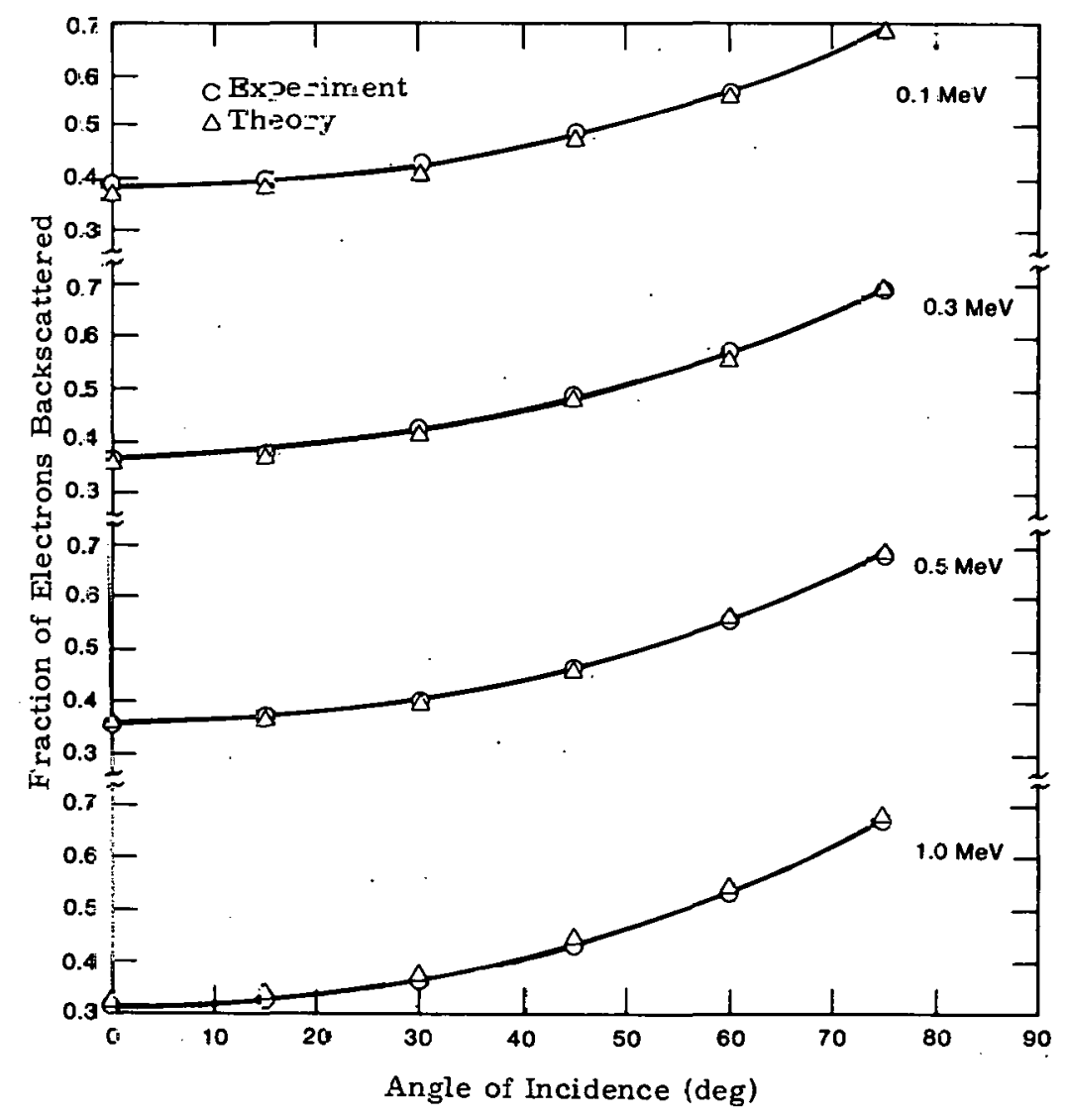

b. Comparison as a Function of Incident Angle

Figure V-E 2 Comparison of Experimental and Theoretical Number Backscatter in Molybdenum 
Table V-E. .2

Fraction of Electrons Backscattered From Molybdenum

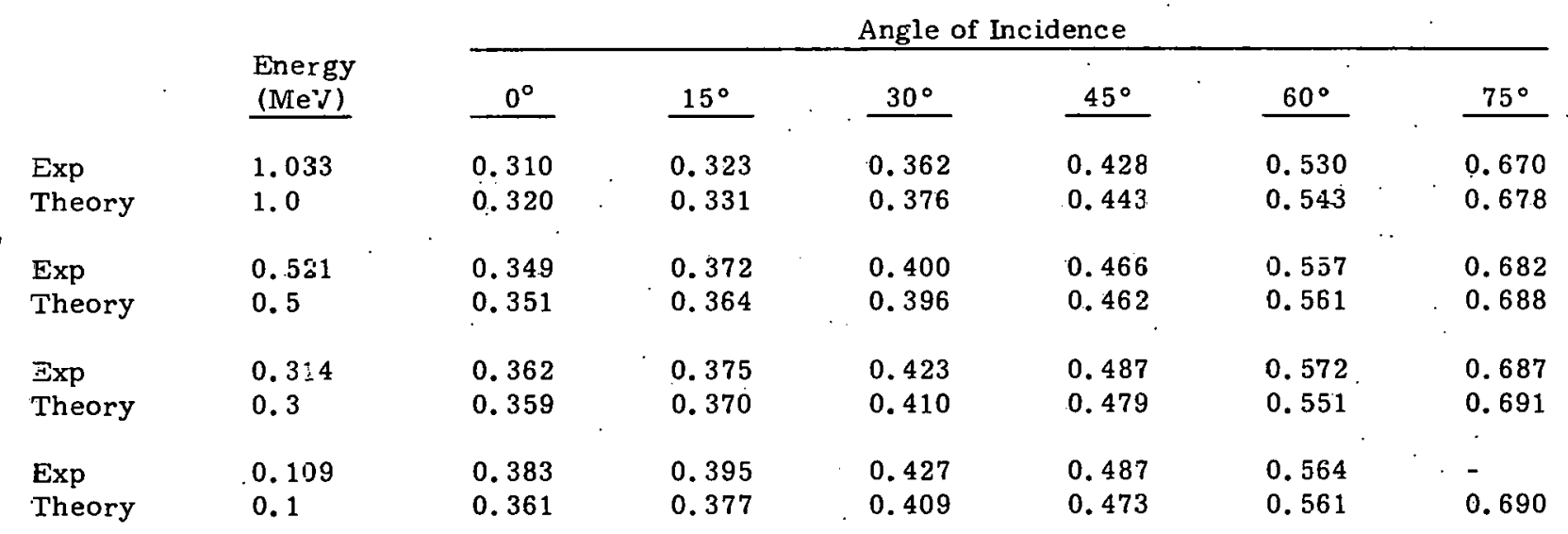


F. Electron Energy and Charge Albedos in Tantalum

Energies $(\mathrm{MeV}): 1.033,0.521,0.314,0.109,0.058$, and 0.032

Angles $\left({ }^{\circ}\right): 0,15,30,45,60$, and 75

Analys is Method: $t_{d}$

Angle Determination Method: Hand set

Calorimeter

Diameter: $5.08 \mathrm{~cm}$

Thickness: $0.053 \mathrm{~cm}$

'l'ahle $\overline{\mathrm{V}}-\mathrm{F}(\mathrm{i})$

A Comparison of Total Energy Deposited in Tantalum

Fraction of Energy Deposited

\begin{tabular}{|c|c|c|c|c|c|}
\hline \multirow{2}{*}{$\begin{array}{l}\text { Nomirial } \\
\text { Energy } \\
\text { (MeV) } \\
\end{array}$} & \multirow{2}{*}{$\begin{array}{l}\text { Angle } \\
\text { (deg) } \\
\end{array}$} & \multirow{2}{*}{$\begin{array}{c}\text { TIGER } \\
\text { Calculation } \\
\end{array}$} & \multirow{2}{*}{$\begin{array}{c}\text { Total } \\
\text { Stopping } \\
\text { Measurement } \\
\end{array}$} & \multicolumn{2}{|c|}{$\begin{array}{c}\text { Integrated } \\
\text { Differential } \\
\text { Measurement* }\end{array}$} \\
\hline & & & & A & B \\
\hline 1.0 & 0 & 0.670 & 0.668 & 0.640 & 0.631 \\
\hline 1.0 & 60 & 0.495 & 0.484 & 0.472 & - \\
\hline 0.5 & 0 & 0.634 & 0.635 & 0.632 & 0.585 \\
\hline 0.5 & 30 & 0.596 & 0.593 & 0.590 & - \\
\hline 0.5 & $60^{\circ}$ & $0.470^{\prime}$ & 0.458 & 0.454 & - \\
\hline 0.3 & 0 & 0.630 & 0.617 & 0.613 & 0.564 \\
\hline
\end{tabular}

* Two different methods were employed to make differential energy deposition measurements in Ta (see Reference 3 for discussion). 
Table V-F(ii)

Theoretically Calculated Fraction of the Incident Electron Energy That Escapes From Tantalum in the Form of Bremsstrahlung

Energy

(MeV)

1.0

0.5

0.3

0.1

0.05

0.025
Angle of Incidence

\begin{tabular}{|c|c|c|c|c|c|}
\hline $0^{\circ}$ & $15^{\circ}$ & $30^{\circ}$ & $45^{\circ}$ & $60^{\circ}$ & $75^{\circ}$ \\
\hline $1.63 \times 10^{-2}$ & $1.49 \times 10^{-2}$ & $1.53 \times 10^{-2}$ & $1.38 \times 10^{-2}$ & 1. $21 \times 10^{-2}$ & $9.65 \times 10^{-3}$ \\
\hline $9.13 \times 10^{-3}$ & $9.30 \times 10^{-3}$ & $9.54 \times 10^{-3}$ & $7.84 \times 10^{-3}$ & 8. $18 \times 10^{-3}$ & $5.79 \times 10^{-3}$ \\
\hline $5.87 \times 10^{-3}$ & $5.67 \times 10^{-3}$ & $6.13 \times 10^{-3}$ & $5.02 \times 10^{-3}$ & $5.85 \times 10^{-3}$ & $3.54 \times 10^{-3}$ \\
\hline $1.80 \times 10^{-3}$ & $2.32 \times 10^{-3}$ & $1.87 \times 10^{-3}$ & $1.77 \times 10^{-3}$ & $1.51 \times 10^{-3}$ & $8.64 \times 10^{-4}$ \\
\hline $7.57 \times 10^{-4}$ & $8.07 \times 10^{-4}$ & $1.01 \times 10^{-3}$ & $1.03 \times 10^{-3}$ & $9.06 \times 10^{-4}$ & $6.83 \times 10^{-4}$ \\
\hline $3.18 \times 10^{-4}$ & $6.31 \times 10^{-4}$ & $5.14 \times 10^{-4}$ & $3.70 \times 10^{-4}$ & $5.21 \times 10^{-4}$ & $3.63 \times 10^{-4}$ \\
\hline
\end{tabular}




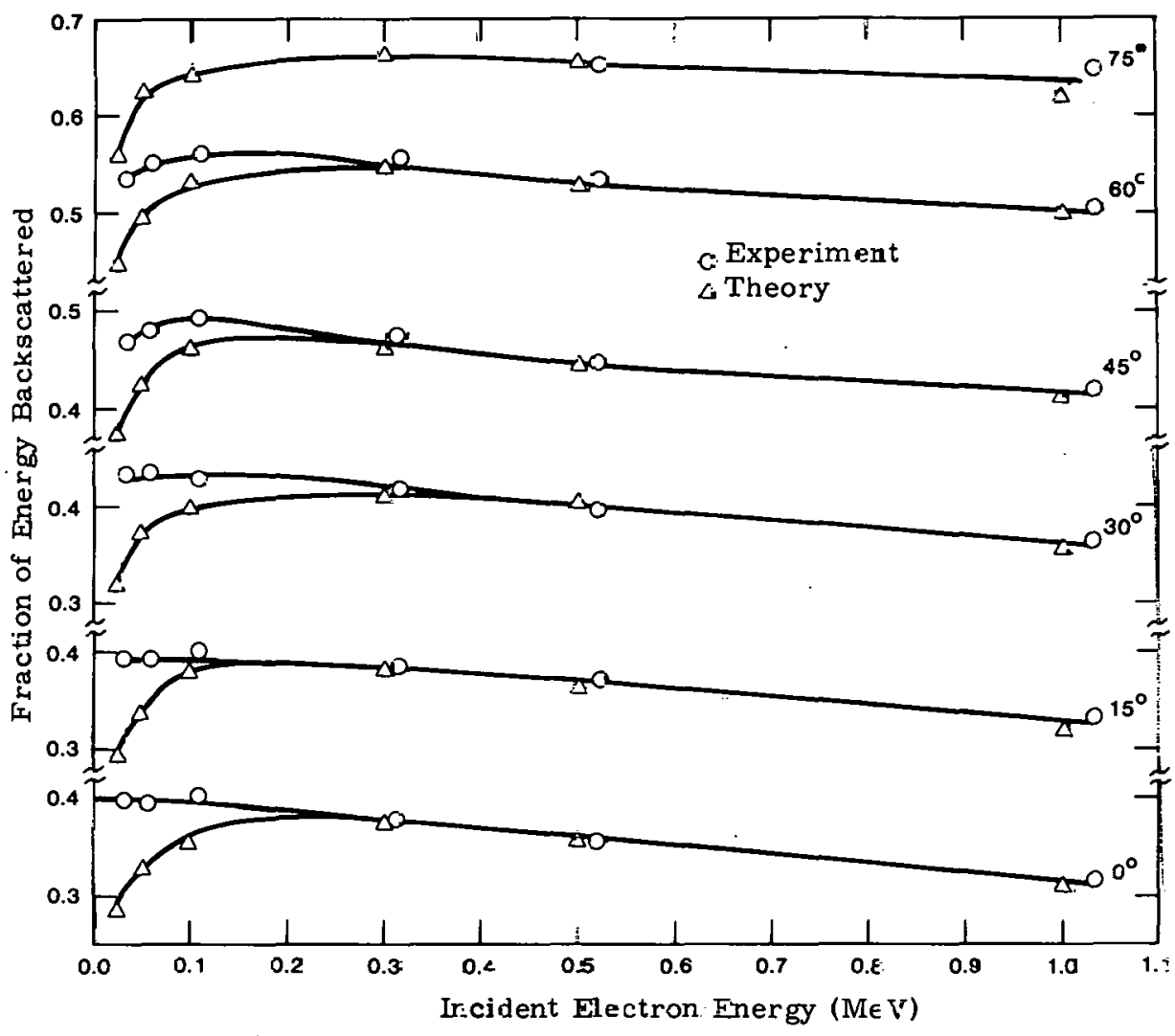

a. Comperison as a Iunction af Incident Energy

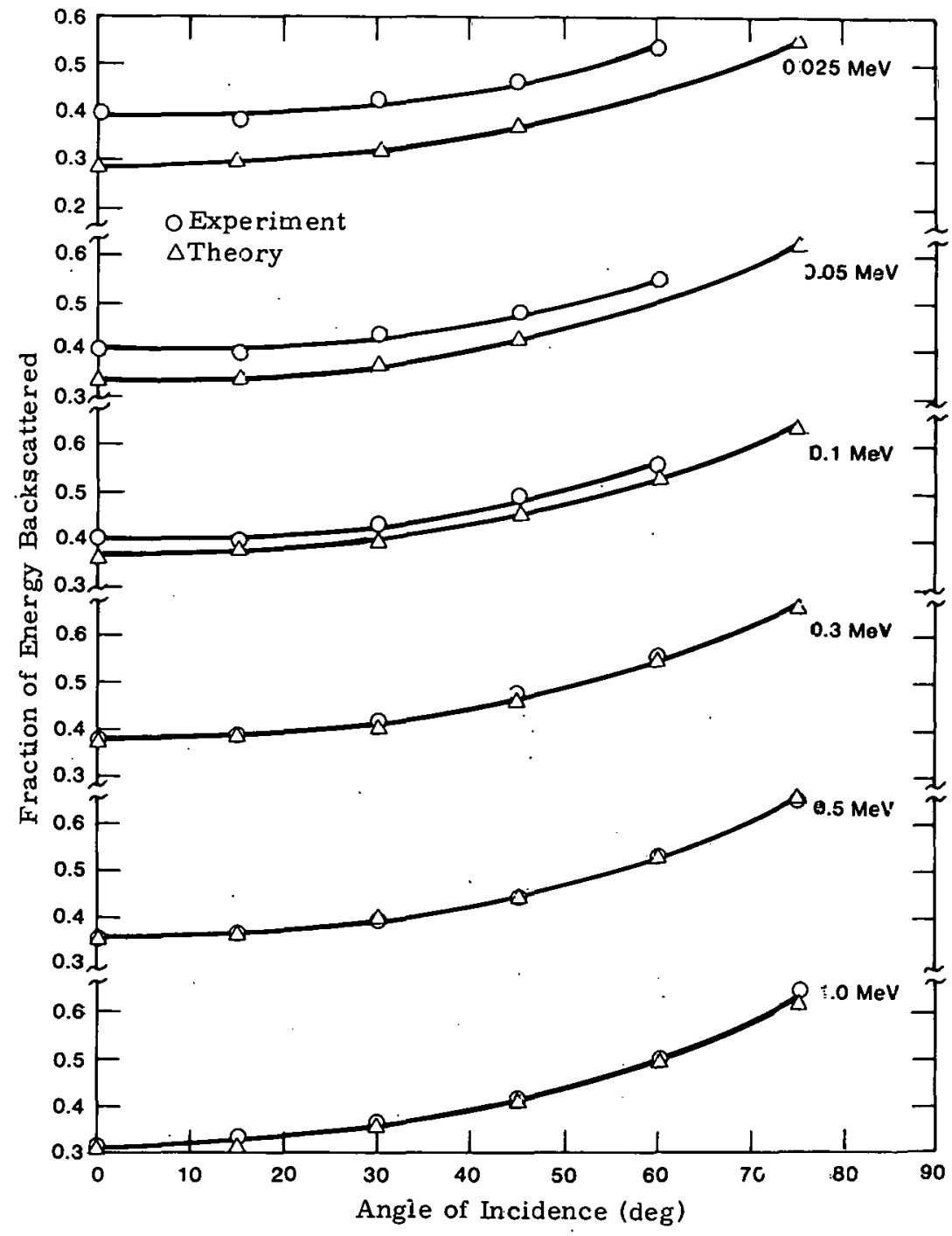

b. Comparison as a Function of Incident Angle

Figure V-F. : Comparison of Experimertal and Theoretical Eaergy Backscatter in Tantalum 
Table V-F.

Fraction of Energy Backscattered From Tantalum ${ }^{1}$

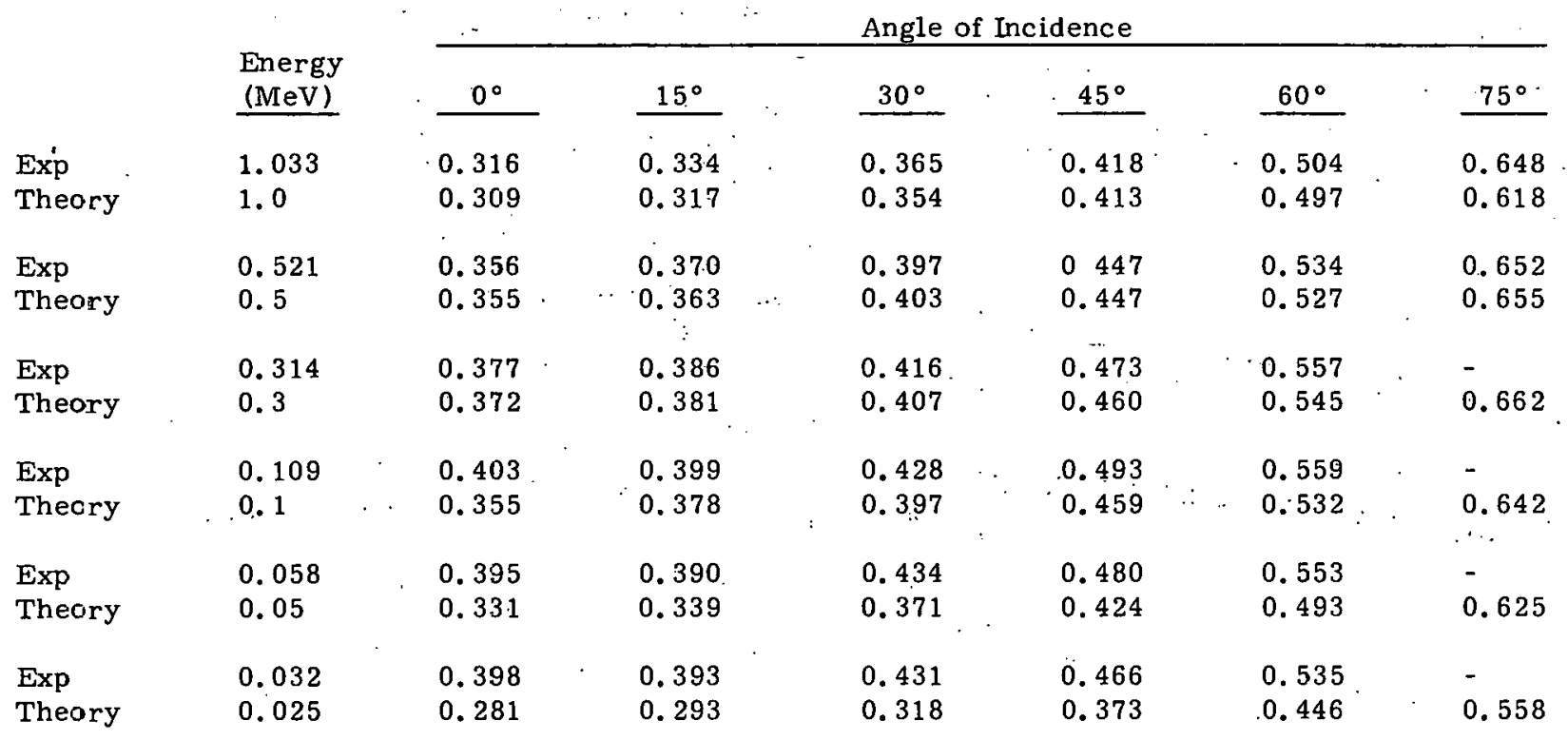

${ }^{1}$ Experimental results adjusted by subtracting the fraction of energy escaping in the form of bremsstrahlung as determined by the TIGER code. 


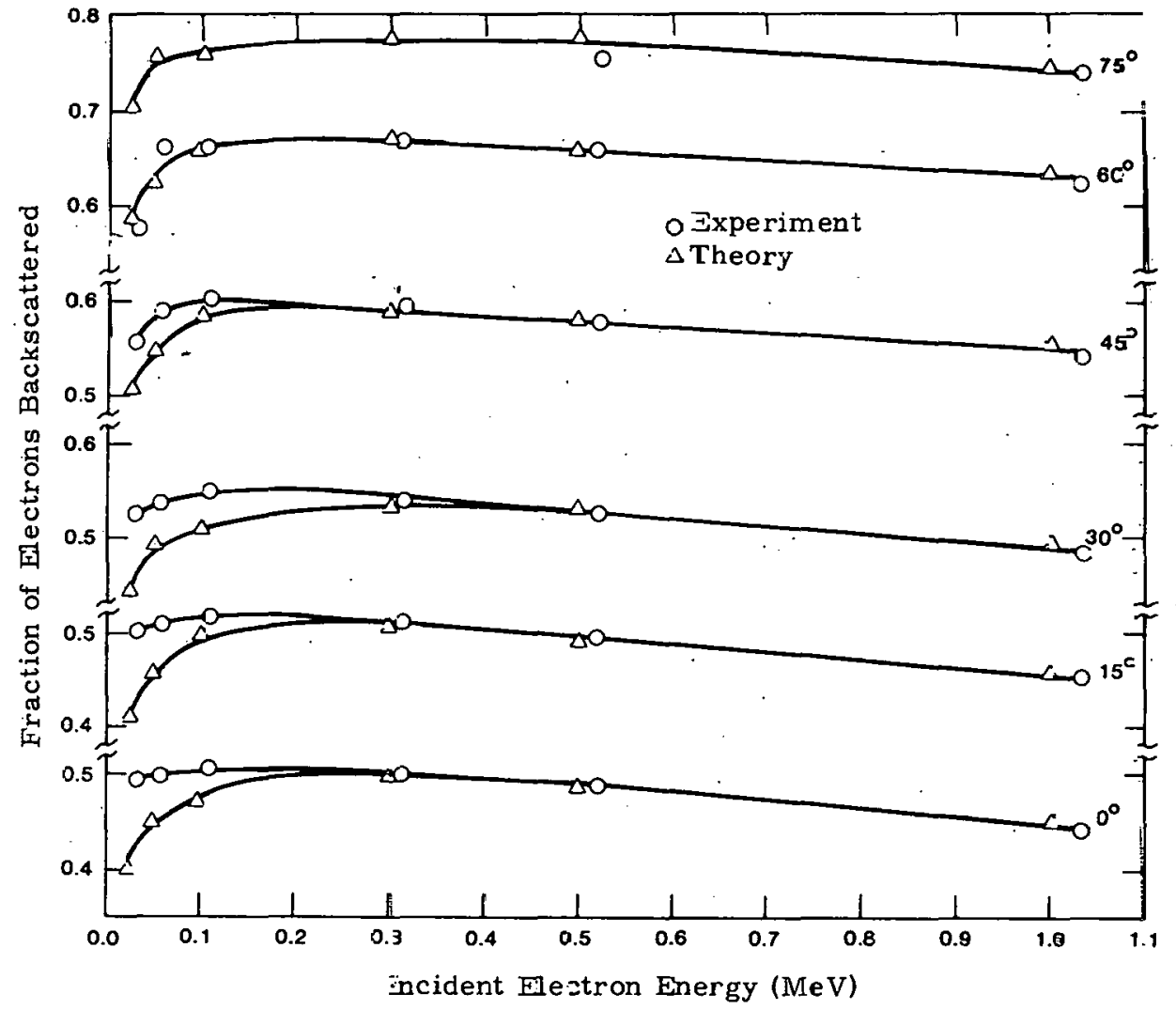

a. Comparison as a Function of Incident Er:ergy

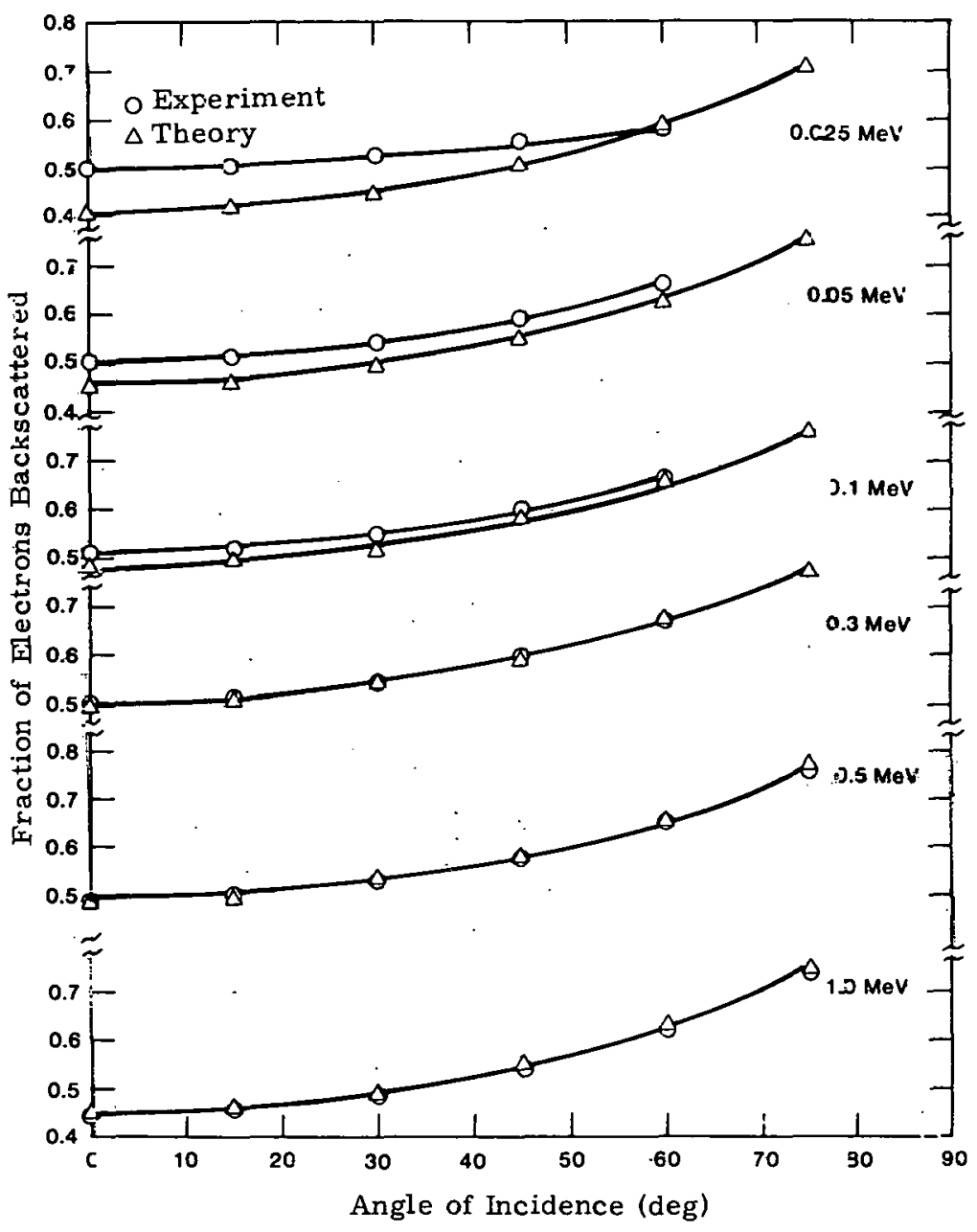

b. Comparison as a Function of Incident Angle

Figure V-F. 2 Comperison of Experimental and T.teoretical Number Backscatter in Tantalum 
Table V-F. 2

Fraction of Electrons Backscattered From Tantalum

\begin{tabular}{|c|c|c|c|c|c|c|c|}
\hline & \multirow{2}{*}{$\begin{array}{l}\text { Energy } \\
\text { (MeVI) }\end{array}$} & \multicolumn{6}{|c|}{ Angle of Incidence } \\
\hline & & $0^{\circ}$ & $15^{\circ}$ & $30^{\circ}$ & $45^{\circ}$ & $60^{\circ}$ & $75^{\circ}$ \\
\hline Exp & 1.033 & 0.440 & 0.452 & 0.483 & 0.540 & 0.621 & 0.739 \\
\hline Theory & 1.0 & 0.449 & 0.457 & 0.498 & 0.557 & 0.635 & 0.747 \\
\hline Exp & 0.521 & 0.486 & 0.495 & 0.526 & 0.578 & 0.657 & 0.752 \\
\hline Tteory & 0.5 & 0.486 & 0.490 & 0.533 & 0.580 & 0.657 & 0.775 \\
\hline Exp & 0.314 & 0.497 & 0.512 & 0.539 & 0.595 & 0.668 & - \\
\hline Theory & 0.3 & 0.496 & 0.505 & 0.533 & 0.587 & $0.67 \dot{2}$ & 0.773 \\
\hline$E \simeq p$ & $0.10 \mathrm{~g}$ & 0.506 & 0.518 & 0.550 & 0.600 & 0.662 & - \\
\hline Theory & 0.1 & 0.472 & 0.496 & 0.512 & 0.583 & 0.659 & 0.758 \\
\hline Exp & 0.058 & 0.497 & 0.508 & 0.539 & 0.589 & 0.662 & - \\
\hline Theory & 0.05 & 0.450 & 0.457 & 0.494 & 0.549 & 0.624 & 0.757 \\
\hline Exp & 0.032 & 0.494 & 0.501 & 0.526 & 0.554 & 0.576 & - \\
\hline Theory & 0.025 & 0.400 & 0.412 & 0.444 & 0.507 & 0.588 & 0.70 .5 \\
\hline
\end{tabular}




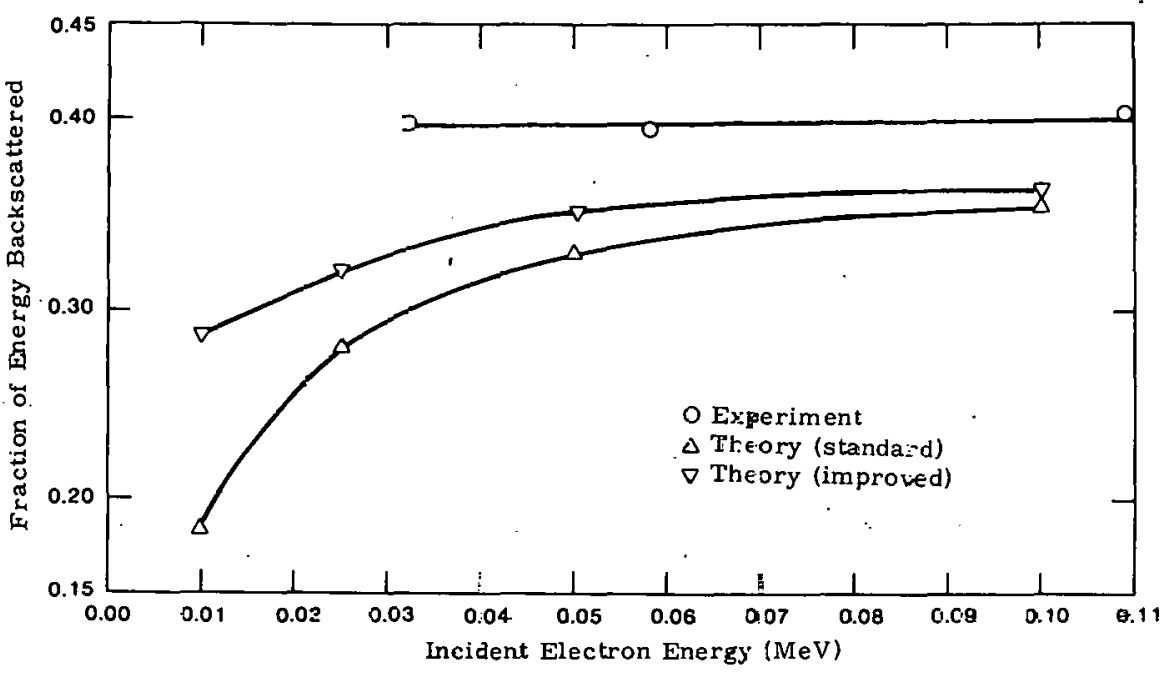

a. Comparison at an Incident Angle of $0^{\circ}$

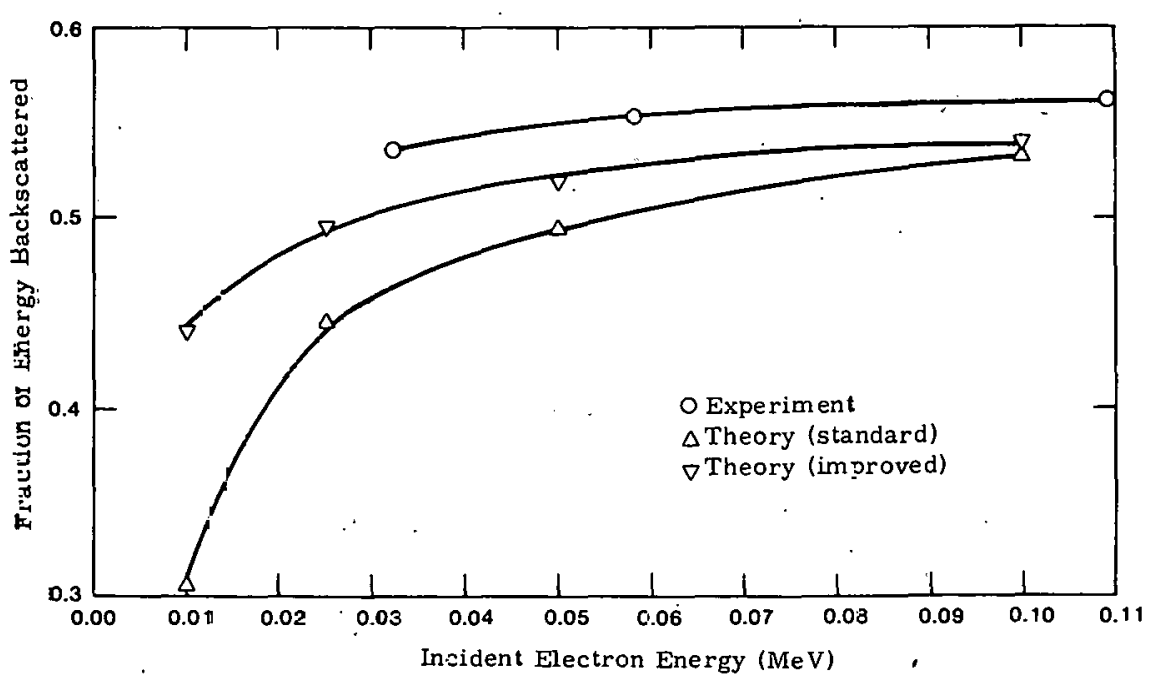

b. Comparison at an Incident Angle of $60^{\circ}$

Figure V-F.3 Comparison of Experiment and Theoretical Energy Backscatter in Tantalum as a Function of Incident Energy Us ing Standard and Ir-proved Theoretical Cross Sections 
Table V-F. 3

Fraction of Energy Backscattered From Tantalum Calculated With Standard and Improved Cross Sections

\begin{tabular}{|c|c|c|c|c|}
\hline & \multirow{2}{*}{$\begin{array}{l}\text { Cross } \\
\text { Sections }\end{array}$} & \multirow{2}{*}{$\begin{array}{l}\text { Energy } \\
(\mathrm{MeV})\end{array}$} & \multicolumn{2}{|c|}{ Angle of Incidence } \\
\hline & & & $0^{5}$ & $60^{\circ}$ \\
\hline Theory & Standard & 0.01 & 0.185 & 0.307 \\
\hline Theory & Improved & 0.01 & 0.287 & 0.441 \\
\hline Theory & Standard & 0.025 & 0.281 & 0.446 \\
\hline Theory & Improved & 0.025 & 0.319 & 0.494 \\
\hline Experiment & & 0.032 & 0.398 & 0.535 \\
\hline Theory & Standard & 0.05 & 0.331 & 0.493 \\
\hline Theory & Improved & 0.05 & 0.352 & 0.517 \\
\hline Experiment & & 0.058 & 0.395 & 0.553 \\
\hline Theory & Standard & 0.10 & 0.355 & 0.532 \\
\hline Theory & Improved & 0.10 & 0.363 & 0.538 \\
\hline Experiment & & 0.109 & 0.403 & 0.559 \\
\hline
\end{tabular}

\footnotetext{
$\overline{1 \text { Experimental }}$ results adjusted by subtracting the fraction of energy escaping in the form of bremsstrahlung as determined by the TIGER code.
} 


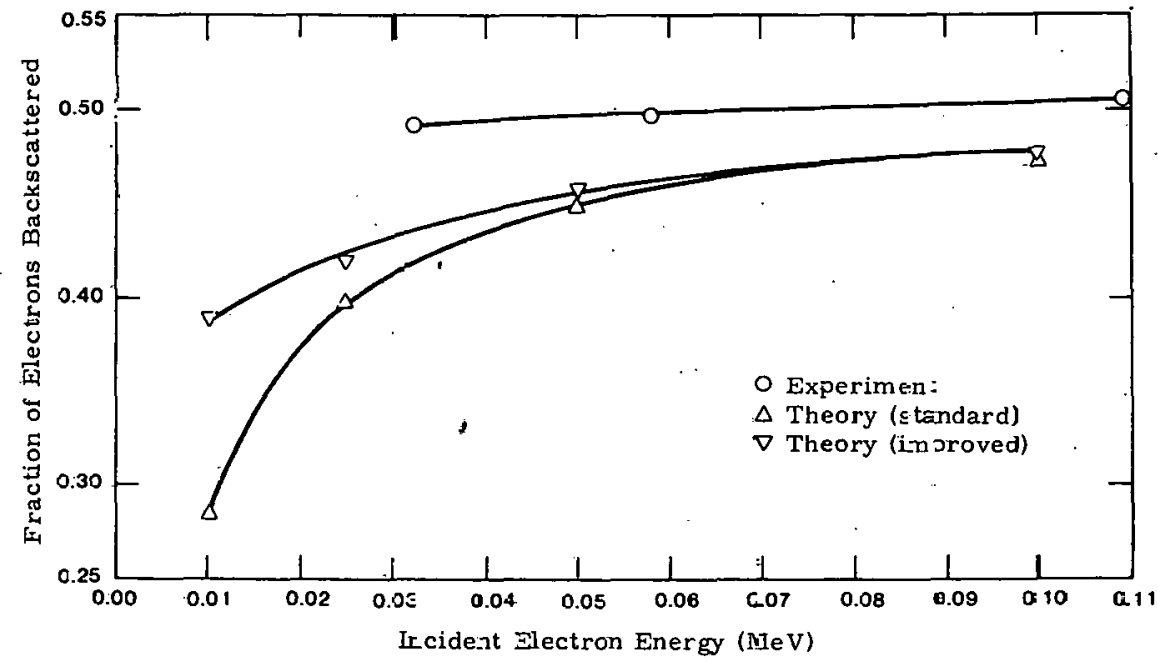

a. Comparison at an Incident f.ngle of $0^{c}$

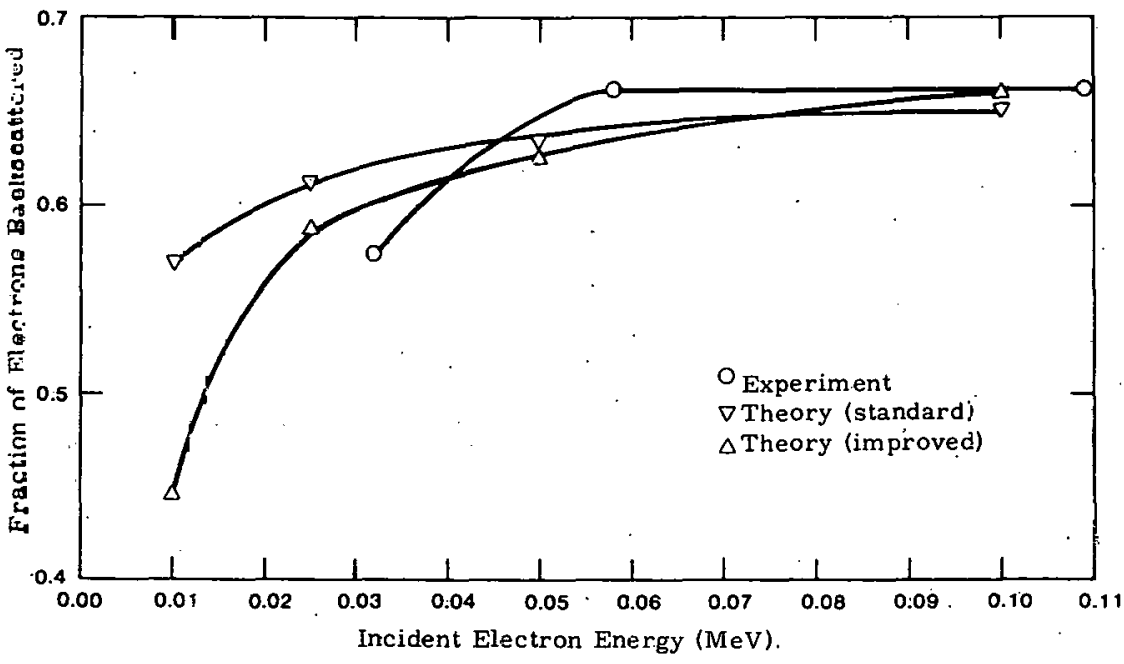

b. Comparison at an Incident Angle of $60^{\circ}$

Figure V-F.4 Comparison of Experimental and Theoretical Number Backscatter in Tantalum as a Function of Incident Energy Using Standasd and Improred Theoretical Cross Sections 
Table V-F. 4

Fraction of Electrons Backscattered From Tantalum Calculated With Standard and Improved Cross Sections

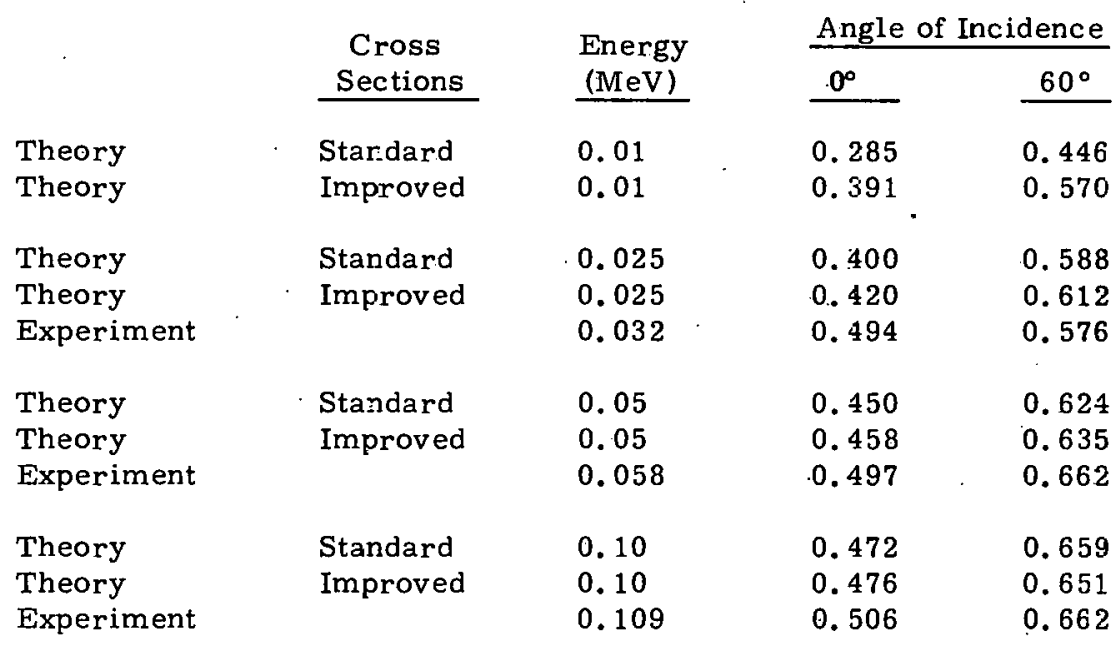


G. Electron Fnergy and Charge Albedos in Uranium

Energies (MeV): $1.033,0.521,0.314,0.109,0.084,0.058$, and 0.032

Angles $\left({ }^{\circ}\right): 0,15,30,45,60$, and 75

Analysis Method: $t_{d}$

Angle Determination Method: Hand set

Calorimeter
Diameter:
$5.08 \mathrm{~cm}$
Thickness:
$0.050 \mathrm{~cm}$

Tabie $V-G(i)$

A Comparison of Total Energy Deposition in U1aulum

Fraction of Energy Deposited

\begin{tabular}{|c|c|c|c|c|}
\hline $\begin{array}{c}\text { Nominal } \\
\text { Energy } \\
\text { (MeV) } \\
\end{array}$ & $\begin{array}{l}\text { Angle } \\
(\mathrm{dcg}) \\
\end{array}$ & $\begin{array}{c}\text { TIGDR } \\
\text { Ealculation } \\
\end{array}$ & $\begin{array}{c}\text { Total } \\
\text { Stopping } \\
\text { Measurement } \\
\end{array}$ & $\begin{array}{c}\text { Integrated } \\
\text { Diffcrivilidl } \\
\text { Measurement }\end{array}$ \\
\hline 1.0 & 0 & 0.61 .5 & 0.555 & $0 . \overline{5} 84^{\prime}$ \\
\hline 1.0 & 60 & 0.427 & 0.394 & 0.413 \\
\hline ก. 5 & 0 & 0.582 & 0.528 & 0.554 \\
\hline 0.3 & 0 & 0.553 & 0.505 & 0.550 \\
\hline
\end{tabular}


Table V-G(ii)

Theoretically Calculated Fraction of the Incident Electron Energy

That Escapes From Uranium in the Form of Bremsstrahlung

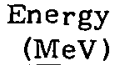

1.0

0.5

0.3

0.109

0.084

0.058

0.032

Angle of Incidence

\begin{tabular}{|c|c|c|c|c|c|}
\hline $0^{\circ}$ & $15^{\circ}$ & $30^{\circ}$ & $45^{\circ}$ & $60^{\circ}$ & $75^{\circ}$ \\
\hline 2. $36 \times 10^{-2}$ & $2.44 \times 10^{-2}$ & $2.30 \times 10^{-2}$ & $2.11 \times 10^{-2}$ & $1.70 \times 10^{-2}$ & $1.47 \times 10^{-2}$ \\
\hline $9.69 \times 10^{-3}$ & $1.16 \times 10^{-2}$ & 9. $97 \times 10^{-3}$ & $9.08 \times 10^{-3}$ & $9.51 \times 10^{-3}$ & $6.63 \times 10^{-3}$ \\
\hline $6.23 \times 10^{-3}$ & $6.85 \times 10^{-3}$ & $5.95 \times 10^{-3}$ & $5.01 \times 10^{-3}$ & $5.52 \times 10^{-3}$ & $4.07 \times 10^{-3}$ \\
\hline $2.54 \times 10^{-3}$ & $2.17 \times 10^{-3}$ & $1.83 \times 10^{-3}$ & $1.86 \times 10^{-3}$ & $1.74 \times 10^{-3}$ & $1.67 \times 10^{-3}$ \\
\hline $1.69 \times 10^{-3}$ & $1: 80 \times 10^{-3}$ & $2.01 \times 10^{-3}$ & $1.16 \times 10^{-3}$ & $1.75 \times 10^{-3}$ & $1.70 \times 10^{-3}$ \\
\hline $1.46 \times 10^{-3}$ & $1.52 \times 10^{-3}$ & $1.33 \times 10^{-3}$ & 1. $32 \times 10^{-3}$ & $1.32 \times 10^{-3}$ & $8.11 \times 10^{-4}$ \\
\hline $1.15 \times 10^{-3}$ & $6.04 \times 10^{-4}$ & $4.89 \times 10^{-4}$ & $1.18 \times 10^{-4}$ & $2.86 \times 10^{-4}$ & $3.74 \times 10^{-4}$ \\
\hline
\end{tabular}




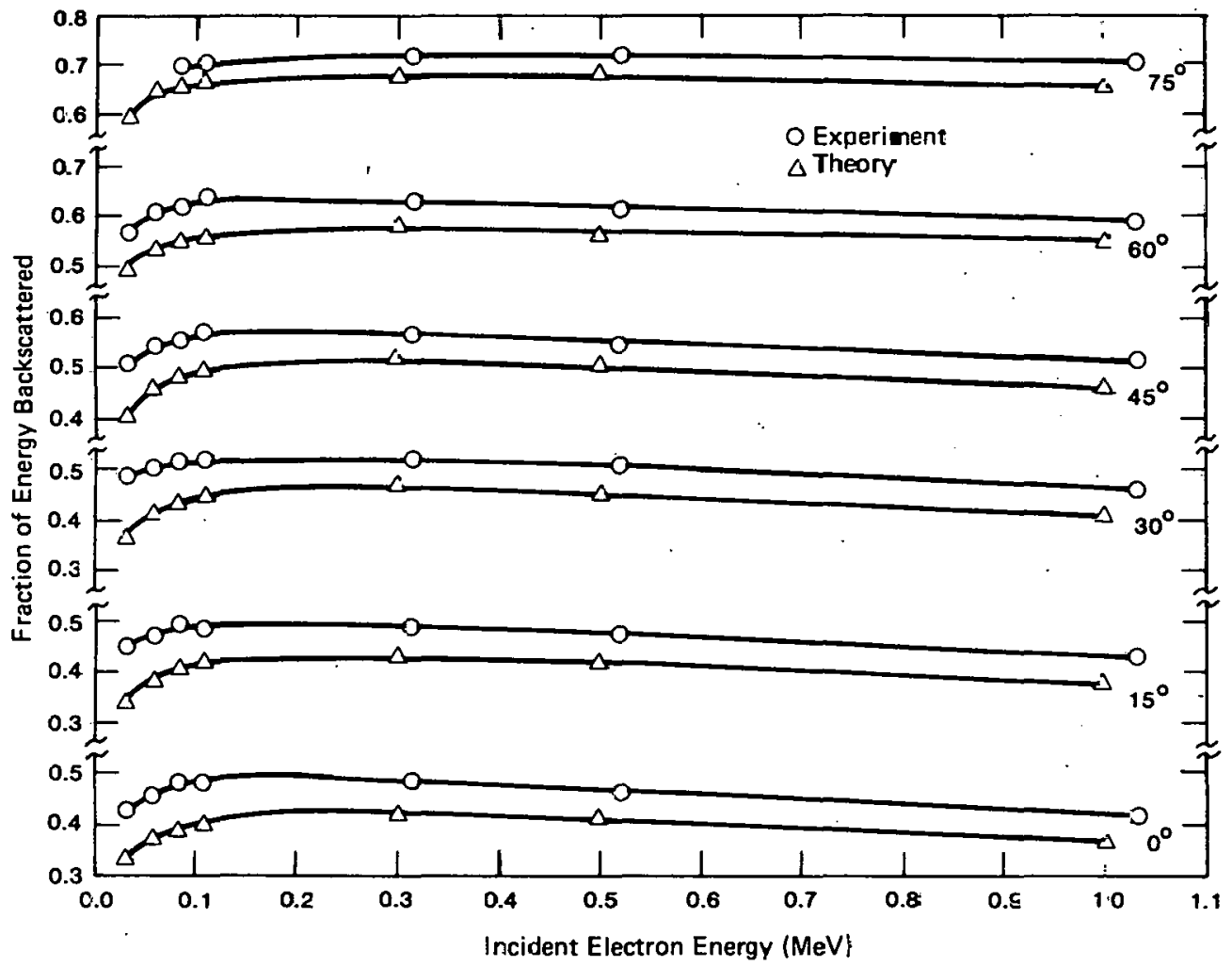

a. Ccmparison as a Function of Incident Er.ergy

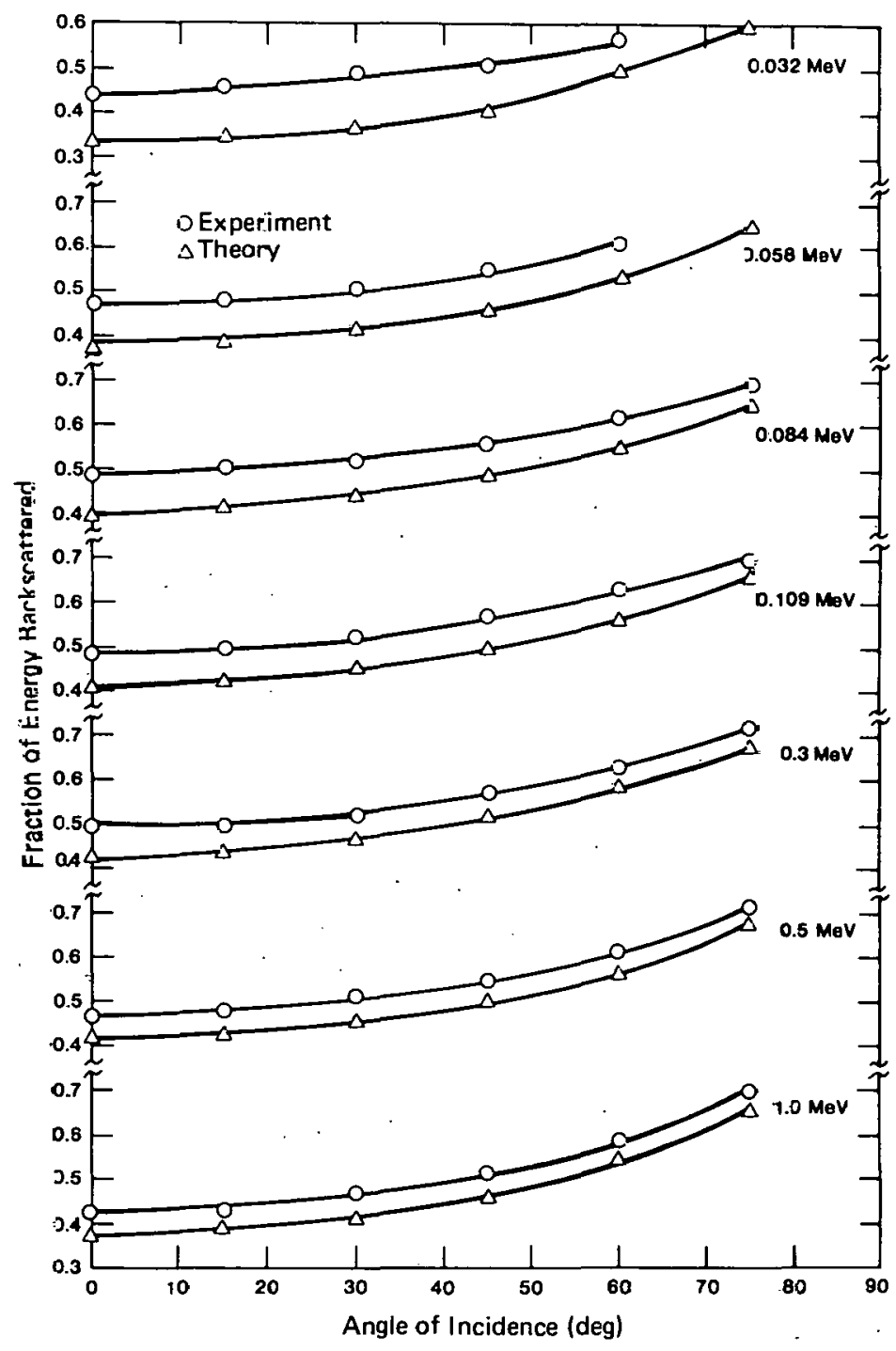

b. Comparison as a Function of Incident Angle

Figure V-G. 1 Comparison of Experimental and Tneoretical Energy Backscatter in Uranium 
Table V-G. 1

Fraction of Energy Backscattered From Uranium ${ }^{1}$

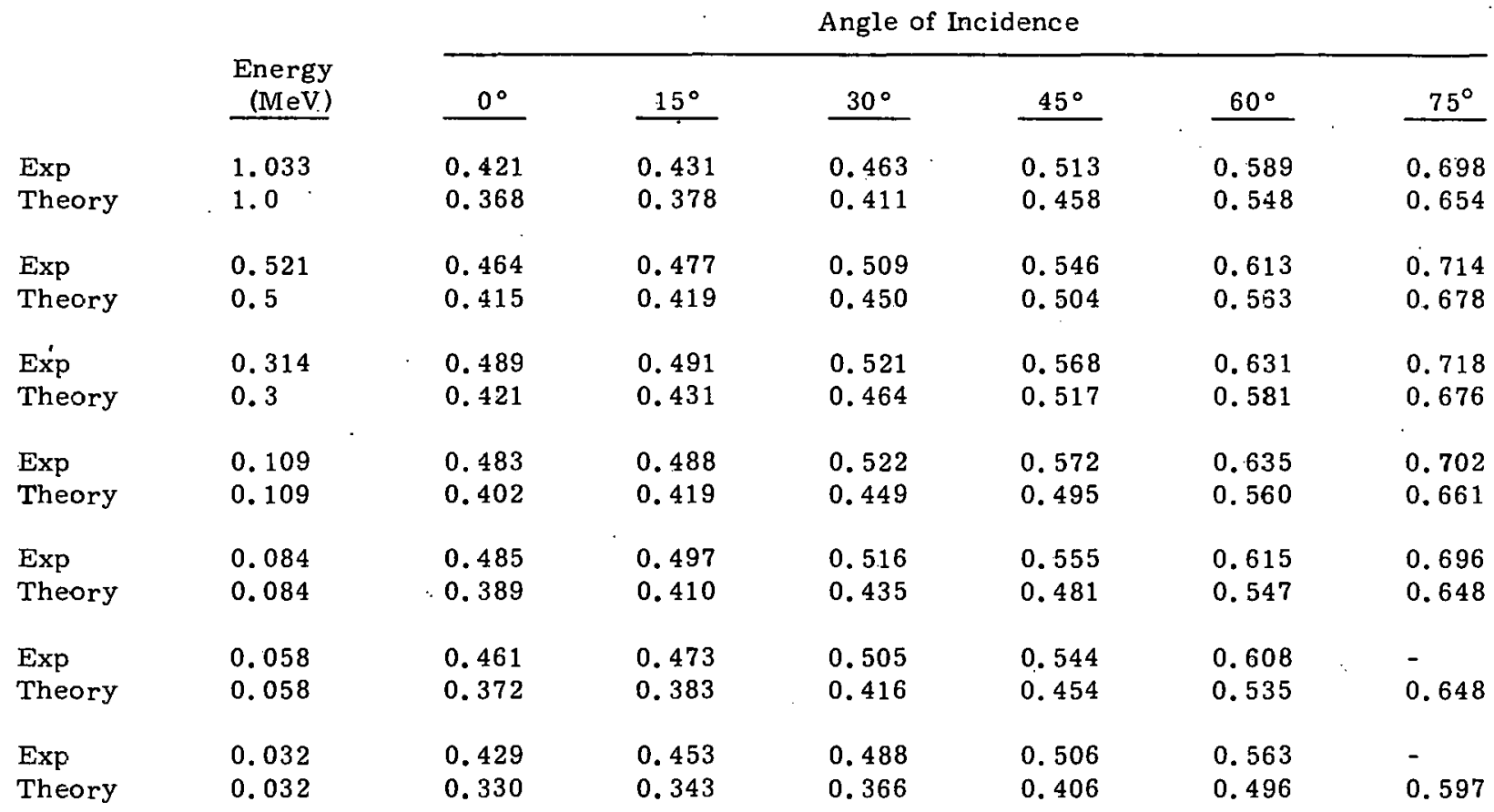

${ }^{1}$ Experimental results adjusted by subtracting the fraction of energy escaping in the form of bremsstrahlung as determined by the TIGER code. 


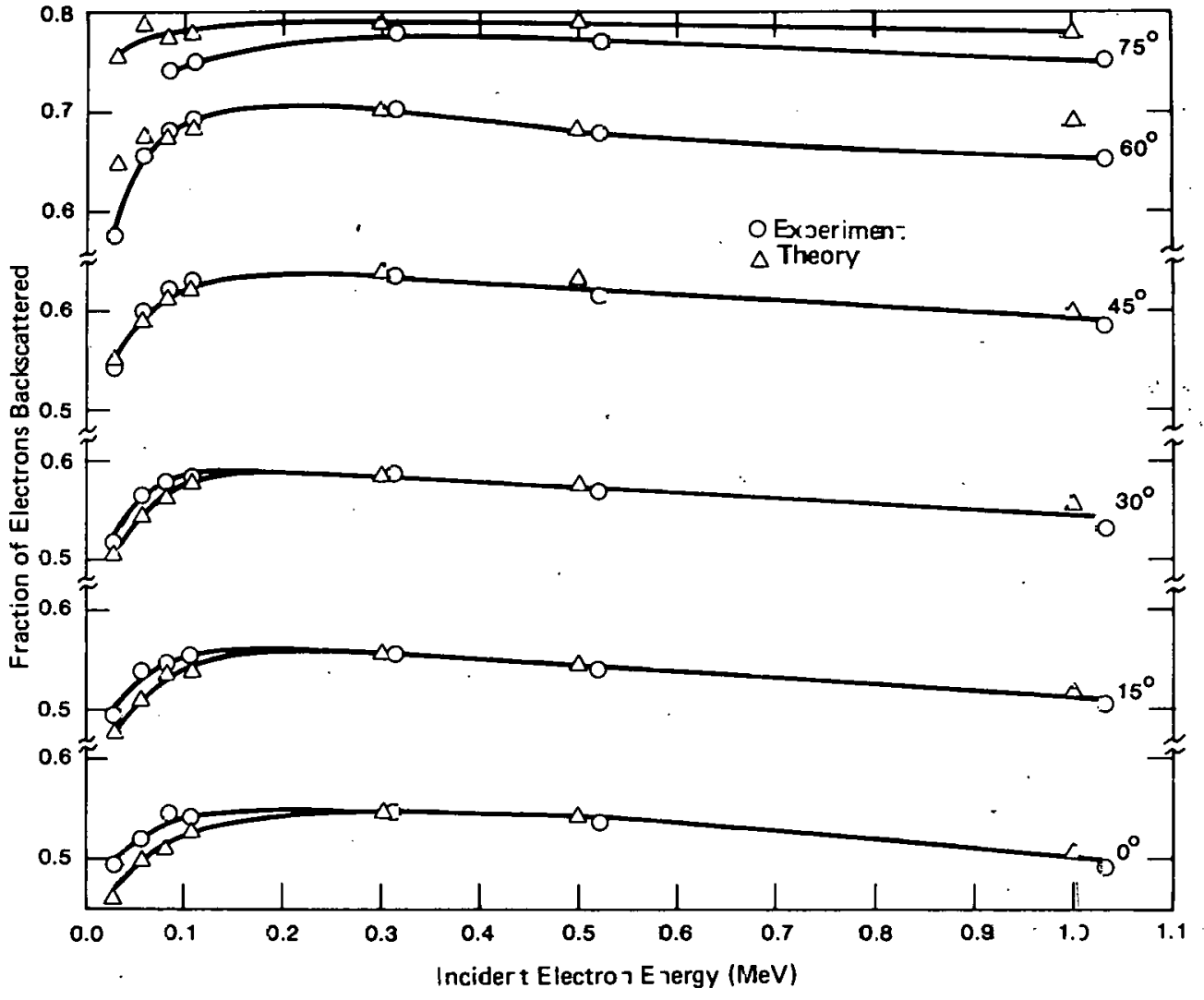

a. Comperison as a Funtition of Incicient Ererey

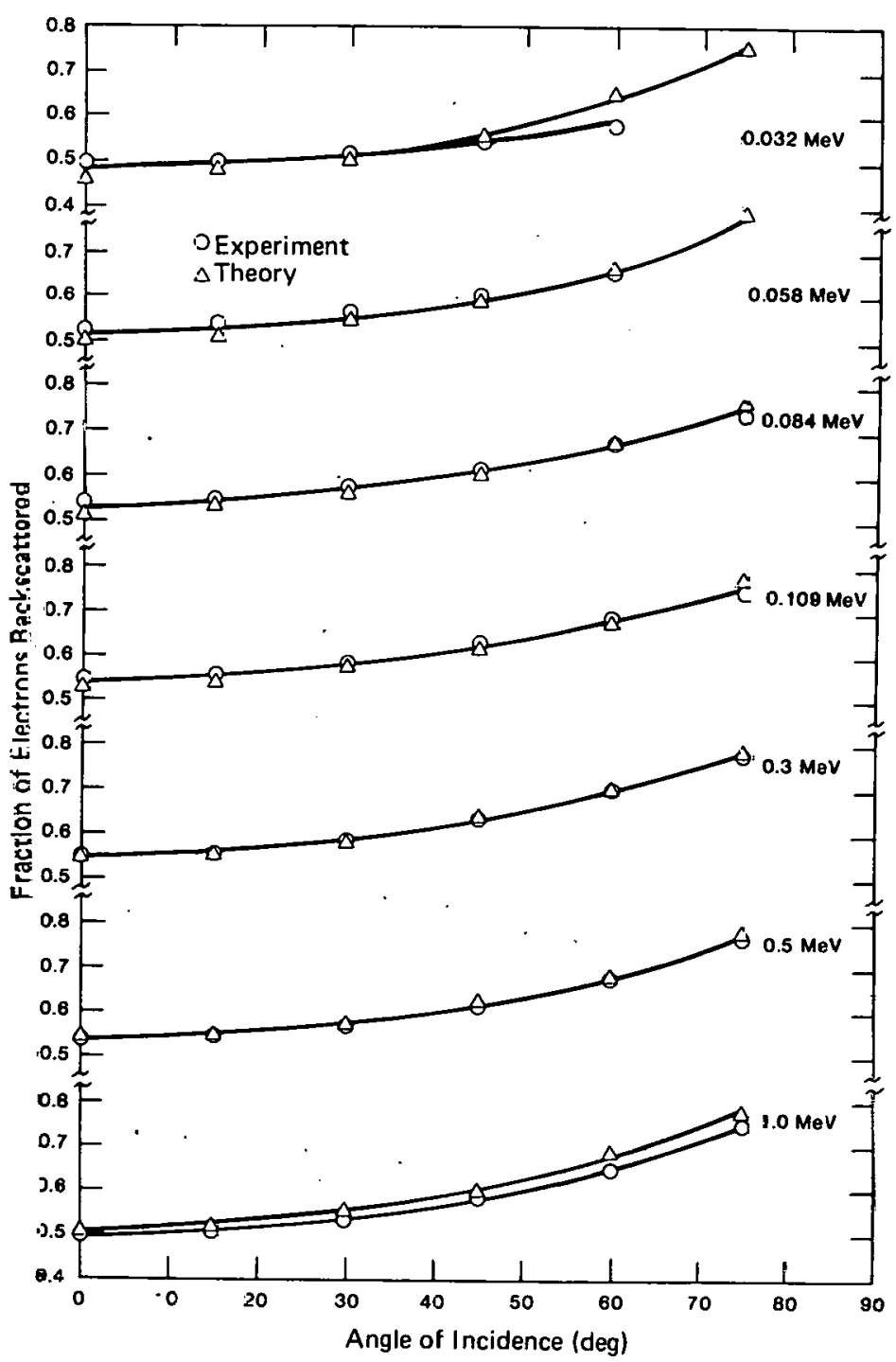

b. Comparison as a Function of Incident Angle

Figure V-G.2 Comparison of Experimental and Theoretical Number Backscatter in Uranium 
Table V-G. 2

Fraction of Electrons Backscattered From Uranium

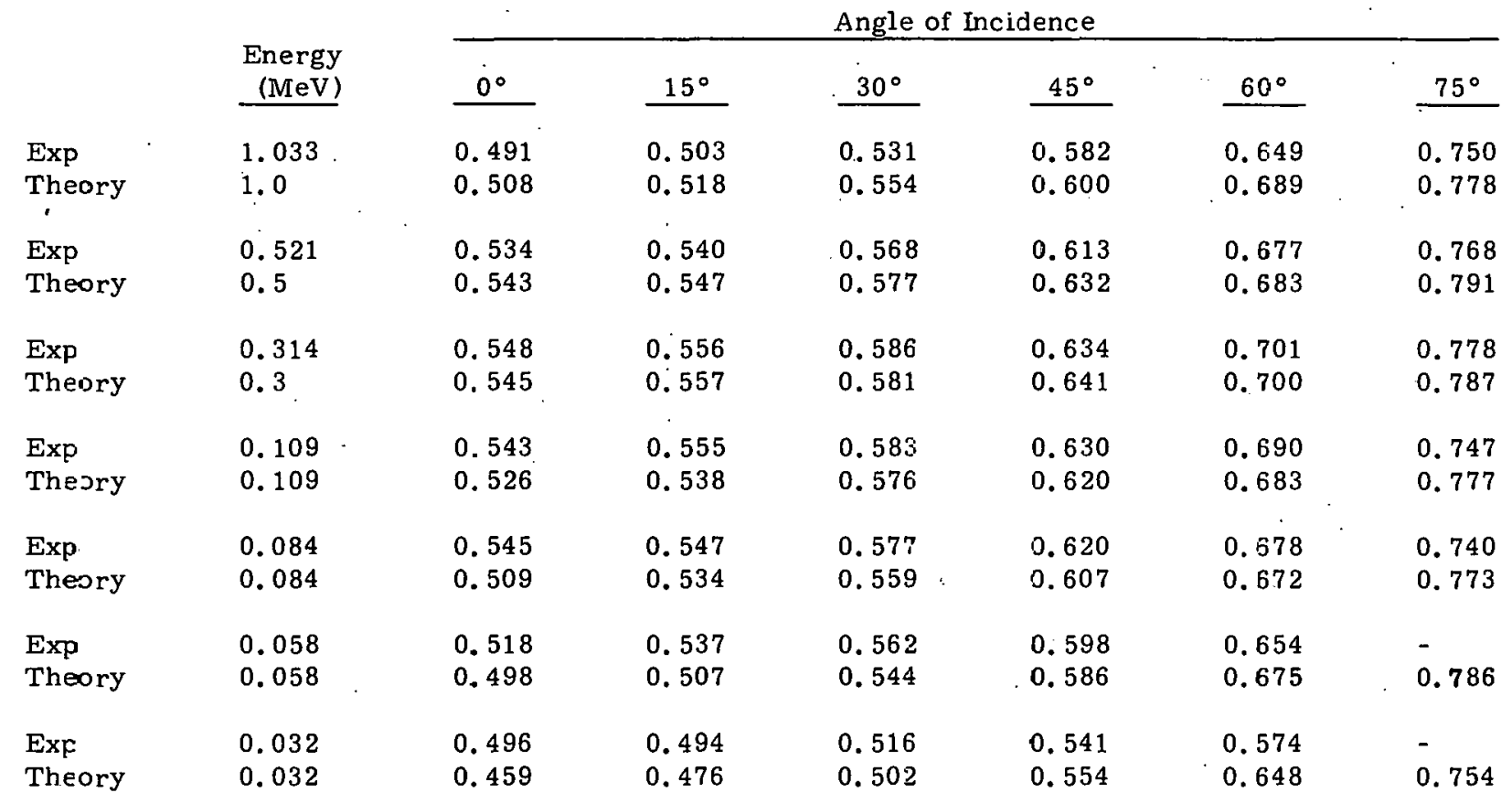




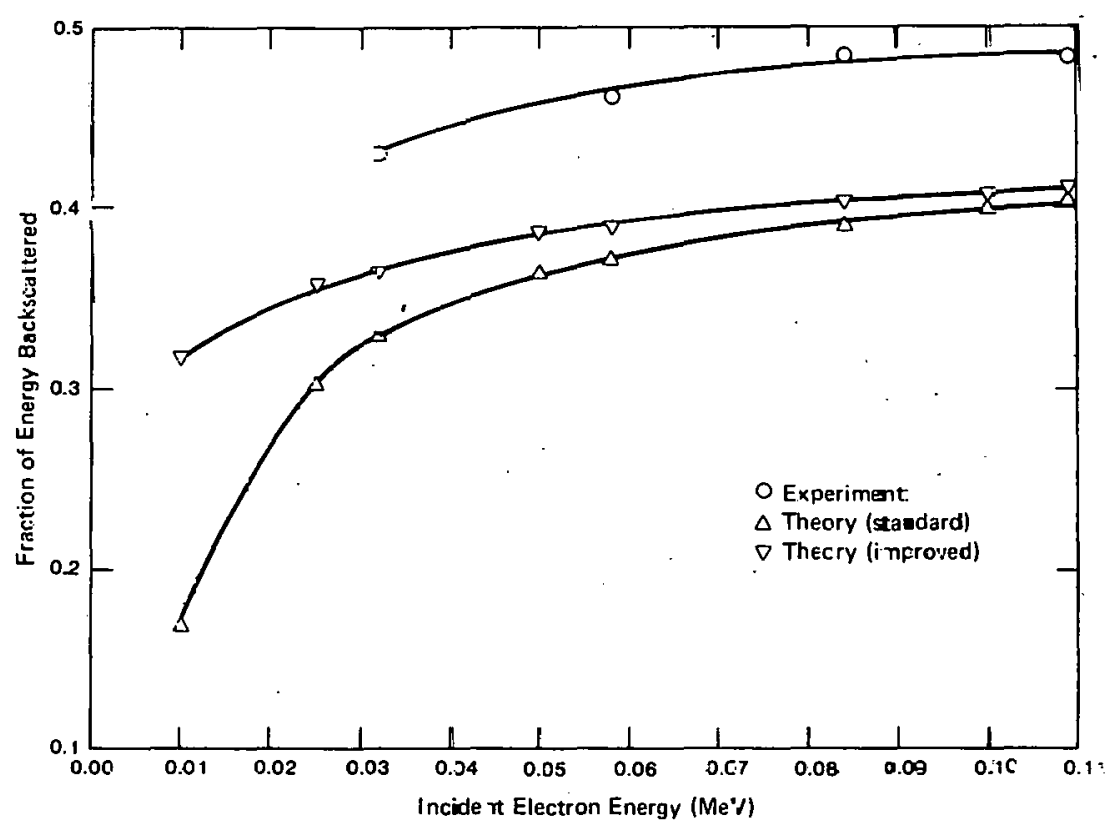

a. Comparisor, at an Incident Angle of $0^{\circ}$

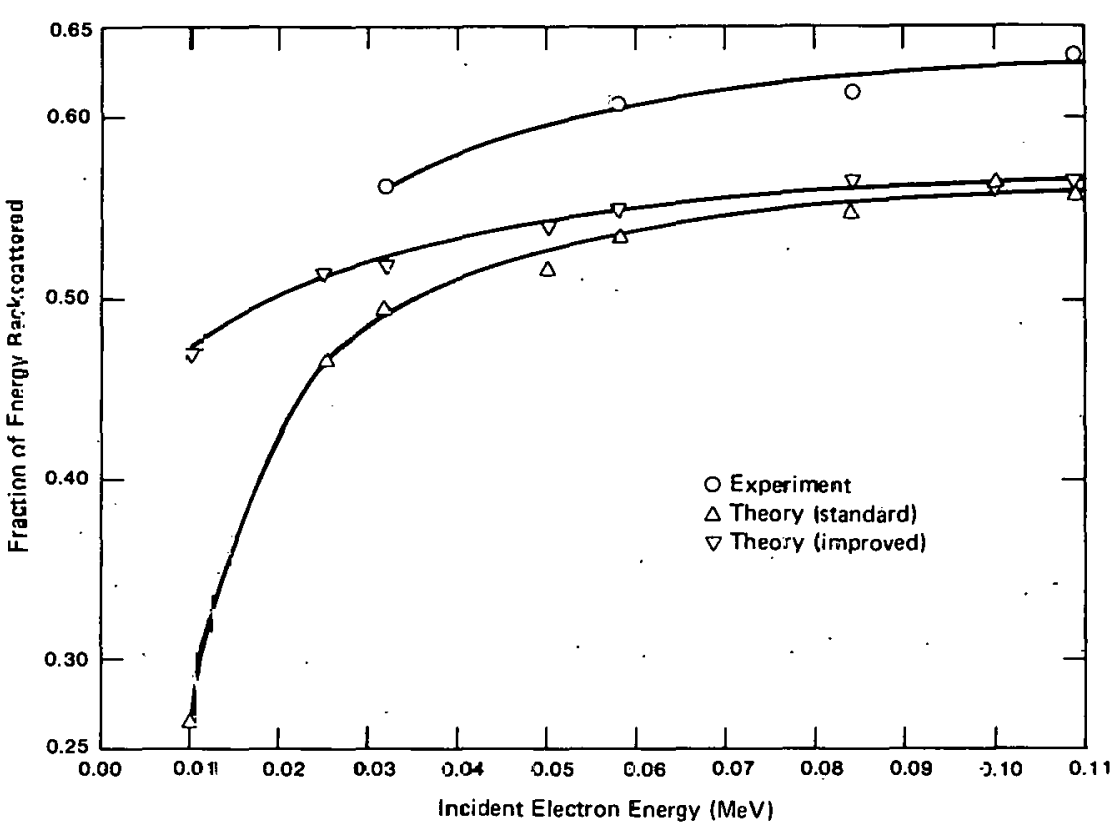

b. Comparison at an incident Angle of $60^{\circ}$

Figuze V-G.3 Comparison of Experimental and Theore:ical Energg Backscatter in Uranium as a Function of Incident Energ $;$ Using Standard and Improved Theoretic $\equiv 1$ Cross Sections 
Table V-G. 3

Fraction of Energy Backscattered From Uranium Calculated With Standard and Improved Cross Sections ${ }^{1}$

\begin{tabular}{|c|c|c|c|c|}
\hline \multirow{2}{*}{. } & \multirow{2}{*}{$\begin{array}{l}\text { Cross } \\
\text { Sections }\end{array}$} & \multirow{2}{*}{$\begin{array}{c}\text { Energy } \\
\text { (MeV) }\end{array}$} & \multicolumn{2}{|c|}{ Angle of Incidence } \\
\hline & & & $0^{\circ}$ & $60^{\circ}$ \\
\hline Theory & Standard & 0.01 & 0.167 & 0.266 \\
\hline Theory & Improved & 0.01 & 0.317 . & 0.470 \\
\hline Theory & Standard & 0.025 & 0.303 & 0.466 \\
\hline Theory & Improved & .0 .025 & 0.358 & 0.515 \\
\hline Theory & Standard & 0.032 & 0.330 & 0.496 \\
\hline Theory & Improved & 0.032 & 0.363 & 0.518 \\
\hline Experiment & & 0.032 & 0.429 & 0.563 \\
\hline Theory & Standard. & 0.05 & 0.364 & 0.517 \\
\hline Theory & Improved & 0.05 & 0.386 & 0.539 \\
\hline Theory & Standard & 0.058 & 0.372 & 0.535 \\
\hline 'Theory & Improved & 0.058 & 0.388 & 0.548 \\
\hline Experiment & & 0.058 & 0.461 & 0.608 \\
\hline Theory & Standard & 0.084 & 0.389 & 0.547 \\
\hline Theory & Improved & 0.084 & 0.403 & 0.565 \\
\hline Experiment & & 0.084 & 0.485 & 0.615 \\
\hline Theory & Standard & 0.10 & 0.400 & 0.565 \\
\hline Theory & Improved & 0.10 & 0.407 & 0.563 \\
\hline Theory & Standard & 0.109 & 0.402 & 0.560 \\
\hline Theory & Improved & 0.109 & 0.411 & 0.563 \\
\hline Experiment & & 0.109 & 0.483 & 0.635 \\
\hline
\end{tabular}

\footnotetext{
$\overline{1_{\text {Experimental }}}$ results adjusted by subtracting the fraction of energy escaping in the form of bremsstrahlung as determined by the TIGER code.
} 


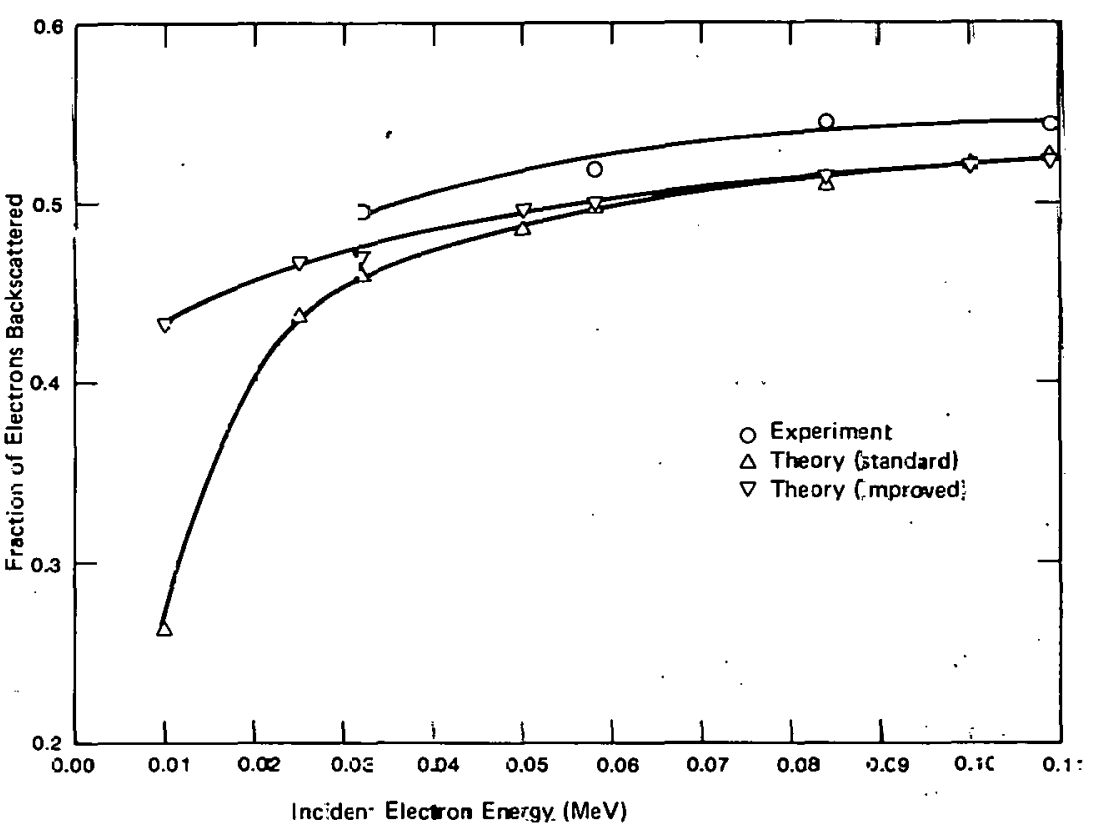

a. Compazis on at an Incident Angle of $0^{\circ}$

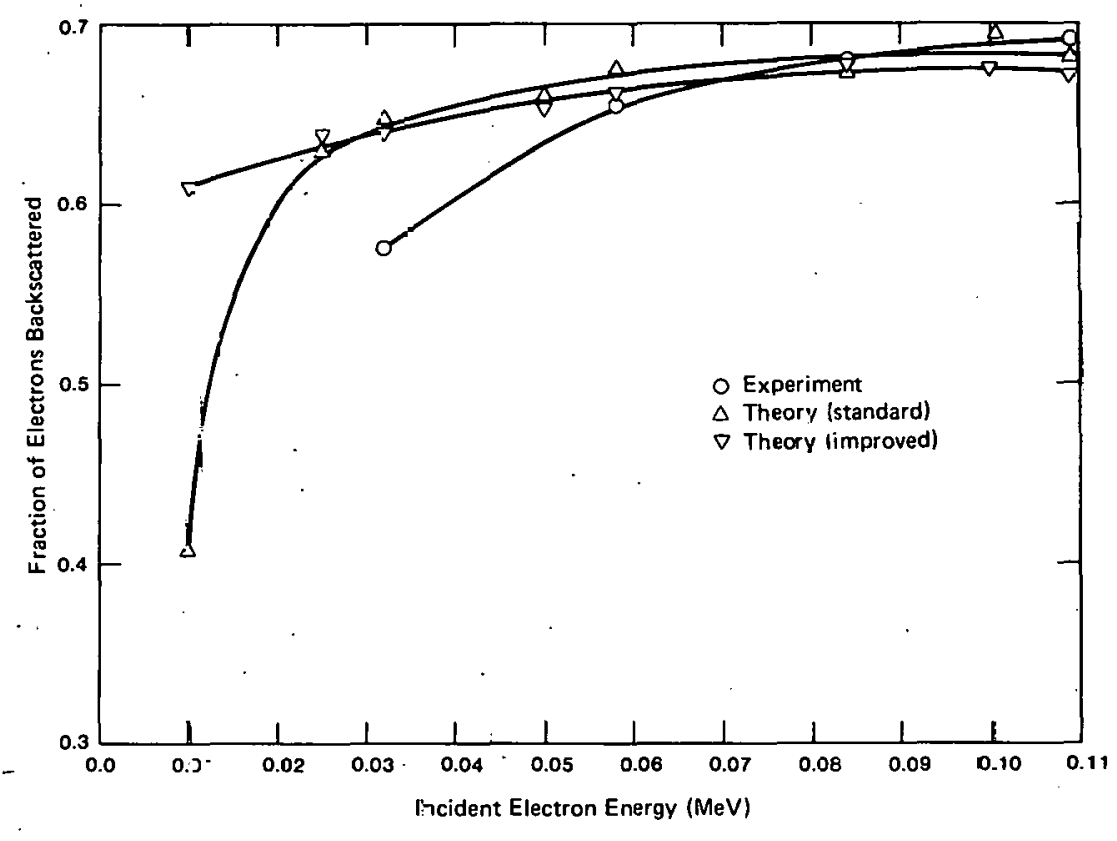

b. Comparison at an Incident Angle of $60^{\circ}$

Figur $\geqslant$ V-G. 4 Comparison of Experimental and Theoretiøal Numbe: Backscatter :n Uranium as a Function of Incident Energy Using StamJard and Improved Theoretical Cross Sections 
Table V-G. 4

Fraction of Electrons Backscattered From Uranium Calculated With Standard and Improved Cross Sections

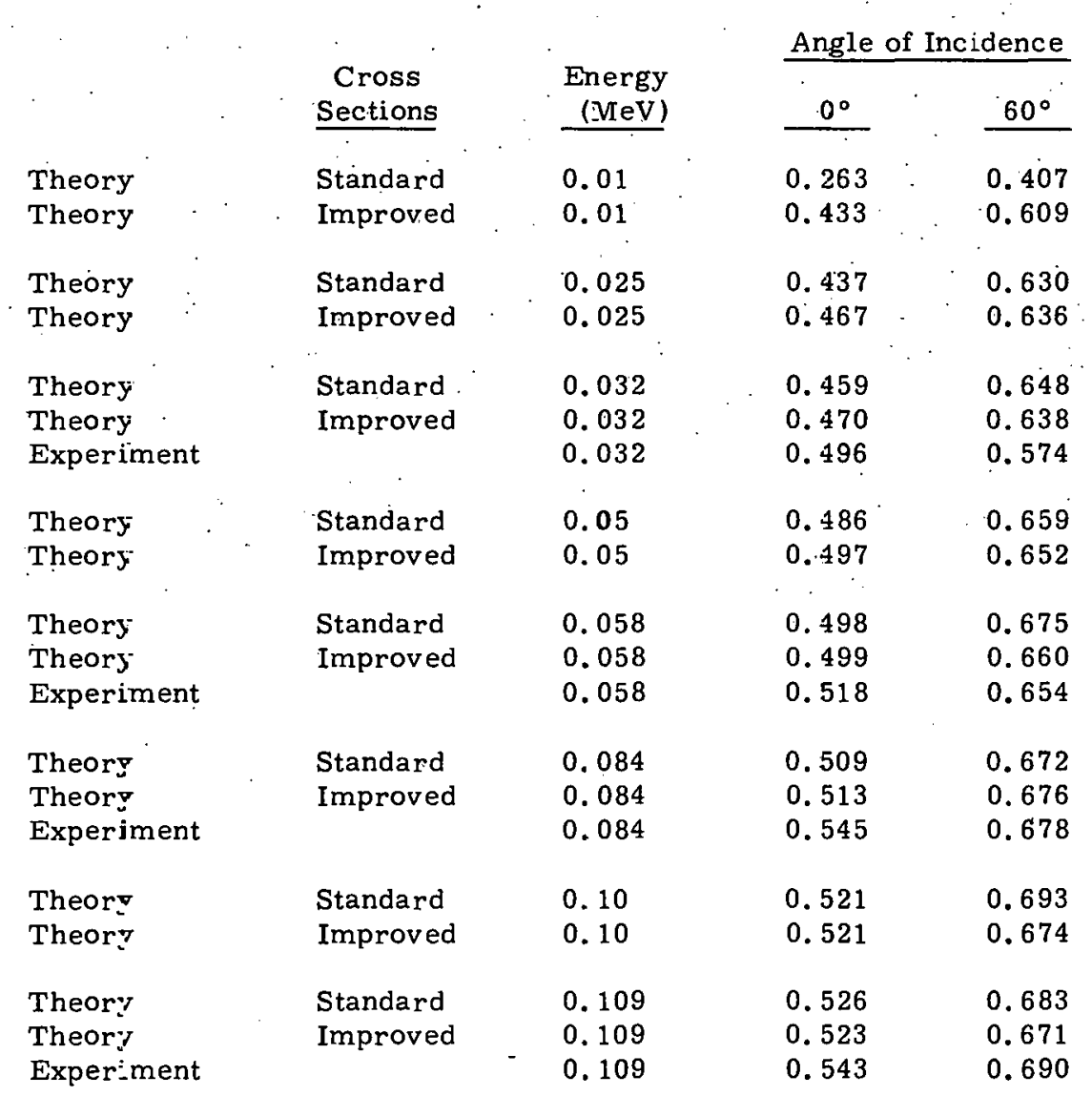


H. Electron Energy and Charge Albedos in Uranium Dioxide

Energies (MeV): $1.0,0.5,0.3$, and 0.1

Angles $\left({ }^{\circ}\right): \quad 0,15,30,45,60$, and 75

Analysis Method: $\mathrm{S}$

Angle Determination Method: Remote set

Calorimeter

Diameter: $4.85 \mathrm{~cm}$

Thickness: $0.083 \mathrm{~cm}$

Table $\mathrm{V}-\mathrm{H}$

Theoretically Calculated Fraction of the Incident Electron Energy That Escapes From Uranium Dioxide in the Form of Bremsstrahlung

\begin{tabular}{|c|c|c|c|c|c|c|}
\hline \multirow{2}{*}{$\begin{array}{l}\text { Energy } \\
(\mathrm{MeV}) \\
\end{array}$} & \multicolumn{6}{|c|}{ Angle of Incidenc } \\
\hline & $0^{\circ}$ & $15^{\circ}$ & $30^{\circ}$ & $45^{\circ}$ & $60^{\circ}$ & $75^{\circ}$ \\
\hline $1,0^{\circ}$ & $2.14 \times 10^{-2}$ & 2. $11 \times 10^{-2}$ & $1.95 \times 10^{-2}$ & $1.93 \times 10^{-2}$ & $1.54 \times 10^{-2}$ & $1.27 \times 10^{-2}$ \\
\hline 0.5 & $9.90 \times 10^{-3}$ & $8.95 \times 10^{-3}$ & $9.47 \times 10^{-3}$ & $8.14 \times 10^{-3}$ & $7.11 \times 10^{-3}$ & ' $6.22 \times 10^{-3}$ \\
\hline 0.3 & $4.97 \times 10^{-3}$ & $3.96 \times 10^{-3}$ & $5,23 \times 10^{-3}$ & $4.16 \times 10^{-3}$ & $3.35 \times 10^{-3}$ & $3.37 \times 10^{-3}$ \\
\hline 0.1 & $1.41 \times 10^{-3}$ & $1.57 \times 10^{-3}$ & $1.62 \times 10^{-3}$ & $1.61 \times 10^{-3}$ & $1.33 \times 10^{-3}$ & $7.87 \times 10^{-4}$ \\
\hline
\end{tabular}




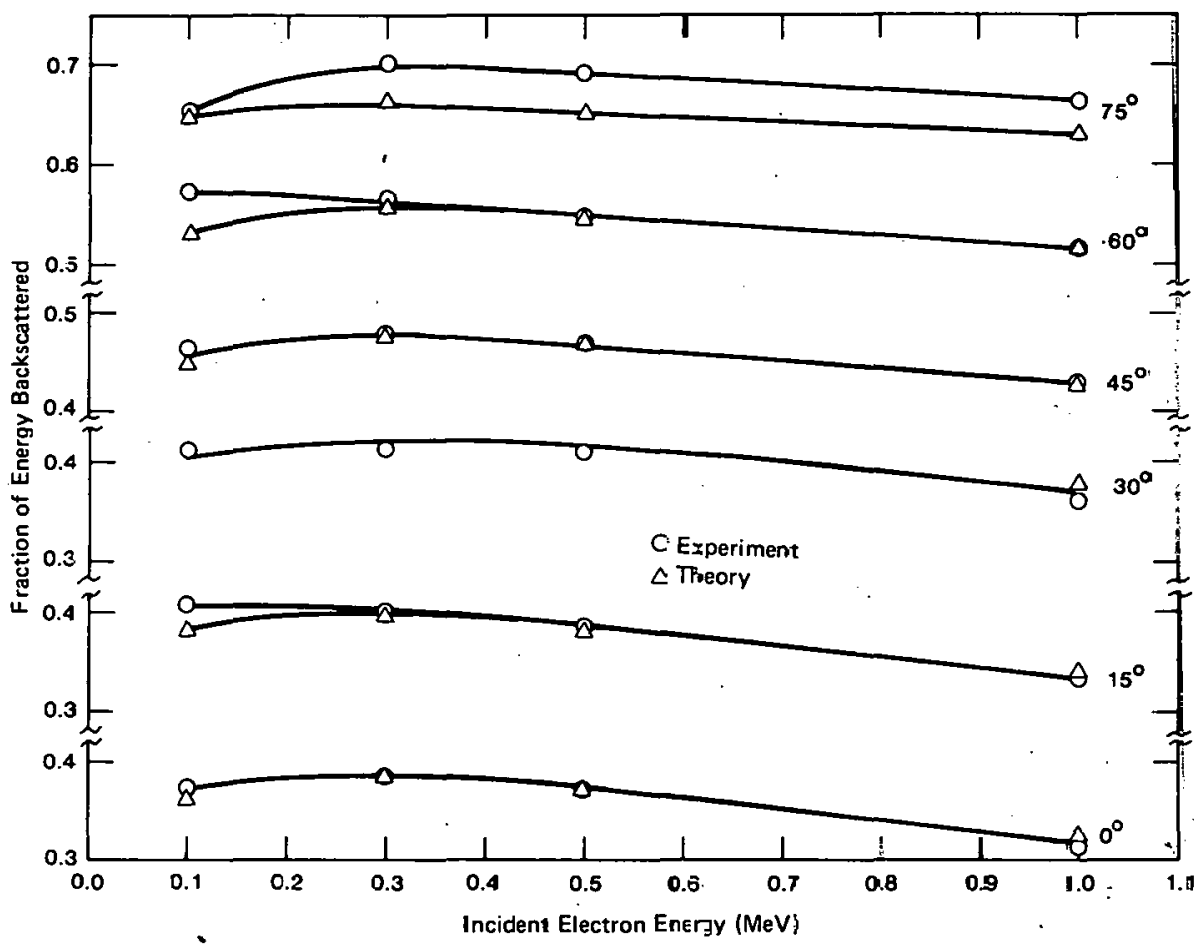

a. Comperison as a Function of Incicent Energy

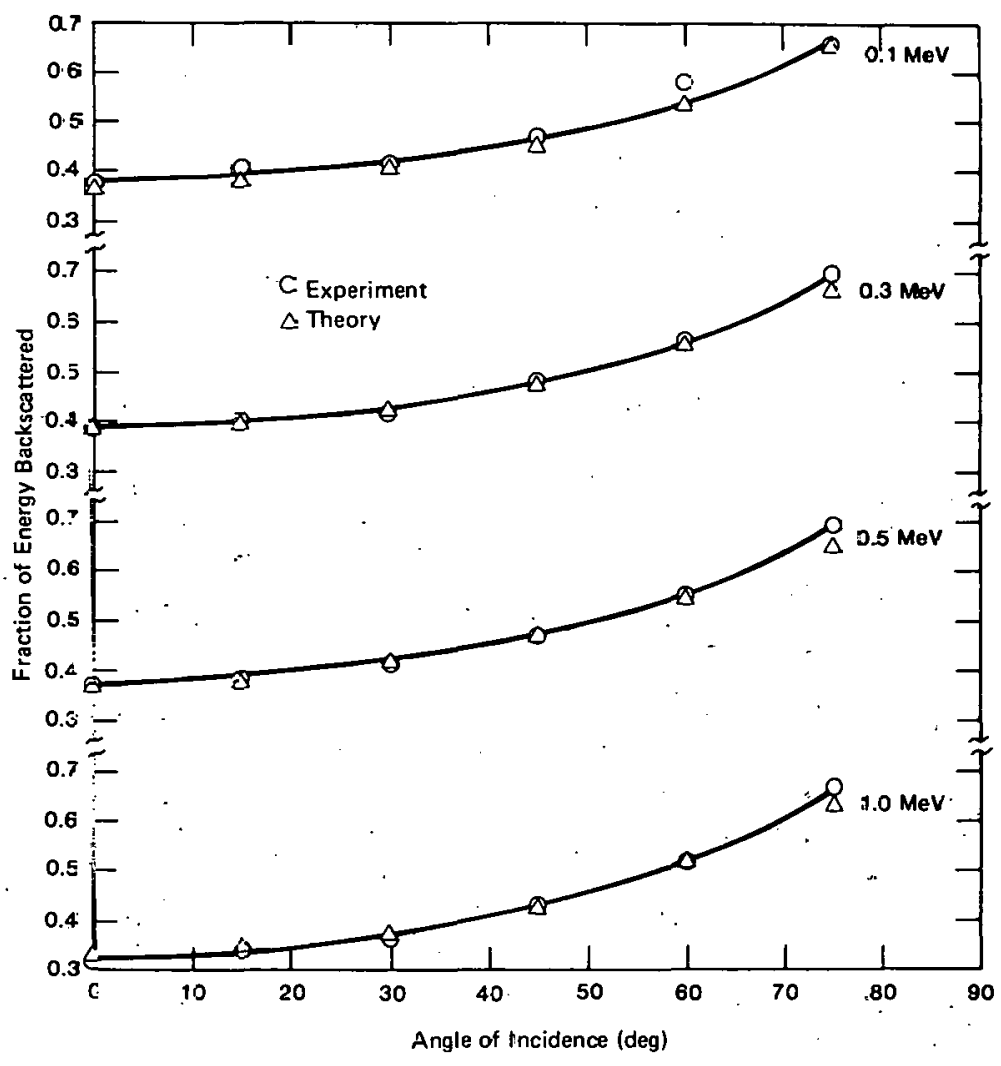

b. Compariscn as a Function of Incident Angle

Figure V-H. 1 Comparison of Experimenzal and The Jretical Energy Backscatter in Uranium Dioxide 
Table V-H. 1

Fraction of Energy Backscattered From Uranium Dioxide ${ }^{1}$

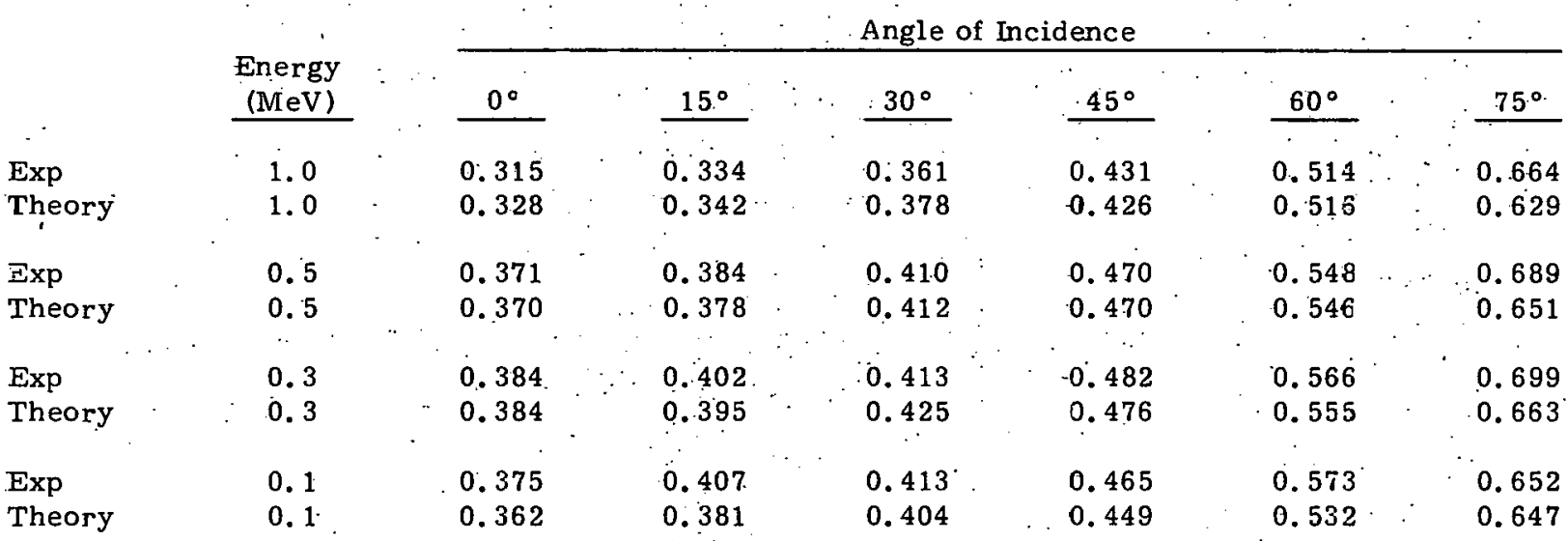

${ }^{1}$ Experimental results adjusted by subtracting the fraction of energy escaping in the form of bremsstrahlung as determined by the TIGER code. 


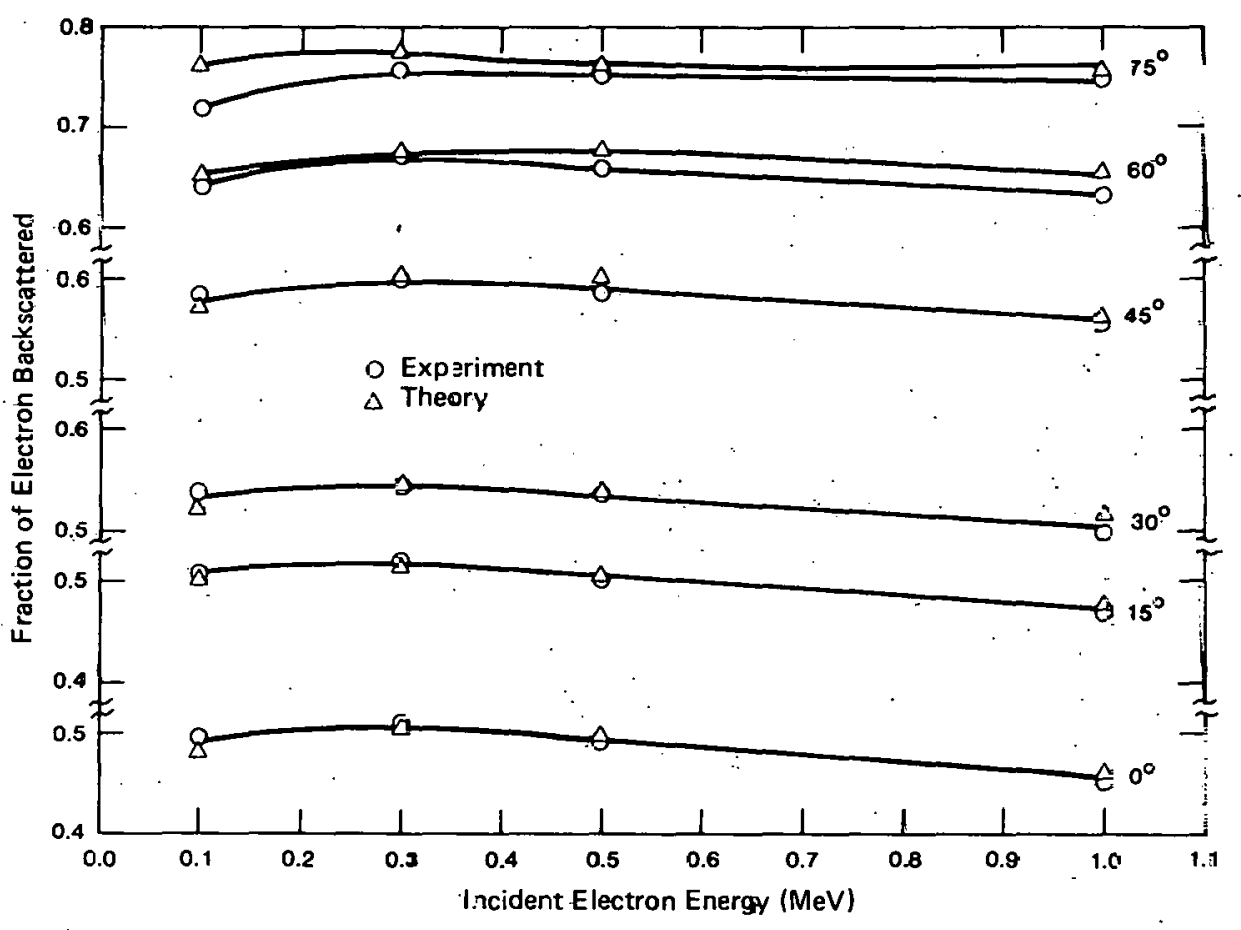

a. Comparison as a Function of Incident Energy

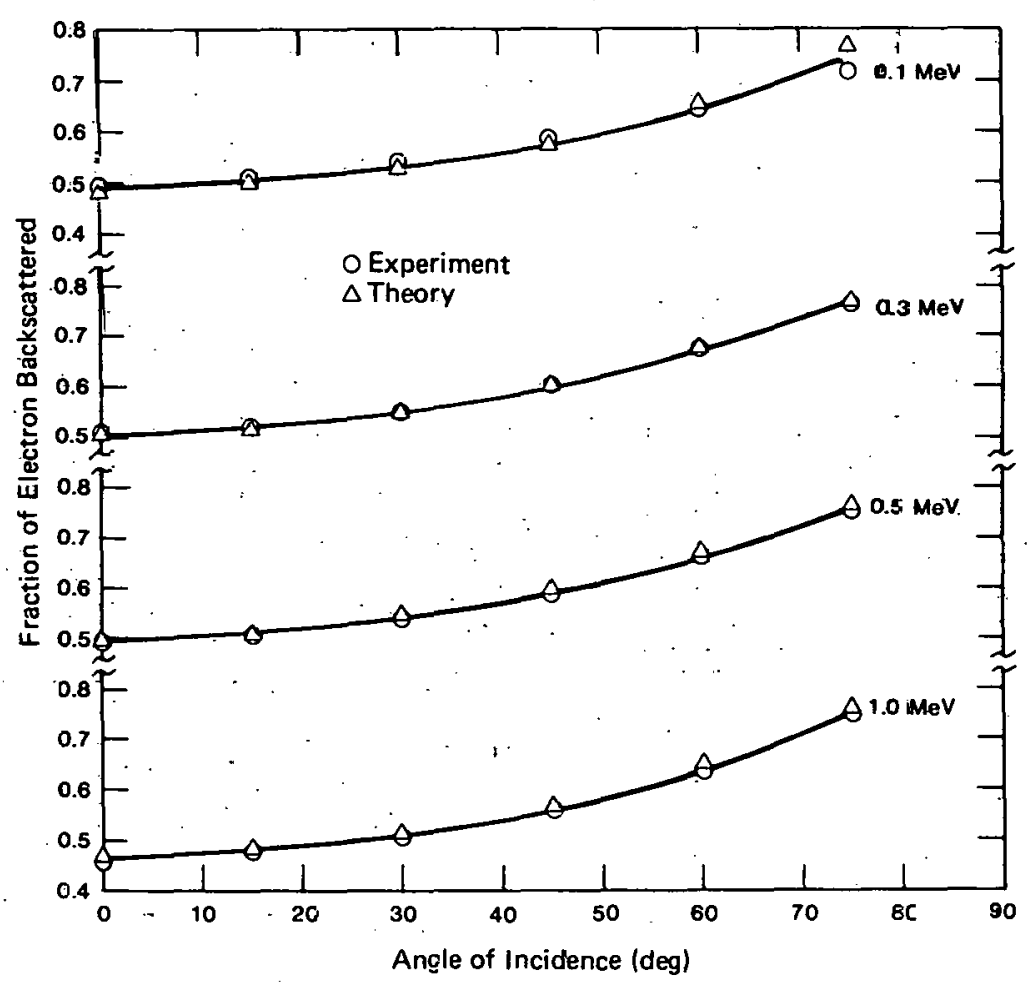

b. Comparisoz as a Function of Incident Angle

Figure V-H. 2 Compariscin of Experimental and Theore:ical Number Backscatter in Uranium Dioxide 
Table V-H. 2

Fraction of Electrons Backscattered From Uranium Dioxide

\begin{tabular}{|c|c|c|c|c|c|c|c|}
\hline & \multirow{2}{*}{$\begin{array}{l}\text { Energy } \\
\left(\mathrm{N}_{-} \mathrm{eV}\right) \\
\end{array}$} & \multicolumn{6}{|c|}{ Angle of Incidence } \\
\hline & & $0^{\circ}$ & $15^{\circ}$ & $30^{\circ}$ & $45^{\circ}$ & $60^{\circ}$ & $75^{\circ}$ \\
\hline Exp & 1. 0 & 0.451 & 0.471 & 0.498 & 0.556 & 0.631 & 0.746 \\
\hline Theory & 1. 0 & 0.463 & 0.480 & 0.516 & 0.566 & 0.655 & 0.759 \\
\hline $\operatorname{Exp}$ & ग. 5 & 0.490 & 0.501 & 0.535 & 0.585 & 0.658 & 0.750 \\
\hline Theory & D. 5 & 0.500 & 0.507 & .0 .540 & 0.603 & 0.677 & 0.762 \\
\hline $\operatorname{Exp}$ & D. 3 & 0.510 & 0.519 & 0.545 & 0.600 & 0.670 & $0.757^{\circ}$ \\
\hline Theory & -. 3 & 0.506 & 0.515 & 0.54 .5 & 0.602 & 0.674 & 0.775 \\
\hline $\operatorname{Exp}$ & 0.1 & 0.494 & 0.503 & 0.539 & 0.583 & 0.643 & 0.718 \\
\hline Theory & ग. 1 & 0.479 & 0.500 & 0.521 & 0.571 & 0.656 & 0.765 \\
\hline
\end{tabular}




\section{Conclusions}

Using a ncw calorimetric method, we have carried out systematic measurements of saturated integral electron energy albedos as a function of target atomic number and incidence angle for source electrons with kinetic energies ranging from 0.025 to $1: 0 \mathrm{MeV}$. Saturated integral electron number albedos were obtained simultaneously. In each case, state-of-the-art predictions were obtained from a Monte Carlo model. The generally good agreement between theory and experiment over this extensive parameter space strongly validates both the theoretical model and the new experimental technique. The new technique offers important advantages over more traditional methods. The following addresses four specific problem areas:

A. For the most part the experimental and theoretical energy albedos agree quite well. There is an obvious disagreement in Ta and $\mathrm{U}$ at low incident energies. This is probably due to the elastic scattering cross sections employed in the standard calculations. As shown in Sertions V-F and V-G. roeulto that unc improved cross sections ${ }^{12}$ are in better agreement with cxpcriment, but there are still significant discrepancies.

B. Even more difficult to understand is the situation with the U energy albedos at higher energies where the theorctical data fall approximately $10 \%$ below the measured results. This is especially disturbing in light of the excellent agreement for $\mathrm{UO}_{\hat{2}}$ where the niaginiludes cledrly lindleate that transport is domınated by the $\mathrm{U}$ constituent. Indeed, these $\mathrm{UO}_{2}$ results lessen our concern over a possible problem with the U cross sections in the transport code, and otrongly ouggeat the presence of a systematic error in the present total-stopping calorimeter data for U. This possibility is further reinforced by the relatively poor agreement between the total-stopping deposition data for $U$ and the integrated differentlal data listed in subsection $V-G$.

C. Except for small incident angles and low atomic numbers where differencing leads to large uncertainties, the present method for obtaining number albedos appears to be competitive with techniques that measure backscatter direotly. Otherwiec, agreement between theory and experiment is very good except at low incident cnergies. In the case of $\mathrm{Ta}$ and $\mathrm{U}$. some of this low-energy disagreement can probably be attributed to the elastic scattering cross sections employed in the calculations. We do not understand those cases in $I T$ and $A 7$ at $1 \mathrm{nw}$ energies where the experimental resuits fald below the theoretical predictions.

D. Finaliy, there appears to be some tendency of our experimental number albedos to fall below the theoretical predictions. Even though the measurements were made at high vacuum, there is the possibility that the $+55-\mathrm{V}$ bias on the calorimeter may have resulted in the collection of a significant number of ionization electrons in the large-volume chambcr, as well as secondaries emitted from surrounding structures. 
1. D. Harder, Proceedings of the Second Symposium on Microdosimetry (Stresa, Italy, 1969), p. 567.

2. K. A. Wright and J. G. Trump, J. Appl. Phys. 33, 687, (1962).

3. G. J. Lockwood, L. E. Ruggles, G. H. Miller, and J. A. Halbleib, "Calorimetric Measurement of Electron Energy Deposition in Extended Media -- Theory vs Experiment," SAND79-0414, Sandia National Laboratories, January 1980.

4. J. A. Halbleib, Sr and W. H. Vandevender, Nucl. Sci. Eng. 57, 94 (1975).

5. G. J. Lockwood, G. H. Miller, and J. A. Halbleib; IEEE Trans. Nucl. Sci. NS-22, 2537 (1975).

6. G. J. Lockwood, J. A. Halbleib, and G. H. Miller, IEEE Trans. Nucl. Sci. NS-25, 1581 (1978).

7. H. S. Carslaw and J. C. Jaeger, Conduction of Heat in Solids (Clarendon, London, 1959), p. 493.

8. G. H. Miller and G. J. Lockwood, IEEE Trans. Nucl. Sci. NS-22, 1072 (1975).

9. M. J. Berger, "Monte Carlo Calculations of the Penetration and Diffusion of Fast Charged Particles," Methods in Computational Physics (Academic, New York, 1963), Vol. 1.

10. M. J. Berger and S. M. Seltzer, "ETRAN Monte Carlo Code System for Electron and Photon Transport Through Extended Media," CCC-107, Radiation Shielding Information Center, Computer Code Collection, Oak Ridge National Laboratory, June 1968.

11. F. Biggs and R. Lighthill, "Analytical Approximations for X-Ray Cross Sections II," SC-RR-71-0507, Sandia Laboratories, December 1971; also F. Biggs and R. Lighthill, "Analytical Approximations for Total Pair Production Cross Sections," SC-RR-68-619. Sandia Laboratories, September 1968.

12. L. G. Haggmark, C. J. MacCallum, and M. E. Riley, Trans. Am. Nucl. Soc. 19, 471 (1974). 
DISTRIBUTION:

Air Force Weapons Lab Iristland Aii Fûl ce Base Albuquerque, NM 87115 For: J. F. Janni, NTYC G. Radke

Oak Ridge National Lab (2) Union Carbide Corp P. O. Box X

Oak Ridge, TN 37830

Attn: R. D. Birkoff R. H. Ritchie

Science Applications, Inc 1651 Old Meadow Rd McLean, VA 22101 Attn: W. L. Chadsey

US Department of Commerce National Burcau of Standards Washington, DC 20234

Attn: M. J. Berger S. M. Seltzer L: V. Spences.

US Naval Research Lab Code 770

Washington, DC 20390

For; J. L. Rlnr.k

J. B. Langworthy

S. K. Searles

Harry Diamond Lab (2)

2800 Powder Mill Rd

Aur'ul'd Facllily

Adelphi, MD 20783

$\Lambda$ tmi $E$. Graybill

K. Karas

Los Alamos Scientific Lab

P. O. Box 1663

Los Alamos, NM 87544

Attn: J. Mack, J-15

Report Librarian

SPIRE Corp

Patriots Park

Bedford, MA 01730

Attn: R. Little

Maxwell Laboratories, Inc 9244 Balboa Ave

San Diego, CA 92123

Attn: A. Kolb

Physics International

2700 Merced St

San I,eandro, CA 94577

Attn: A. J. Toepfer
University of Texas

Department of Physics

System Cancer Center

M. D. Anderson Hospital

and Tumor Institute

6723 Bertner

Houston, TX 77030

Attn: J. R. Marbach :

US Naval Résearch Lab.

Code 6680

Washington, DC 20375

For: J. Criss

D. B. Brown

Brookhaven National Lab

Tipton, Nr 11073

Attn: R. M. Stcrnheimer

R. F. Peierls

L'Garde, Inc

1555 Placentia Avenue

Nowport Bcaeh, CA 02003

Attn: M. Thomas

Kaman Sciences Corp

P. O. Box 7463

rnlnrade'springo, CO 00039

Altu: W. L. ware

Mathematical Applications Froun, Inr 180 South Broadway

White Plains, NY 10605

For: W. Gruber

R. Nágle

R. Goldstein

P. S. Mittelman

M. H. Kalos

Science Applications, Inc P. O. Box 2351

1250 Prospect St

La Jolla, CA 92037

For: E. A. Straker

W. H. Bcott, Jr

N. R. Byrı

Mission Research Corp

735 State St

Santa Barbara, CA 93101

Attn: C. L. Longmire

M. D. Anderson Hospital (2)

Texas Medical Center

Houston, TX 77030

Attn: Peter Almond

Physics Dept 
DISTRIBUTION (Cont):

Karolinska Institute

Dept of Radiation Physics

Fack

S-104 01 Stockholm, SWEDEN

Attn: A. Brahme

Institut Gustave Roussy

94800 Villejuif, FRANCE

Attn: A. Dutreix

Institut fur Medizinische Physik und Biophysik

D 3400 Gottingen.

Gosslerstr. 10, WEST GERMANY

Attn: D. Harder

Institut $\mathrm{f}$. Biophysik

Univ Kliniken

D-6650 Homberg 3, WEST GERMANY

Attn: Mr. and Mrs. Hans Leetz

Regional Hospital

Radiation Physics Dept

S-901 85 Umea, SWEDEN

Attn: H. Svensson

Unite de Radiotherapie et de

Neutrontherapie

Centre des Tumerus UCL 54.69

av. Hippocrate, 54

B. 1200 Bruxelles, BELGIUM

Attn: A. Wanbersie

Air Force Cambridge Lab (4)

L. G. Hanscom Field

Bedford, MA 01730

Attn: J. N. Bradford

E. A. Burke

A. R. Frederickson

J. C. Garth

Northrup Research \& Technology Center (2)

3401 W. Broadway

Hawthorne, CA 90250

Attn: W. Hant

G. Duckworth

The Aerospace Corp

P. O. Box 92957

Los Angeles, CA 90009

For: D. G. Swanson

C. Crummer

R. Pruett

C. Greenhow

Experimental \& Mathematical

Physics Consultants

Box 66331

Los Angeles, CA 90000

Attn: T, M. Jordan

\begin{tabular}{|c|c|}
\hline 1110 & J. D. Plimpton \\
\hline 1112 & C. R. Mehl \\
\hline 1112 & G. H. Miller \\
\hline 1112 & K. M. Gilbert \\
\hline 1112 & J. J. Hohlfelder \\
\hline 1242 & S. B. Roeske \\
\hline 1310 & R. L. Hagengruber \\
\hline 1314 & L. A. Boye \\
\hline 1315 & P. M. Cashwell \\
\hline 2100 & B. L. Gregory \\
\hline 2646 & W. H. Vandevender \\
\hline 3151 & B. J. Tolman \\
\hline 4200 & G. Yonas \\
\hline 4210 & J. B. Gerardo \\
\hline 4211 & E. J. McGuïre \\
\hline 4211 & M. E. Riley \\
\hline 4211 & T. A. Green \\
\hline 4211 & J. M. Peek \\
\hline 4212 & R. A. Gerber \\
\hline 4216 & A. W. Johnson \\
\hline 4218 & J. K. Rice \\
\hline 4220 & M. Cowan \\
\hline 4230 & J. E. Powell \\
\hline 4231 & F. Biggs \\
\hline 4231 & J. A. Halbleib \\
\hline 4231 & C. J. MacCallum \\
\hline 4231 & J. E. Morel \\
\hline 4231 & C. N. Vittitoe \\
\hline 4232 & W. Beezhold \\
\hline 4232 & G. J. Lockwood \\
\hline 4232 & L. E. Ruggles \\
\hline 4232 & L. P. Posey. \\
\hline 4233 & G. A. Zawadzkas \\
\hline 4234 & D. H. McDaniel \\
\hline 4240 & G. K. Kuswa. \\
\hline 4241 & J. R. Freeman \\
\hline 4242 & L. P. Mix \\
\hline 4243 & J. Chang \\
\hline 4244 & P. A. Miller \\
\hline 4247 & M. M. Widner \\
\hline 4247 & K. Matzen \\
\hline 4247 & A. V. Farnsworth, \\
\hline 4247 & M. A. Sweeney \\
\hline 4250 & T. H. Martin \\
\hline 4252 & J. P. Vendevender \\
\hline 4252 & D. L. Johnson \\
\hline 4253 & K. R. Prestwich \\
\hline 4253 & M. T. Buttram \\
\hline 4253 & R. B. Miller \\
\hline 4253 & J. J. Ramirez \\
\hline 4254 & S. A. Goldstein \\
\hline 4365 & J. H. Renken \\
\hline 4365 & T. F. Wrobel \\
\hline 4365 & E. F. Hartman \\
\hline 4420 & J. V. Walker \\
\hline 4423 & D. A. McArthur \\
\hline 4424 & P. J. McDaniel \\
\hline 4445 & W. H. Buckalew \\
\hline 5631 & W. Herrmann \\
\hline 5534 & D. A. Bens on \\
\hline
\end{tabular}


DISTRIBUTION (Cont):

8341 L. G. Haggmark

8211 M. $\Lambda$. Found

3141 L. J. Erickson (5)

3151 W. L. Garner (3)

3154-3 C. H. Dalin (25)

For: DOE/TIC (Unlimited Release) 


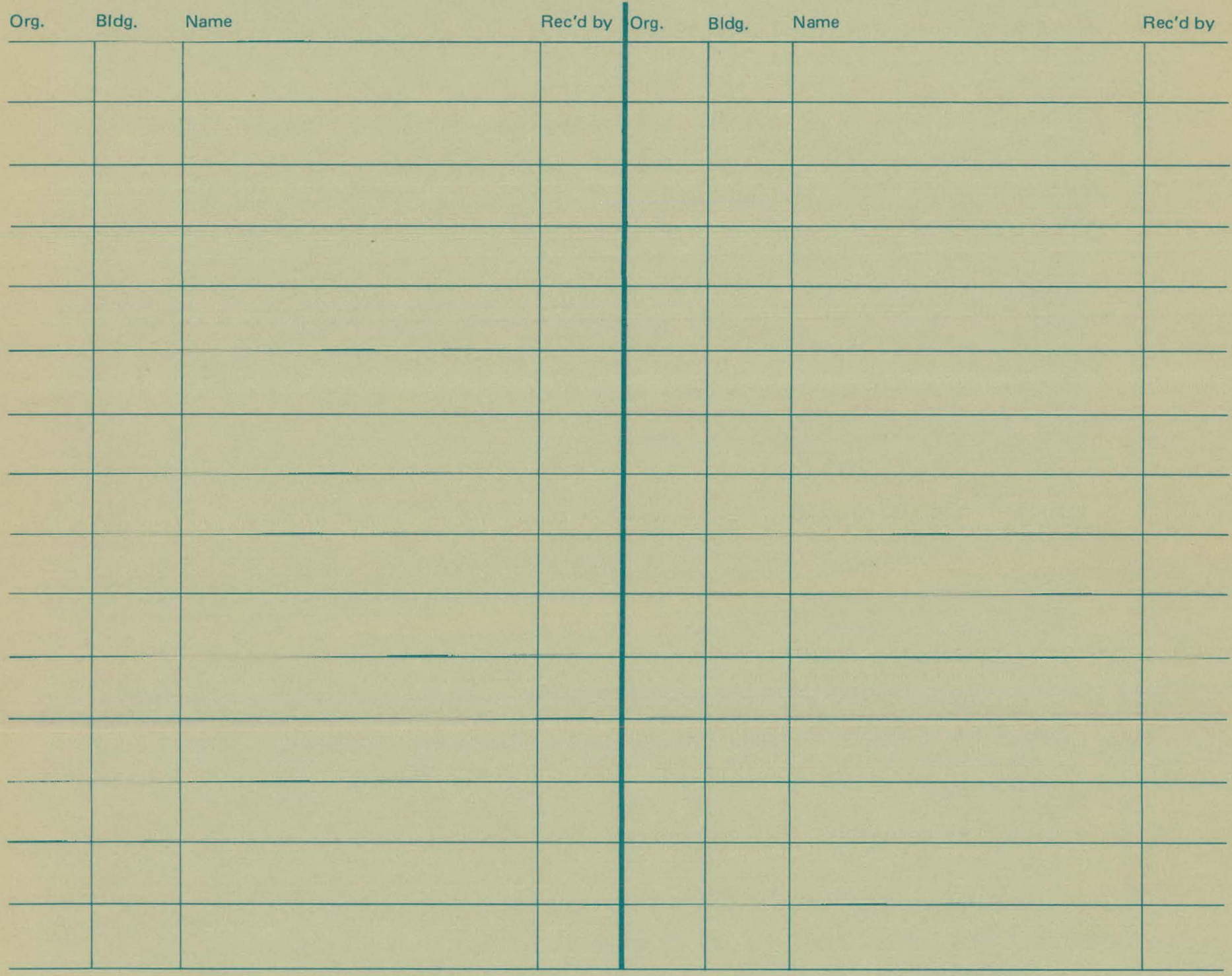

